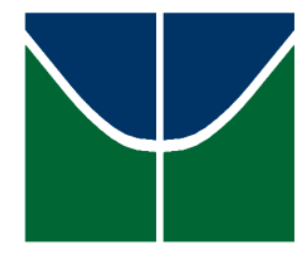

Universidade de Brasília

Instituto de Ciências Biológicas

Programa de Pós-graduação em Ecologia

INTERAÇÕES TRÓFICAS PIPER (PIPERACEAE) - LAGARTAS DE

LEPIDOPTERA NO CERRADO DO BRASIL CENTRAL

RAIANE SEREJO RABELO

Brasília-DF

Setembro de 2016 


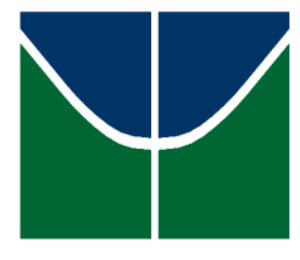

Universidade de Brasília

Instituto de Ciências Biológicas

Programa de Pós-graduação em Ecologia

\title{
INTERAÇÕES TRÓFICAS PIPER (PIPERACEAE) - LAGARTAS DE LEPIDOPTERA NO CERRADO DO BRASIL CENTRAL
}

\begin{abstract}
Aluna: Raiane Serejo Rabelo
Orientadora: Prof ${ }^{a}$. Ivone Rezende Diniz

Dissertação apresentada ao Programa de Pós Graduação em Ecologia como requisito para a obtenção do título de Mestre em Ecologia.
\end{abstract}

Brasília, setembro de 2016 


\section{AGRADECIMENTOS}

Aos meus pais, por toda compreensão, amor e apoio durante toda a minha vida.

À minha orientadora, Ivone Rezende Diniz, por toda a amizade, ajuda, compreensão, paciência, disponibilidade e pelos vários momentos durante o mestrado em que foi "uma luz no fim do túnel" para mim.

Ao Lee Dyer, por todo o grande incentivo, parceria, e por toda a ajuda para planejar e pensar este projeto.

Às minhas co-orientadoras não oficias Cintia Lepesqueur e Tara Massad, por toda amizade e ajuda com análises estatísticas, campo, idéias, identificações e com minhas várias dúvidas.

Aos meus amigos Thayane, Hanna Pamella, Vanessa e Tacito pela super ajuda durante todo o campo desse trabalho, sem a qual este trabalho nunca teria sido realizado, e pelas divertidas aventuras em meio aos carrapatos, cobras e pegadas suspeitas atrás dos Pipers.

Ao Mardônio, por não somente transportar, mais principalmente, ser um grande amigo e ajudante, sempre.

À Lydia Yamaguchi, pela realização da análise fitoquímica, e por toda a boa vontade e disponibilidade.

À Neuza, pela amizade, ajuda, e pelos momentos de cumplicidade nas nossas muitas "horas difíceis" na reta final dos nossos trabalhos.

À Priscila, Eloisio, André e Ricardo pela amizade.

À Universidade de Brasília, Departamento de Zoologia e ao Programa de PósGraduação em Ecologia, pelas instalações, pelos professores e seus ensinamentos que facilitaram a realização deste trabalho.

À Coordenação de Aperfeiçoamento de Pessoal de Nível Superior (CAPES), pelo auxílio financeiro, na forma de bolsa de Mestrado. 


\section{SUMÁRIO}

Resumo

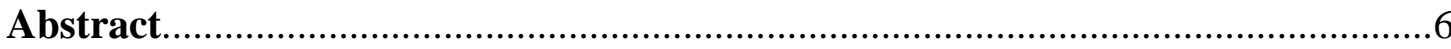

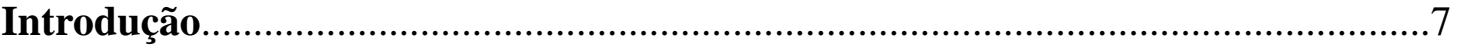

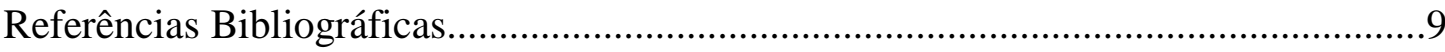

Capítulo I - Caracterização da fauna de lepidópteros de Piper em Matas de Galeria: relações espaciais e temporais

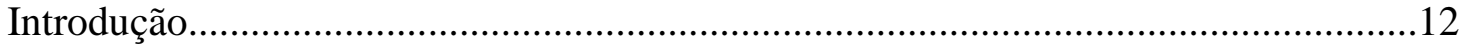

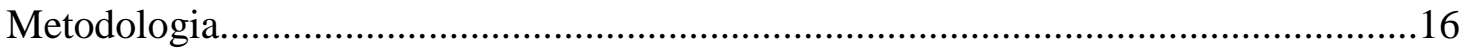

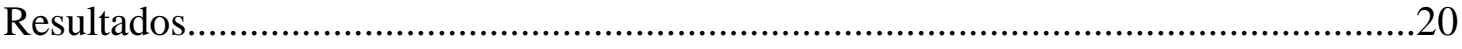

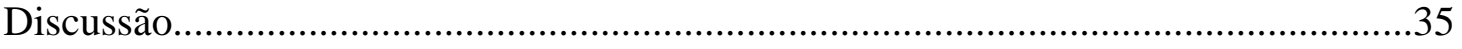

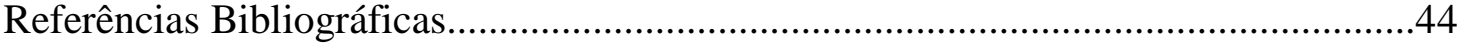

Capítulo II - Efeitos da origem do genótipo (populações) e fitoquímica de Piper arboreum (Piperaceae) na herbivoria e nos seus herbívoros

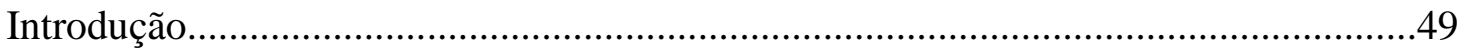

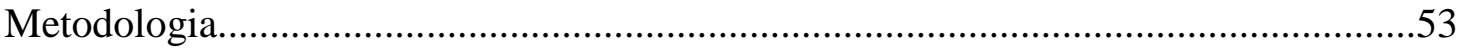

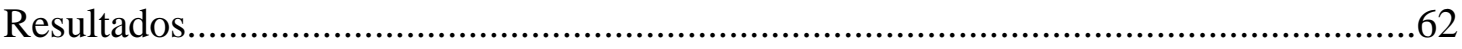

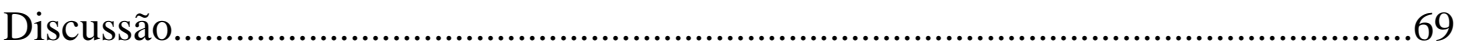

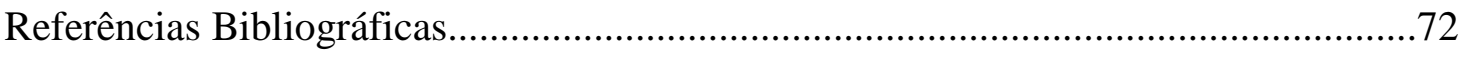

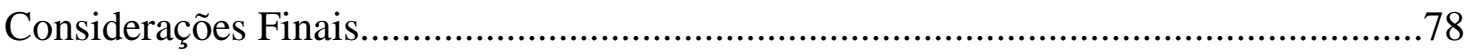

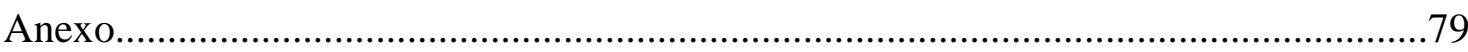

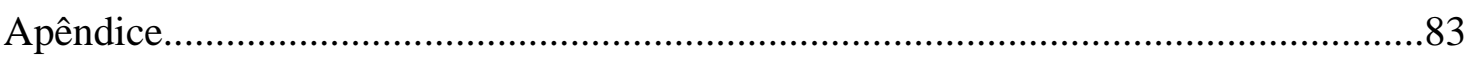




\section{RESUMO}

O primeiro capítulo caracterizou os lepidópteros associados à Piper (Piperaceae) em Matas de Galeria do Cerrado do Distrito Federal e Goiás, já que não havia conhecimento anterior. As vistorias foram feitas em 354 parcelas de $10 \mathrm{~m}^{2}$ em sete áreas, de maio de 2015 a abril de 2016. Foram encontradas 12 espécies de Piper, sendo a mais comum $P$. arboreum. Quatro mil plantas foram vistoriadas e as lagartas contadas, identificadas e criadas em laboratório, em folhas de Piper até a emergência. Foram encontradas 331 lagartas, sendo 243 identificadas em 60 espécies. O modelo de efeito misto mostrou variação sazonal significativa na abundância de lagartas, o índice de similaridade de Jaccard mostrou variação espacial na composição de espécies em $P$. arboreum, com baixa similaridade entre áreas. $\mathrm{O}$ alto número de espécies raras de lagartas em $P$. arboreum explica as diferenças encontradas. O padrão encontrado para a comunidade de lepidópteros foi semelhante ao do cerrado sentido restrito. $\mathrm{O}$ segundo capítulo, experimental, avaliou os efeitos da origem genotípica e da variação fitoquímica (composição e diversidade fitoquímica) na herbivoria foliar cumulativa de $P$. arboreum. Três plantas-mãe (genótipos) de $P$. arboreum foram coletadas de quatro áreas de origem (DF e GO), distantes uma das outras de, pelo menos, 20Km. Cada planta foi cortada em seis partes para a formação de estaquias (clones) que foram plantadas em vasos e dispostas em três matas de galeria - áreas experimentais. Cada área experimental continha quatro genótipos, observados mensalmente por um ano. $\mathrm{O}$ resultado da análise da composição química mostrou que houve dois quimiotipos: plantas com mistura de amidas ou com metil 3-geranil-4-hidroxibenzoato. Esta variação química afetou significativamente a herbivoria que foi menor nas plantas com o quimiotipo-amida. Os resultados sugerem que a origem genotípica e a diversidade fitoquímica (de grupos funcionais) não afetaram a herbivoria.

Palavras-chave: Cerrado; composição química; genótipo; Piper arboreum; sazonalidade; similaridade. 


\begin{abstract}
The first chapter described the lepidopteran species on Piper (Piperaceae) in gallery forest in the Cerrado of Central Brazil (Federal District and Goiás), as there was no previous knowledge. Samples were conducted in seven areas from May 2015 to April 2016. Four thousand plants of 12 species of Piper were inspected for caterpillars in 354 plots. I found 331 caterpillars in the field but only 243 of 60 species have emerged in the laboratory. P. arboreum was the commonest host plant in all areas. There was a significant seasonal variation in abundance of caterpillars on Piper (Mixed Effect Model), and spatial variation in species composition associated to P. arboreum (Jaccard Similarity Index). Patterns found for the lepidopteran in the gallery forests was similar to that of cerrado strict sense. The community similarity among areas was low, that may be explained by the high number of rare species of Lepidoptera. The second chapter, an experimental work, aimed to evaluate the effects of genotypic origin and of composition and phytochemical diversity of $P$. arboreum on cumulative leaf herbivory. The experiment was set up in three areas within gallery forests, and the observation were made, monthly, for a year. Genotypes came from four areas distant from each other at least $20 \mathrm{Km}$. The results showed that chemical composition show two chemotypes: plants with a mixture of amides and those with methyl 3-geranyl-4-hydroxybenzoate, and such composition affects significantly the herbivory, being lower on plants containing amides than to the other chemotype. The analysis for phytochemical diversity (of functional groups) for 12 genotypes (=12 x four three experimental areas) did not show any effect. The results suggest also that the genotypic origin did not affect herbivory. These results confirm the strong negative effects of these amides on Piper herbivores, which corroborates findings in other studies.
\end{abstract}

Key-words: Cerrado; chemical composition; genotype; Piper arboreum; seasonality; similarity. 


\section{INTRODUÇÃO}

O Cerrado apresenta uma alta biodiversidade de lepidópteros (Brown Jr. \& Mielke, 1967), como também um alto endemismo, pois 19\% destas espécies são endêmicas deste bioma (Brown Jr. \& Gifford, 2002). A composição de espécies de lepidópteros varia entre o mosaico de tipos de formações vegetais do Cerrado (Pinheiro \& Ortiz, 1992). Estudos de lagartas de lepidópteros e suas plantas hospedeiras, no cerrado sentido restrito do Distrito Federal, vêm sendo realizados nos últimos 21 anos (ex: Diniz \& Morais, 1995, 1997, 2002; Morais et al., 1999; Diniz et al., 2001; Scherrer et al., 2010), e já evidenciaram diversos padrões para a comunidade de lagartas, como a alta riqueza e a baixa abundância da maioria das espécies, baixa frequência nas plantas hospedeiras, e pico de abundância na estação seca (Price et al., 1995, Diniz \& Morais, 1997). Entretanto, estudos sobre a associação da fauna de lagartas de lepidópteros e plantas hospedeiras ainda não foram realizados em Matas de Galeria do Cerrado.

As Matas de Galeria destacam-se pela alta riqueza botânica (Felfili, 1995). Esta diversidade inclui espécies da Mata Atlântica, da Floresta Amazônica e, ainda, das bacias do rio Paraná (Oliveira Filho \& Ratter, 1995), o que faz com que haja baixa similaridade florística com o cerrado sentido restrito (Felfili \& Silva Júnior, 1992). Uma efetiva conservação das espécies tropicais, depende do conhecimento básico da distribuição espacial dos organismos e das interações entre espécies dentro das comunidades (Diniz \& Morais, 1997). Assim, o conhecimento das interações entre lagartas de lepidópteros e suas plantas hospedeiras em Matas de Galeria é de suma importância para o entendimento da funcionalidade ecossistêmica e de ações de conservação da fauna de lepidópteros da região.

O gênero Piper (Piperaceae) tem mais de mil espécies já registradas, sendo amplamente distribuído na região Neotropical (Dyer \& Palmer, 2004). No Brasil, o 
gênero apresenta ampla distribuição nas Matas de Galeria do Brasil Central (Ribeiro \& Walter, 2008). Piper e seus herbívoros já foram estudados no Brasil e na América Central (ex: Marquis, 1991; Dyer \& Gentry, 2002; Janzen \& Hallwachs, 2005; Shimbori, 2009). Tais estudos mostraram que este gênero apresenta uma grande diversidade de herbívoros associados, especialmente lagartas de lepidópteros. Entretanto, a associação da fauna de lagartas de lepidópteros com as espécies de Piper no bioma Cerrado ainda é desconhecida. Este gênero de planta apresenta grande diversidade fitoquímica (Dyer \& Palmer, 2004) e vem sendo utilizado como modelo para estudos relacionados aos efeitos bottom-up de plantas nos herbívoros (Dyer et al., 2003; Jeffrey et al., 2014).

O presente trabalho foi dividido em dois capítulos. O primeiro investigou alguns aspectos da variação espacial e temporal da composição, abundância e riqueza de espécies de lagartas de lepidópteros associadas às espécies de Piper (Piperaceae). As coletas do trabalho foram realizadas em sete áreas de Matas de Galeria do Cerrado do Distrito Federal e Goiás, pelo período de 12 meses (Capítulo I)

O segundo capítulo tratou de um estudo experimental para investigar possíveis efeitos da origem do genótipo e da fitoquímica de Piper arboreum Aubl. (Piperaceae) na herbivoria e em seus herbívoros associados. $P$. arboreum foi selecionado como hospedeira, objeto de estudo, por ser uma espécie de planta amplamente distribuída nas Matas de Galeria do Cerrado (Capítulo II). 


\section{REFERÊNCIAS BIBLIOGRÁFICAS}

Brown Jr.K.S. \& Gifford, D.R. 2002. Lepidoptera in the cerrado landscape and the conservation of vegetation, soil and topographical mosaics.In: Oliveira, P.S. \& Marquis, R.J. (eds.). The Cerrados of Brazil. Ecology and Natural History of a Neotropical Savanna. Columbia University Press, New York, 201-217.

Brown Jr.K.S. \& Mielke, O.H. 1967. Lepidoptera of the Central Brazil Plateau. I. Preliminary list of Rhopalocera (continued): Lycaenidae, Pieridae, Papilionidae, Hesperiidae.Journal of the. Lepidopterist Society, 21(3):145-168.

Diniz, I.R. \& Morais, H.C. 1995. Larvas de Lepidoptera e suas plantas hospedeiras em um cerrado de Brasília, Distrito Federal, Brasil. Revista Brasileira de Entomologia, 39: 755-770.

Diniz, I.R. \& Morais, H.C. 1997. Lepidopteran caterpillar fauna of Cerrado host plants. Biodiversity and Conservation, 6: 817-836.

Diniz, I.R. \& Morais, H.C. 2002. Local pattern of host plant utilization by lepidopteran larvae in the cerrado vegetation. Entomotropica, 17(2): 115-119.

Diniz, I.R., Morais, H.C. \& Camargo, A.J.A. 2001. Host plant of lepidopteran caterpillar in the cerrado of Distrito Federal, Brazil. Revista Brasileira de Entomologia, 45: 107-122.

Dyer, L.A., Dodson, C.D., Stireman, J.O., Tobler, M.A., Smilanich, A.M., Fincher, R.M. \& Letourneau, D.K. 2003. Synergistic effects of three Piper amides on generalist and specialist herbivores. Journal of Chemical Ecology, 29: 2499-2514.

Dyer, L. \& Gentry, G.L. 2002. Caterpillars of La Selva, Costa Rica. Disponível em: http://www.caterpillars.org. Acessado em julho de 2016.

Dyer, L.A. \& Palmer, A.N. 2004. Piper. A model genus for studies of evolution, chemical ecology, and trophic interactions. In L. Dyer, C.D. Dodson \& J. Richards (eds.). Kluwer Academic Publishers, Boston, 117-139.

Felfili, J.M. 1995. Diversity, structure and dynamics of a gallery forest in central Brazil. Vegetation, 117: 1-15.

Felfili, J.M. \& Silva-Júnior, M.C. 1992. Floristic composition, phytosociology and comparison of cerrado and gallery forests at Fazenda Água Limpa, Federal District, Brazil. In: Nature and dynamics of forest-savanna boundaries. Chapman \& Hall, London, 393-415.

Janzen, D.H. \& Hallwachs, W. 2005. Dynamic database for an inventory of the macrocaterpillar fauna, and its food plants and parasitoids, of the Area of Conservation Guanacaste (ACG), northwestern Costa Rica. Disponível em: http://janzen.sas.upenn.edu/84. Acessado em julho de 2016.

Jeffrey, C.S., Leornard, M.D., Glassmire, A.E., Dodson, C.D., Richards, L.A., Kato, M.J. \& Dyer, L.A. 2014. Anti-herbivore prenylated benzoic acid derivatives from Piper kelleyi. Journal of Natural Products, 77: 148-153.

Marquis, R.J. 1991. Herbivore fauna of Piper (Piperaceae) in a Costa Rican wet forest: diversity, specificity, and impact. .In: P.W. Price, T.M. Lewinsohn, G.W. Fernandes \& W.W. Benson (eds.), Plant-animal interactions - evolutionary ecology in tropical and temperate regions, John Wiley \& Sons, Inc., New York, 179-208.

Morais, H.C., Diniz, I.R. \& Silva, D.M.S. 1999. Caterpillar seasonality in a central Brazilian cerrado. Revista de Biologia Tropical, 47: 1025-1033.

Oliveira-Filho, A.T. \& Ratter, J.A. 1995. A study of the origin of Central Brazilian forests by the analysis of plant distribution patterns. Edinburgh Journal of Botany, 52(2): 1-54.

Pinheiro, C.E. \& Ortiz, J.V. 1992. Communities of fruit-feeding butterflies along a vegetation gradient in central Brazil.Journal of Biogeography, 19: 505-511. 
Price, P.W., Diniz, I.R., Morais, H.C. \& Marques, E.S.A. 1995. The abundance of insect herbivore species in the tropics: the high local richness of rare species. Biotropica, 2: 468-478.

Ribeiro, J.F.; Walter, B.M.T. 2008. As principais fitofitofisionomias do bioma Cerrado. In: Sano, S.M.; Almeida, S.P.; Ribeiro, J.F. (eds.). Cerrado:ecologia e flora. Brasília: Embrapa, 2: 151-212.

Scherrer, S., Diniz, I.R. \& Morais, H.C. 2010. Climate and host plant characteristics effects on lepidopteran caterpillar abundance on Miconia ferruginata DC. and Miconia pohliana Cogn (Melastomataceae). Brazilian Journal of Biology, 70: 103-109.

Shimbori, E. M. 2009. Sistema hospedeiro-parasitoide associado à Piper glabratum Künth e P. mollicomum Künth (Piperaceae) no município de São Carlos, SP. Tese (Doutorado em Ciências Biológicas) - Universidade Federal de São Carlos, São Carlos,185 p. 


\section{Capítulo I}

Caracterização da fauna de lepidópteros de Piper em Matas de Galeria: relações espaciais e temporais 


\section{INTRODUÇÃO}

A área do bioma Cerrado já ocupou $23 \%$ do território brasileiro, notadamente no planalto central (Ratter et al., 1997). A vegetação do Cerrado é caracterizada por um mosaico de fitofisionomias que vão desde formações mais fechadas como as florestais; cerradão e matas de galeria, ciliar e seca até formações mais abertas como as savânicas; cerrado sentido restrito, parque cerrado, palmeiral, vereda e as campestres como os campos sujo, limpo e rupestre (Ribeiro \& Walter, 1998).

As matas de galeria do Bioma Cerrado são florestas sempre verdes, que há 20 anos correspondiam a cerca de 5\% do bioma Cerrado (Dias, 1996), localizando-se em geral no fundo dos vales, seguindo os cursos d'água de pequenos rios e córregos, com distribuição esparsa formando manchas (Ribeiro \& Walter, 1998). Estas matas compõem uma rede que conecta a Mata Atlântica e a Floresta Amazônica, no sentido noroeste-sudeste, atravessando o Cerrado como se fossem corredores de migração de espécies (Rizzini, 1979; Oliveira-Filho \& Ratter, 1995). No Cerrado do Brasil Central são consideradas como refúgios florestais para a fauna em ambiente dominado por savana (Meave et al., 1991). Além disto, possuem papel importante na proteção dos recursos hídricos (Lima \& Zakia, 2001).

As Matas de Galeria também se destacam pela alta riqueza botânica (Felfili, 1995; Felfili et al., 2001). Esta diversidade inclui espécies da Mata Atlântica, Floresta Amazônica e das bacias do rio Paraná (Oliveira Filho \& Ratter, 1995), o que faz com que haja baixa similaridade florística com o cerrado sentido restrito (Felfili \& Silva Júnior, 1992). Comparativamente, a flora das florestas estacionais brasileiras tem maior idade (Cretáceo superior) que a dos cerrados (Terciário médio) (Veloso, 1963; Eiten, 1972), o que sugere que a flora das Matas de Galeria do Cerrado é mais antiga que a flora presente no cerrado sentido restrito. 
A região do bioma Cerrado é caracterizada por duas estações bem marcadas: a chuvosa, entre outubro e abril, quando ocorrem mais de $90 \%$ da pluviosidade, e a seca, que se prolonga de maio a setembro (Espinoza et al., 1982). Entretanto, há indicações de que o ambiente florestal sofre uma menor influência da sazonalidade climática da região (Gouveia \& Felfili, 1998), isto porque as plantas das matas de galeria não apresentam queda de folhas evidente durante a estação seca (Ribeiro \& Walter, 1998), e os eventos reprodutivos parecem ocorrer mais equitativamente ao longo do ano do que no cerrado sentido restrito (Gouveia \& Felfili, 1998).

Entre as plantas que compõem o sub-bosque das matas de galeria encontram-se as do gênero Piper (Piperaceae), composto por arbustos-herbáceas (a grande maioria), trepadeiras, e árvores de pequeno porte (arvoretas) (Dyer \& Palmer, 2004; Ribeiro \& Walter, 2008). Este gênero de plantas é facilmente identificado no campo, devido às suas características marcantes como as bases das folhas oblíquas e assimétricas encontradas em várias espécies (Figura 1), inflorescências e infrutescências alongadas e bem características (Figura 1) e, ainda, ao cheiro tipicamente "picante" derivado do esmagamento de folhas ou caules (Dyer \& Palmer, 2004) e, devido a isto, é muito utilizado como sistema de investigação em vários locais. 


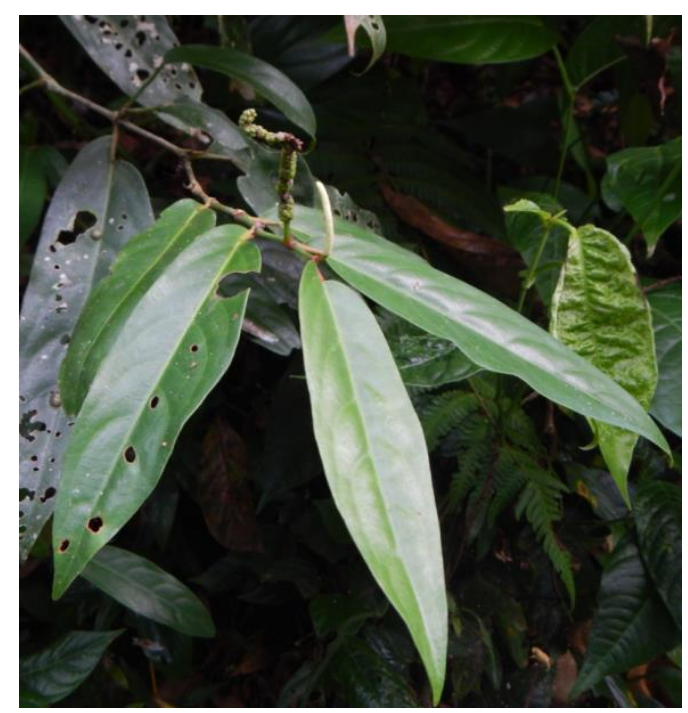

B) Base foliar assimétrica e detalhe da infrutescência

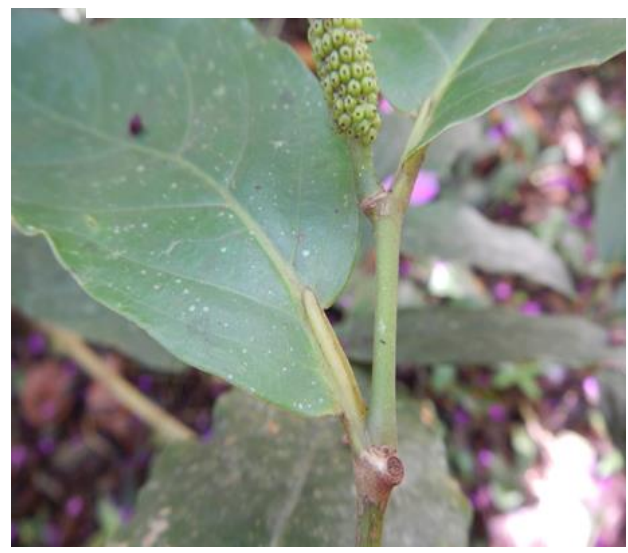

Figura 1. A) Exemplar de Piper arboreum Aubl. (Piperaceae) com destaque para a inflorescência típica; B) Base foliar assimétrica encontrada em várias espécies de Piper (Fotos Mata Atlântica, Reserva Serra Bonita: Cintia Lepesqueur).

Piper é constituído por um grande número de espécies e, juntamente com Peperomia compõe os maiores gêneros da família Piperaceae, cada um com cerca de 1.000 espécies registradas (Guimarães et al., 1978). O gênero é amplamente distribuído em sub-bosques de florestas tropicais ocorrendo, principalmente, na região Neotropical (700 spp.) e no sul asiático (300 spp.) (Jaramillos \& Manos, 2001; Dyer \& Palmer, 2004). Dentre as espécies de Piper, P. arboreum destaca-se pela ampla distribuição nas Américas Central e do Sul (Yuncker, 1972). Devido à grande amplitude geográfica e ao provável isolamento de populações, eventos de especiação podem ter ocorrido, o que nos leva à predição de que, na verdade, esse possa ser um complexo de espécies. No Brasil, esta espécie é comumente encontrada na depressão central e no litoral e já foi registrada em vários estados, incluindo Goiás (Yuncker, 1972) e Distrito Federal (Guarino \& Walter, 2005). 
No cerrado sentido restrito do Distrito Federal (DF), as pesquisas de interações entre lagartas de Lepidoptera e plantas hospedeiras vêm sendo realizadas intensivamente nos últimos anos (ver Diniz \& Morais, 1995; 1997, 2002; Morais et al., 1999; Diniz et al., 2001; Scherrer et al., 2010, 2016), com padrões reconhecidos para a comunidade de lagartas de Lepidoptera em diferentes plantas hospedeiras. Entretanto, estes estudos não contemplaram estas interações em áreas de mata de galeria, onde este conhecimento é praticamente nulo na região.

Em outros biomas, vários estudos sobre Piper e seus herbívoros hospedeiros foram realizados, no Brasil (Shimbori, 2009) e em vários países da América Central (Marquis, 1991; Dyer \& Gentry, 2002; Janzen \& Hallwachs, 2005; Tepe et al., 2014). Estes estudos têm mostrado uma alta diversidade de herbívoros associados ao gênero, especialmente lagartas de lepidópteros.

Nesse contexto, os objetivos do presente trabalho foram: 1) Caracterizar a fauna de lagartas de lepidópteros associadas às espécies de Piper em áreas de matas de galeria do Distrito Federal e Goiás, com análise dos seguintes parâmetros: composição, riqueza, abundância, diversidade, parasitismo e frequência nas plantas hospedeiras; 2) Comparar os padrões encontrados para a fauna de lagartas de lepidópteros associada à Piper em áreas de matas de galeria com os padrões já encontrados no mesmo sistema em plantas do cerrado sentido restrito; 3) Identificar e comparar o período de pico de abundância e riqueza de lagartas com o encontrado para o cerrado sentido restrito (pico na estação seca); 4) Utilizar P. arboreum como espécie modelo para caracterizar a comunidade de Lepidoptera associada ao gênero e comparar a similaridade desta comunidade em áreas de matas de galeria do Distrito Federal e Goiás. 


\section{METODOLOGIA}

\section{Área de estudo}

O estudo de interações entre lagartas de Lepidoptera e as espécies de Piper foi realizado de maio de 2015 a abril de 2016, em sete áreas de Mata de Galeria do Cerrado com diferentes distâncias entre si, para conferir uma maior representatividade da comunidade de lepidópteros que consomem Piper, no Distrito Federal e em Goiás (Tabela 1). As distâncias foram calculadas usando as coordenadas geográficas pela calculadora geográfica online da Divisão de Processamento de Imagens do Instituto Nacional de Pesquisas Espaciais (DPI-INPE). Cinco áreas de estudo estão em Unidades de Conservação no Distrito Federal (DF): Fazenda Água Limpa (FAL), Parque Nacional de Brasília (PNB), Estação Ecológica de Águas Emendadas (ESECAE), Reserva Ecológica do Roncador (RECOR) e Jardim Botânico de Brasília (JBB), com altitudes variando de $1.013 \mathrm{~m}$ até $1.151 \mathrm{~m}$ (Tabela 1 ). As outras duas estão localizadas no perímetro urbano de Pirenópolis e no Parque Nacional da Chapada dos Veadeiros (PNCV) (GO), com altitudes variando de 902m a 1.243m (Tabela 1).

O Cerrado do Brasil Central apresenta clima úmido tropical, com duas estações bem definidas (inverno seco e verão úmido) (Ribeiro \& Walter, 1998). A FAL, o JBB e a RECOR fazem parte da área de proteção ambiental (APA) Gama e Cabeça de Veado, que apresenta média anual de temperatura e de precipitação de $22,1{ }^{\circ} \mathrm{C}$ e $1.453 \mathrm{~mm}$, respectivamente (Santos \& Henriques, 2010). A ESECAE apresenta temperatura média anual de aproximadamente $20^{\circ} \mathrm{C}$, e precipitação anual total de cerca de $1.500 \mathrm{~mm}$ (Maia \& Baptista, 2008), e o PNB apresenta média anual de temperatura e precipitação de $21^{\circ} \mathrm{C}$ e $1.600 \mathrm{~mm}$, respectivamente (Funatura/Ibama, 1998). O PNCV apresenta temperatura e precipitação média anual que varia entre 24 a $26^{\circ} \mathrm{C}$ e 1500 a $1750 \mathrm{~mm}$, 
respectivamente (Ibama/Proaves, 1998), e o município de Pirenópolis apresenta média anual de temperatura de $22^{\circ} \mathrm{C}$, e de precipitação de $1.800 \mathrm{~mm}$ (Venturoli et al., 2011).

Tabela 1. A) Áreas de estudo (seguindo a ordem de latitude), coordenadas geográficas e altitude (m) e B) distância entre as áreas utilizadas para os estudos de interações entre lagartas de Lepidoptera e espécies de Piper em áreas de Matas de Galeria no Cerrado de Goiás e Distrito Federal, de maio de 2015 a abril de 2016 (PNCV= Parque Nacional da Chapada dos Veadeiros, GO; ESECAE= Estação Ecológica de Águas Emendadas, e $\mathrm{PNB}=$ Parque Nacional de Brasília, DF; Pirenópolis= mata de galeria no perímetro urbano, GO; JBB= Jardim Botânico de Brasília, FAL= Fazenda Água Limpa, e RECOR= Reserva Ecológica do Roncador, DF).

\begin{tabular}{|c|c|c|c|c|c|c|}
\hline $\begin{array}{l}\text { A) Áreas/Coordenadas } \\
\text { Geográficas }\end{array}$ & Latitude & Longitude & \multicolumn{2}{|c|}{ Altitude } & & \\
\hline PNCV & $14^{\circ} 08^{\prime} 07.7^{\prime \prime}$ & $47^{\circ} 40^{\prime} 14.4^{\prime \prime}$ & \multicolumn{2}{|c|}{$1.247 \mathrm{~m}$} & & \\
\hline ESECAE & $15^{\circ} 35^{\prime} 17.8^{\prime \prime}$ & $47^{\circ} 39^{\prime} 38.6^{\prime \prime}$ & \multicolumn{2}{|c|}{$1.041 \mathrm{~m}$} & & \\
\hline PNB & $15^{\circ} 43^{\prime} 54.2^{\prime \prime}$ & $47^{\circ} 54 ' 57.1^{\prime \prime}$ & \multicolumn{2}{|c|}{$1.013 \mathrm{~m}$} & & \\
\hline Pirenópolis & $15^{\circ} 50^{\prime} 41.1^{\prime \prime}$ & $48^{\circ} 57 ' 50.5^{\prime \prime}$ & \multicolumn{2}{|c|}{$902 \mathrm{~m}$} & & \\
\hline JBB & $15^{\circ} 53^{\prime} 20.0^{\prime \prime}$ & $47^{\circ} 50^{\prime} 35.5^{\prime \prime}$ & \multicolumn{2}{|c|}{$1.079 \mathrm{~m}$} & & \\
\hline FAL & $15^{\circ} 56^{\prime} 25.6^{\prime \prime}$ & $47^{\circ} 56^{\prime} 24.8^{\prime \prime}$ & \multicolumn{2}{|c|}{$1.141 \mathrm{~m}$} & & \\
\hline RECOR & $15^{\circ} 56^{\prime} 49.6^{\prime \prime}$ & $47^{\circ} 52^{\prime} 08.5^{\prime \prime}$ & \multicolumn{2}{|c|}{$1.115 \mathrm{~m}$} & & \\
\hline B) Áreas/Distância em Km entre as áreas & PNCV & \multicolumn{2}{|c|}{ ESECAE PNB } & \multicolumn{2}{|c|}{ Pirenópolis JBB } & FAL \\
\hline $\mathrm{PNCV}$ & & & & & & \\
\hline ESECAE & 156,04 & & & & & \\
\hline PNB & 178,61 & 41,78 & & & & \\
\hline Pirenópolis & 235,42 & 151,99 & 12,94 & & & \\
\hline JBB & 194,91 & 47,67 & 19,06 & 120,17 & & \\
\hline FAL & 201,84 & 58,67 & 23,24 & 110,21 & 11,82 & \\
\hline RECOR & 201,61 & 54,52 & 24,36 & 117,87 & 7,01 & 8 \\
\hline
\end{tabular}




\section{Coleta de dados}

As coletas das lagartas e identificação das espécies de Piper foram feitas em parcelas temporárias de $10 \mathrm{~m}^{2}$ tendo como planta de centro pré-determinada, $P$. arboreum Aubl. (Piperaceae), com o objetivo de obter maior informação sobre a comunidade de Lepidoptera associada à esta espécie, para uma possível relação com o experimento com $P$. arboreum em Matas de Galeria do DF (ver capítulo II) e comparar a similaridade da comunidade entre as áreas amostradas.

No campo uma planta de $P$. arboreum era selecionada como centro da parcela, onde eram amarradas e estendidas quatro cordas $(5 \mathrm{~m})$ para a formação de quadrantes, para facilitar a vistoria de todas as espécies e indivíduos de Piper presentes à procura de lagartas. Para cada parcela todas as espécies de Piper encontradas foram contabilizadas e identificadas por taxonomista por fotos e exsicatas, sendo esta última feita apenas na primeira vez que cada nova espécie de Piper era encontrada. Mesmo assim, a identificação de algumas espécies não foi possível e, neste caso, foram classificadas como morfoespécies.

Inicialmente, foi feita a contagem do número de indivíduos de cada espécie de Piper para o cálculo posterior da densidade total e de cada espécie por parcela. Posteriormente, foi feito o mesmo para as lagartas encontradas com anotações sobre o número de indivíduos e de espécies de Lepidoptera como também o cálculo da porcentagem de plantas com lagartas.

Todos os ovos, pupas e lagartas de Lepidoptera encontrados em cada indivíduo de Piper da parcela foram coletados. No laboratório foram fotografados e receberam números de referência correspondentes à data, parcela e local de coleta e foram colocados em potes plásticos individuais identificados para a criação ou manutenção. As 
lagartas foram alimentadas com folhas da mesma espécie de planta na qual foi encontrada em campo e criadas sem controle das condições de temperatura e umidade. Todas as anotações de desenvolvimento foram feitas até as emergências dos estágios adultos dos lepidópteros ou parasitoides (Diptera e Hymenoptera).

Todos os adultos foram conservados no freezer até o momento da montagem e identificados por especialista ou por comparação com a coleção de referência e, posteriormente, tombados e depositados na Coleção Entomológica do Departamento de Zoologia da Universidade de Brasília.

\section{Análise Estatística}

O índice de diversidade de Shannon foi utilizado para calcular a diversidade de espécies de Lepidoptera (lagartas) e de espécies de Piper em cada área de estudo. Também foram construídas duas curvas de rarefação de espécies para cada área de estudo; com e sem intervalo de confiança de 95\%. O índice de similaridade de Jaccard foi utilizado para a elaboração de um dendograma para verificar a similaridade entre a comunidade de lagartas de lepidópteros associada à $P$. arboreum entre as áreas de estudo. Para averiguar a perda de informação do dendograma foi elaborada uma matriz de similaridade utilizando esse mesmo índice. Uma vez que as áreas amostradas possuem diferentes esforços de amostragem, o índice de Jaccard foi considerado mais adequado, por não considerar a abundância e sim apenas a presença ou ausência das espécies, minimizando assim as diferenças de esforço amostral.

Para investigar se a abundância e a riqueza de lagartas de lepidópteros nas parcelas (variáveis respostas) diferiram entre as estações seca e chuvosa, foram feitos modelos lineares de efeito misto (lme), um para cada uma das variáveis respostas, 
contendo a estação como variável preditora (efeito fixo) e a parcela como efeito aleatório. O teste Shapiro Wilk foi procedido para analisar a normalidade das variáveis respostas, que foram transformadas em raiz quadrada, para assumir o pressuposto de normalidade dos dados nesse tipo de análise. Todas as análises foram realizadas utilizando o software R 3.3.1 (R Development Core Team, 2016), com exceção das curvas de rarefação de espécies, que foram realizadas com o software PAST versão 3.14 (Hammer et al., 2001).

\section{RESULTADOS}

Foram encontradas 12 espécies de Piper nas sete áreas de estudo, com variação de densidade média por parcela e riqueza de duas a 10 espécies por área (Tabela 2). A área que apresentou a maior riqueza de espécies de Piper foi o PNCV, seguido do JBB. Já foram registradas 18 espécies de Piper para o Distrito Federal - DF (Proença et al., 2001; Mendonça et al., 2008). Destas, sete foram encontradas no DF no presente estudo, e as espécies Piper hillianum C. DC. e morfoespécie 5, não registradas no DF para estes estudos, foram encontradas no DF para o presente trabalho. Para o Goiás, já foram registradas nove espécies de Piper (Mendonça et al., 2008), e destas apenas duas, P. arboreum e Piper aduncum L., foram registradas para o presente trabalho; além disso, outras oito espécies foram registradas (Tabela 2). O índice de diversidade de Shannon mostrou que a área do PNCV apresentou uma maior diversidade de espécies de Piper, seguida do JBB e da RECOR (Tabela 2). P. arboreum foi a única espécie encontrada em todas as áreas amostradas, e apresentou a maior densidade média em todos os locais (Tabela 2). Quatro espécies, Piper cernuum Vell., Piper regnellii (Miq.) DC. e as morfoespécies 4 e 6, foram encontradas em apenas uma área de estudo. 
Tabela 2. Total de Piper vistoriados, riqueza e índice de diversidade de Shannon de espécies de Piper e densidade média de cada espécie de Piper por parcela $\left(10 \mathrm{~m}^{2}\right)$ para cada uma das áreas amostradas em matas de galeria do Goiás e do Distrito Federal $(\mathrm{PNCV}=$ Parque Nacional da Chapada dos Veadeiros, GO; ESECAE = Estação Ecológica de Águas Emendadas e PNB= Parque Nacional de Brasília, DF; Pirenópolis= mata de galeria no perímetro urbano, $\mathrm{GO} ; \mathrm{JBB}=$ Jardim Botânico de Brasília, FAL= Fazenda Água Limpa, e RECOR= Reserva Ecológica do Roncador, DF). Total de Piper $=$ total de indivíduos de Piper vistoriados em cada área; $\mathrm{N}^{\circ}$ de Piper $\mathrm{sp} .=$ número total de indivíduos vistoriados de cada espécie de Piper; Shannon_H=índice de Shannon.

\begin{tabular}{|c|c|c|c|c|c|c|c|c|}
\hline & PNCV & ESECAE & PNB & Pirenópolis & JBB & FAL & RECOR & \multirow[b]{5}{*}{$\mathrm{N}^{\mathrm{o}}$ de Piper sp. } \\
\hline Total de Piper & 648 & 436 & 444 & 584 & 886 & 715 & 496 & \\
\hline Riqueza (12 espécies) & 10 & 3 & 4 & 2 & 8 & 3 & 4 & \\
\hline \multirow[t]{2}{*}{ Shannon_H } & 1.64 & 0.696 & 0.794 & 0.275 & 1.3 & 0.426 & 1.3 & \\
\hline & \multicolumn{7}{|c|}{ Densidade média de cada espécie de Piper por parcela $\left(10 \mathrm{~m}^{2}\right)$} & \\
\hline Piperarboreum Aubl. & 7,42 & 6,12 & 9,77 & 13,23 & 7,03 & 14,17 & 5,74 & 3.107 \\
\hline Piper aduncum L. & 4 & $\mathrm{x}$ & 0,41 & 0,05 & 2,89 & 0,02 & 2,37 & 494 \\
\hline Piper caldense C. DC. & 3,13 & 0,31 & $\mathrm{X}$ & $\mathrm{x}$ & 1,58 & $\mathrm{x}$ & 2,3 & 362 \\
\hline Piper cernuum Vell. & 0,05 & $\mathrm{x}$ & $\mathrm{X}$ & $\mathrm{x}$ & $\mathrm{x}$ & $\mathrm{x}$ & $\mathrm{x}$ & 2 \\
\hline Piper crassinervium H. B. \& K. & 0,18 & 0,28 & 0,77 & $\mathrm{x}$ & 0,09 & $\mathrm{x}$ & 0,37 & 80 \\
\hline Piper hillianum C. DC. & 0,29 & $\mathrm{x}$ & $\mathrm{X}$ & $\mathrm{x}$ & 0,08 & $\mathrm{x}$ & $\mathrm{x}$ & 17 \\
\hline Piper tectoniifolium Kunth & $\mathrm{x}$ & $\mathrm{x}$ & $\mathrm{X}$ & $\mathrm{x}$ & 0,15 & 0,67 & $\mathrm{x}$ & 43 \\
\hline Piper xylosteoides (Kunth) S. & 1,24 & $\mathrm{x}$ & $\mathrm{X}$ & $\mathrm{x}$ & 0,09 & $\mathrm{x}$ & $\mathrm{x}$ & 54 \\
\hline Piper regnellii (Miq.) DC. & $\mathrm{x}$ & $\mathrm{x}$ & 0,46 & $\mathrm{x}$ & $\mathrm{x}$ & $\mathrm{x}$ & $\mathrm{x}$ & 18 \\
\hline Morfoespécie 4 & 0,08 & $\mathrm{x}$ & $\mathrm{X}$ & $\mathrm{x}$ & $\mathrm{x}$ & $\mathrm{x}$ & $\mathrm{x}$ & 3 \\
\hline Morfoespécie 5 & 0,21 & $\mathrm{x}$ & $\mathrm{X}$ & $\mathrm{x}$ & 0,05 & $\mathrm{x}$ & $\mathrm{x}$ & 12 \\
\hline Morfoespécie 6 & 0,45 & $\mathrm{x}$ & $\mathrm{X}$ & $\mathrm{x}$ & $\mathrm{x}$ & $\mathrm{x}$ & $\mathrm{x}$ & 17 \\
\hline
\end{tabular}

O estudo foi realizado em diferentes períodos e com diferentes esforços de amostragem entre as áreas (Tabela 3). Foram vistoriadas mais de 4.000 plantas do gênero Piper em 354 parcelas de sete áreas de estudo e encontrados 331 lepidópteros (número considerado como abundância total) que incluiu os ovos, lagartas e pupas 
(Tabela 3), em 246 plantas. Destes 331 lepidópteros encontrados, 243 emergiram como adultos no laboratório ou foram identificados taxonomicamente, resultando em 60 espécies. Assim, esta abundância $(n=243)$ foi utilizada para as análises que envolviam a riqueza e composição de espécies.

A ocorrência de Lepidoptera por indivíduo de Piper foi muito baixa, com uma média de 0,08 indivíduos por planta. Considerando o número total de parcelas vistoriadas, foram coletados 0,9 Lepidoptera por parcela. A amplitude da abundância de lagartas variou de zero a 17 indivíduos e a riqueza de zero a cinco espécies, por parcela. A abundância e riqueza de espécies variaram também entre as áreas de estudo (veja Tabela 3). 
Tabela 3. Áreas de estudo, períodos amostrais, número de parcelas e de Piper examinados e abundância e riqueza de Lepidoptera encontrados em espécies de Piper, em sete áreas de Mata de Galeria no Cerrado de Goiás e do Distrito Federal (Abund.=abundância de Lepidoptera em cada período amostral; Abund./riq./área= Abundância/riqueza de espécies de Lepidoptera, por área de estudo; PNCV= Parque Nacional da Chapada dos Veadeiros, GO; ESECAE= Estação Ecológica de Águas Emendadas, e PNB= Parque Nacional de Brasília, DF; Pirenópolis= mata de galeria no perímetro urbano, GO; JBB= Jardim Botânico de Brasília, FAL= Fazenda Água Limpa, e RECOR= Reserva Ecológica do Roncador, DF).

\begin{tabular}{|c|c|c|c|c|}
\hline Áreas (n ${ }^{\circ}$ total de parcelas)/períodos amostrais & $\mathrm{N}^{\circ}$ de parcelas & $\mathbf{N}^{\circ}$ de Piper spp. & Abund. & Abund./riq./área \\
\hline \multicolumn{5}{|l|}{ PNCV (38) } \\
\hline $05-06 / 2015$ & 12 & 196 & 35 & $48 / 16$ \\
\hline $03-04 / 2016$ & 26 & 452 & 13 & \\
\hline \multicolumn{5}{|l|}{ ESECAE (65) } \\
\hline $05-06 / 2015$ & 16 & 157 & 34 & $46 / 09$ \\
\hline $08-11 / 2015$ & 26 & 157 & 6 & \\
\hline $01 / 16$ & 12 & 38 & 0 & \\
\hline $03-04 / 2016$ & 11 & 84 & 6 & \\
\hline \multicolumn{5}{|l|}{ PNB (39) } \\
\hline $05-06 / 2015$ & 16 & 209 & 27 & $51 / 10$ \\
\hline $08 / 15$ & 5 & 16 & 0 & \\
\hline $03-04 / 2016$ & 18 & 220 & 24 & \\
\hline \multicolumn{5}{|l|}{ Pirenópolis (44) } \\
\hline $10 / 15$ & 12 & 145 & 1 & $45 / 11$ \\
\hline $02-04 / 2016$ & 32 & 439 & 44 & \\
\hline \multicolumn{5}{|l|}{ JBB (44) } \\
\hline $10 / 15$ & 12 & 145 & 1 & $19 / 12$ \\
\hline $02-04 / 2016$ & 32 & 439 & 44 & \\
\hline \multicolumn{5}{|l|}{ FAL (54) } \\
\hline $07 / 15$ & 6 & 78 & 40 & $87 / 25$ \\
\hline $09-10 / 2015$ & 18 & 201 & 10 & \\
\hline $12 / 15$ & 12 & 172 & 22 & \\
\hline $02-04 / 2016$ & 18 & 263 & 15 & \\
\hline \multicolumn{5}{|l|}{ RECOR (40) } \\
\hline 06-07/2015 & 16 & 278 & 16 & $35 / 10$ \\
\hline $03-04 / 2016$ & 24 & 218 & 19 & \\
\hline Total geral & 354 & 4.209 & 331 & \\
\hline
\end{tabular}


$\mathrm{Na}$ área da Mata de Galeria da FAL houve o maior registro considerando a abundância e riqueza de espécies de Lepidoptera (Tabela 3) enquanto a área de menor registro foi o JBB (Tabela 3). A proporção de ocupação de lagartas de lepidopteros nas plantas foi de 9,4\% no PNB, 2,2\% no JBB, 7,9\% na FAL, 7,7\% na ESECAE, 5,7\% no PNCV, 5,4\% em Pirenópolis e 4,8\% na RECOR, com uma ocupação total de apenas $5,8 \%$ das plantas vistoriadas.

As 60 espécies de Lepidoptera, todas folívoras, estavam distribuídas em 15 famílias. A família Geometridae foi a mais representativa, com 13 espécies, seguida de Erebidae e Tortricidae, ambas com oito espécies. Sessenta e cinco porcento (65\%) das espécies foram representadas por apenas um indivíduo (singletons) e $25 \%$ foram representadas por menos de 10 indivíduos e, portanto, consideradas raras (90\% das espécies). Apenas $10 \%$ das espécies foram representadas por mais de 10 indivíduos. São elas: Gonodonta nutrix Stoll, 1780 (Noctuiidae) (15\%) da abundância da fauna, Eois binaria Guenee, 1858 (12\%), Eois tegularia Guenee, 1858 (9\%) e Geometridae sp. 6 (6\%) (Geometridae), Arctiinae sp.4 (Erebidae) (9\%) e Memphis moruus boisduvali W. Comstock, 1961 (Nymphalidae) (7\%). O gênero Quadrus (Hesperiidae) foi bastante representativo, representando $13 \%$ das lagartas que foram encontradas, mais devido à alta taxa de mortalidade das lagartas por parasitoides, patógenos, ou por causas indeterminadas, a maioria dos indivíduos não pode ser identificado, visto que as lagartas desse gênero são muito semelhantes. Esses indivíduos foram inseridos nas tabelas como Quadrus spp., e provavelmente são Quadrus cerealis Stoll, 1782 ou Quadrus u-lucida Plötz, 1884, as duas espécies do gênero Quadrus encontradas regularmente em Piper no presente estudo. 
Apesar da riqueza de espécies ter sido muito alta, apenas 11 espécies representando oito famílias foram identificadas pelos seus nomes binomiais (Tabela 4; Anexo 1).

Tabela 4. Espécies de Lepidoptera consumidoras de Piper spp. coletadas em Matas de Galeria (Goiás e Distrito Federal, Brasil), de maio de 2015 a abril de 2016 (destaque em negrito para as espécies mais abundantes).

\begin{tabular}{llc}
\hline \multicolumn{1}{c}{ Lepidoptera } & \\
\hline Família & Espécie & Abund. (\%) \\
\hline \multirow{2}{*}{ Bombycidae } & Zanola verago (Cramer, 1777) & $(0,4 \%)$ \\
Geometridae & Eois binaria (Guenee, 1858) & $\mathbf{( 1 2 \% )}$ \\
& Eois tegularia (Guenee, 1858) & $\mathbf{( 9 \% )}$ \\
Hesperiidae & Quadrus cerealis (Stoll, 1782) & $(1,6 \%)$ \\
& Quadrus u-lucida (Plötz, 1884) & $(0,8 \%)$ \\
Noctuidae & Gonodonta nutrix (Stoll, 1780) & $\mathbf{( 1 5 \% )}$ \\
Nymphalidae & Ithomia agnosia zikani (d'Almeida, 1940) & $(0,4 \%)$ \\
& Memphis moruus boisduvali (W. Comstock, 1961) & $(\mathbf{7 \%})$ \\
Oecophoridae & Inga haemataula (Meyrick, 1912) & $(0,4 \%)$ \\
Riodinidae & Anteros lectabilis (Stichel, 1909) & $(1,2 \%)$ \\
Tortricidae & Platynota rostrana (Walker, 1863) & $(0,8 \%)$ \\
& & \\
\hline
\end{tabular}

A composição de espécies também foi variável entre as áreas. As espécies mais abundantes na FAL foram todas da família Geometridae (48\% da fauna), sendo Eois binaria com 22 indivíduos (30\%) e Geometridae sp. 6 com 13 indivíduos (18\%). No PNCV a espécie mais abundante foi também da família Geometridae; Eois tegularia, com 18 indivíduos (42\%). Na RECOR e em Pirenópolis a espécie mais abundante foi Gonodonta nutrix, com 14 (42\%) e 11 (38\%) dos indivíduos, respectivamente. No PNB a espécie mais abundante foi Arctiinae sp.4, com oito individuos (30\%). Na ESECAE o gênero Quadrus apresentou maior abundância em relação aos outros gêneros. O JBB 
não apresentou uma espécie dominante típica. A maioria das espécies foi representada por apenas um indivíduo (singleton). Em todas as áreas amostradas foi observada uma baixa proporção de espécies com abundância maior que 10 indivíduos, em duas áreas não houve espécies nesta faixa enquanto nas outras houve apenas uma ou duas com tal abundância (Tabela 5). Por outro lado, houve registro de alta proporção de singletons que variou de $50 \%$ a $91 \%$ da fauna por área (Tabela 5).

Tabela 5. Riqueza e abundância de espécies de lagartas de lepidópteros folívoros em espécies de Piper nas sete áreas de mata de galeria do DF e do GO, amostradas no período de maio/2015 a abril/2016, (Lepid. spp.= riqueza de Lepidoptera; $\mathrm{N}>10=$ espécies representadas por mais de 10 indivíduos; Raras= espécies representadas por menos de 10 indivíduos; $(\%)=$ porcentagens; PNCV= Parque Nacional da Chapada dos Veadeiros, GO; ESECAE= Estação Ecológica de Águas Emendadas, e PNB= Parque Nacional de Brasília, DF; Piren.= mata de galeria no perímetro urbano de Pirenópolis, GO; JBB= Jardim Botânico de Brasília, FAL= Fazenda Água Limpa, e RECOR= Reserva Ecológica do Roncador, DF).

\begin{tabular}{lllll}
\hline Local & Lepid. spp. & $\mathrm{N}>10$ & Raras (\%) & Singletons $(\%)$ \\
\hline PNCV & 16 & $1(6)$ & $5(31)$ & $10(62)$ \\
ESECAE & 9 & $1 *(11)$ & $3(33)$ & $5(55)$ \\
PNB & 10 & 0 & $3(30)$ & $7(70)$ \\
Piren. & 11 & $1(9)$ & $2(18)$ & $8(72)$ \\
JBB & 12 & 0 & $1(8)$ & $11(91)$ \\
FAL & 25 & $2(8)$ & $8(32)$ & $15(60)$ \\
RECOR & 10 & $1(10)$ & $4(40)$ & $5(50)$ \\
*Quadrus spp. & & & &
\end{tabular}


A abundância e riqueza média de lagartas por parcela variou entre as áreas. A área da FAL apresentou a maior abundância e riqueza média de lagartas por parcela, seguida do PNCV. As menores médias de abundância e riqueza de lagartas por parcela foram encontradas no JBB (Figura 2). O desvio padrão foi alto para todas as áreas, devido ao grande número de parcelas que apresentaram ausência de lagartas.

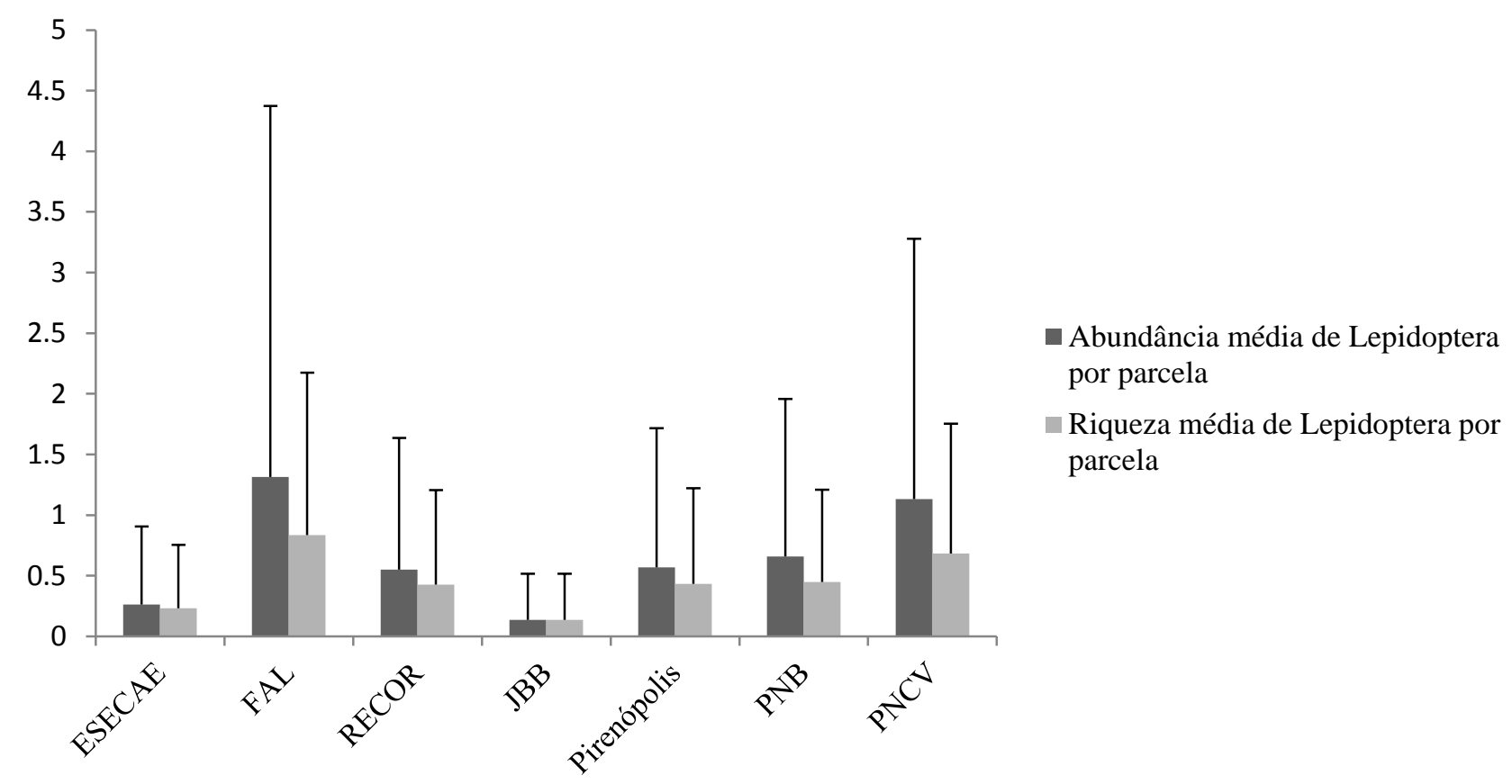

Figura 2. Abundância e riqueza média de Lepidoptera por parcela nas áreas de matas de galeria amostradas no Distrito Federal-DF e Goiás-GO (PNCV=Parque Nacional da Chapada dos Veadeiros e Pirenópolis=mata de galeria no perímetro urbano (GO) e ESECAE=Estação Ecológica de Águas Emendadas, FAL=Fazenda Água Limpa, RECOR=Reserva Ecológica do Roncador, JBB=Jardim Botânico de Brasília e PNB=Parque Nacional de Brasília, no DF).

As curvas de rarefação mostram que o JBB apresentou a maior riqueza de espécies de lepidópteros, apesar de possuir a menor abundância, seguido da FAL e do 
PNCV (Figura 3). As outras áreas apresentaram uma riqueza similar (Figura 3).

Nenhuma das áreas amostradas apresentou uma tendência assíntota, indicando que a riqueza das comunidades de lepidópteros nas áreas amostradas é representada por um número maior de espécies do que o observado.

A

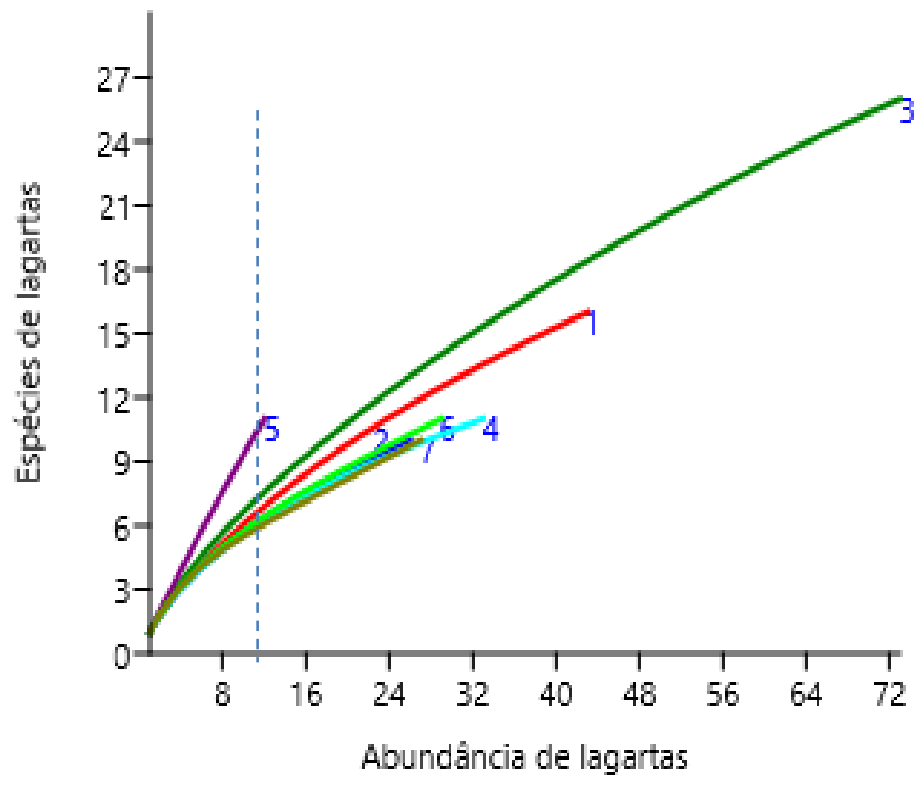

$\mathrm{B}$

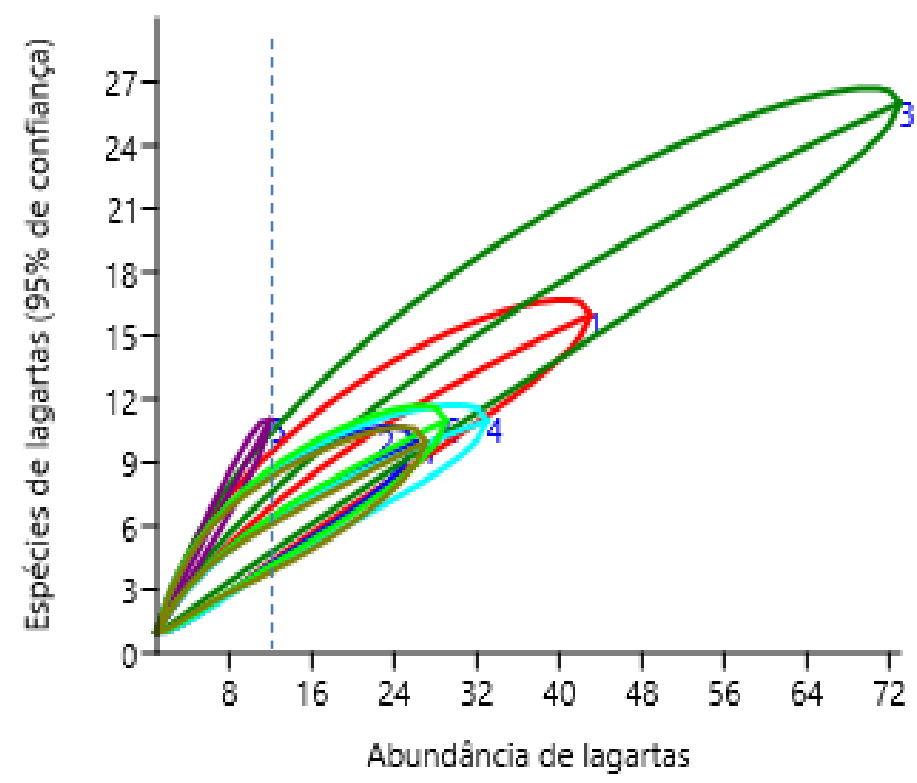

Figura 3. Curvas de rarefação de espécies de lepidópteros das áreas amostradas, sem (A) e com (B) intervalo de confiança de 95\% (1=Parque Nacional da Chapada dos Veadeiros; 2=Estação Ecológica de Aguas Emendadas; 3=Fazenda Água Limpa; 4=Reserva Ecológica do Roncador; 5=Jardim Botânico de Brasília; 6=mata de galeria no perímetro urbano de Pirenópolis; 7=Parque Nacional de Brasília). A linha tracejada representa o ponto em que as diferentes comunidades de lepidópteros foram comparadas. 
O mais alto índice de diversidade de lagartas foi encontrado na FAL, e o mais baixo foi encontrado em Pirenópolis (Tabela 6).

Tabela 6. Índice de diversidade de Shannon das comunidades de lagartas de Lepidoptera em espécies de Piper para cada uma das áreas de estudo $(\mathrm{FAL}=$ Fazenda Água Limpa, RECOR= Reserva Ecológica do Roncador, JBB= Jardim Botânico de Brasília, PNB= Parque Nacional de Brasília, e ESECAE= Estação Ecológica de Águas Emendadas, no DF; Piren.= perímetro urbano de Pirenópolis e PNCV= Parque Nacional da Chapada dos Veadeiros, GO).

\begin{tabular}{lllllllrr}
\hline $\begin{array}{l}\text { H - Índice } \\
\text { de Shannon }\end{array}$ & Áreas & & & & & & & \\
\hline & FAL & RECOR & JBB & PNB & ESECAE & Pirenópolis & PNCV \\
\cline { 2 - 10 } & $\mathbf{2 , 5 3 1}$ & 1,899 & 2,369 & 1,877 & 1,731 & $\mathbf{1 , 7 2 8}$ & 2,152 \\
\hline
\end{tabular}

A maioria das espécies de Lepidoptera (80\%) ocorreu em apenas uma das áreas de estudo, sendo que apenas uma espécie, Memphis moruus, ocorreu em todas as áreas. Gonodonta nutrix ocorreu em seis áreas, e Eois binaria e Arctiinae sp.4 ocorreram em cinco das áreas. As outras espécies ocorreram em apenas uma até três das áreas amostradas (Anexo 1).

Considerando apenas a distribuição da comunidade de Lepidoptera em $P$. arboreum, a área da FAL teve 24 espécies de lepidópteros, Pirenópolis 10, PNB, JBB e ESECAE tiveram nove espécies cada uma, e PNCV e RECOR, sete espécies cada uma (Anexo 2). A área da FAL apresentou 14 singletons, o JBB oito, Pirenópolis sete, PNB seis e PNCV e RECOR três singletons cada uma. 
O dendograma de similaridade (Índice de Jaccard, baseado na presença ou ausência de espécies), levando em conta a composição de lepidópteros registrados em $P$. arboreum; revelou a formação de dois grupos de áreas. $\mathrm{O}$ grupo 1 foi composto pela RECOR e pelo JBB, que apresentam menos de $10 \mathrm{~km}$ de distância uma da outra (Tabela 1, Figura 4), e o grupo 2 pelas áreas ESECAE, PNB, FAL, PNCV e Pirenópolis (Figura 4). Entretanto, as áreas mais similares foram RECOR e ESECAE, e as áreas menos similares foram PNCV e Pirenópolis, PNCV e PNB, e PNCV e JBB, que também são as áreas que apresentam uma distância de mais de 150km uma da outra (Tabela 1 e 7).

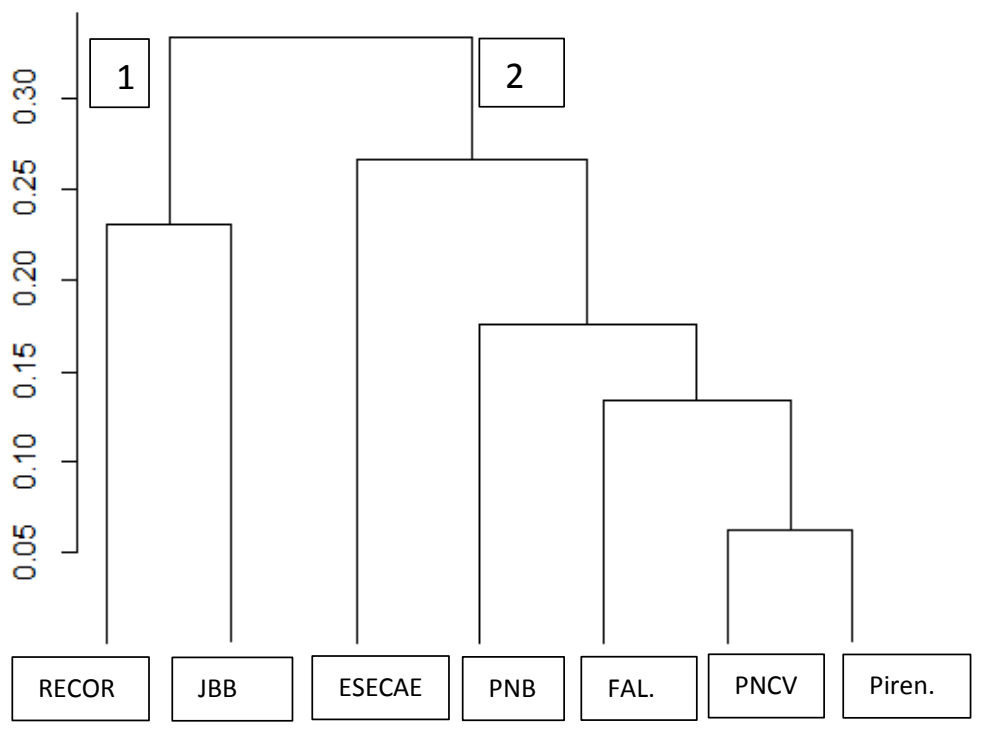

Figura 4. Dendograma de agrupamento de espécies de Lepidoptera utilizando o índice de similaridade de Jaccard (presença e ausência), para a comunidade de lagartas de Lepidoptera em $P$. arboreum das matas de galeria amostradas $($ Piren. $=$ mata de galeria no perímetro urbano de Pirenópolis e PNCV=Parque Nacional da Chapada dos Veadeiros, GO; e ESECAE=Estação Ecológica de Águas Emendadas, FAL=Fazenda Água Limpa, RECOR=Reserva Ecológica do Roncador, JBB=Jardim Botânico de Brasília e PNB=Parque Nacional de Brasília, DF). 
Em geral, todos os índices de similaridade da comunidade de lagartas de lepidópteros em P. arboreum entre as áreas amostradas foram baixos (Tabela 7). As áreas que apresentaram o maior índice de similaridade, RECOR e ESECAE, apresentaram apenas quatro espécies em comum, o que corresponde a 33\% das espécies de lagartas em $P$. arboreum encontradas nestas áreas.

Tabela 7. Matriz de similaridade utilizando de Jaccard, para a comunidade de lagartas de Lepidoptera em P. arboreum das matas de galeria amostradas (Pirenópolis e PNCV= Parque Nacional da Chapada dos Veadeiros, GO; ESECAE= Estação Ecológica de Águas Emendadas, FAL=Fazenda Água Limpa, RECOR=Reserva Ecológica do Roncador, JBB=Jardim Botânico de Brasília e PNB=Parque Nacional de Brasília, DF).

\begin{tabular}{lllllll}
\hline & PNCV & ESECAE & RECOR & JBB & FAL & Pirenópolis \\
\hline ESECAE & 0,143 & & & & & \\
RECOR & 0,167 & $\mathbf{0 , 3 3 3}$ & & & & \\
JBB & $\mathbf{0 , 0 6 7}$ & 0,286 & 0,231 & & & \\
FAL & 0,107 & 0,222 & 0,148 & 0,179 & & \\
Pirenópolis & $\mathbf{0 , 0 6 3}$ & 0,267 & 0,308 & 0,188 & 0,133 & \\
PNB & $\mathbf{0 , 0 6 3}$ & 0,267 & 0,214 & 0,267 & 0,133 & 0,176 \\
\hline
\end{tabular}

Considerando o total de lagartas coletadas, $10 \%$ das lagartas estavam parasitadas, mas houve variação entre as áreas de estudo. Pirenópolis apresentou 20\% das lagartas parasitadas, ESECAE 15\%, FAL e PNB 10\% cada, RECOR 8.5\%, PNCV 2\% e a área do JBB não apresentou nenhuma lagarta parasitada.

Considerando todos os lepidópteros, a maioria dos indivíduos foram encontrados em $P$. arboreum. As outras espécies de Piper amostradas apresentaram todas menos de 
10\% dos indivíduos encontrados (Figura 5). Nenhum indivíduo de Lepidoptera foi encontrado em $P$. regnellii. Quanto à riqueza, houve registro de 51 espécies associadas à $P$. arboreum, oito à $P$. aduncum e seis à $P$. caldense. As outras espécies de Piper que apresentaram indivíduos de Lepidoptera tiveram de uma a duas espécies de lepidópteros.

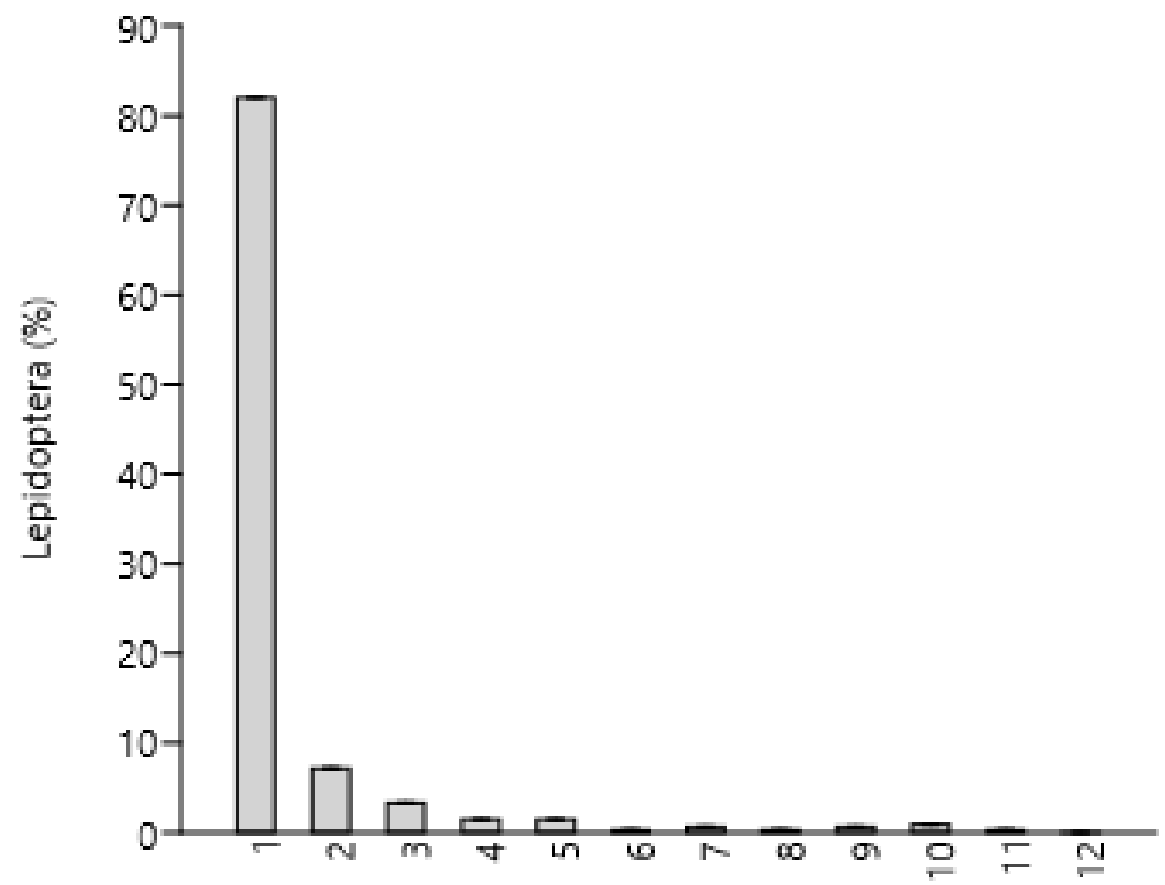

Figura 5. Indivíduos de Lepidoptera (\%) encontrados em espécies de Piper amostradas nas matas de galeria no DF e no Goiás, de maio de 2015 a abril de 2016 (Tabela 3) $(1=P . \quad$ arboreum $; 2=P$. aduncum; 3=P. caldense; $4=P$. tectoniifolium; 5=P. crassinervium; $6=P$. cernuum $; 7=P$. xylosteoides $; 8=P$. hillianum $; 9=$ Morfoespécie $4 ;$ 10=Morfoespécie 5; 11=Morfoespécie 6;12=P. regnellii).

A frequência de plantas com lepidópteros também variou entre as espécies de Piper. A morfoespécie 4 apresentou 33\% das plantas com lepidópteros, a morfoespécie 
$516 \%, P$. crassinervium $8,5 \%, P$. tectoniifolium e P. xylosteoides $7 \%$ e 7,4\%, respectivamente, $P$. arboreum 6,2\%, $P$. hillianum e morfoespécie $65,8 \%$ cada e $P$. aduncum e $P$. caldense $4,4 \%$ e $3,3 \%$, respectivamente.

O pico da abundância média de lagartas por parcela ocorreu na primeira metade da estação seca (julho; Figura 6). Após este período houve um brusco declínio, com um aumento discreto novamente em dezembro, e de fevereiro a março. A riqueza média de lagartas por parcela não apresentou um pico, e houve pouca variação entre os meses. $\mathrm{O}$ desvio padrão para a abundância e riqueza média de lagartas por parcela foi alto em todas os meses, devido ao grande número de parcelas que apresentaram ausência de lagartas.

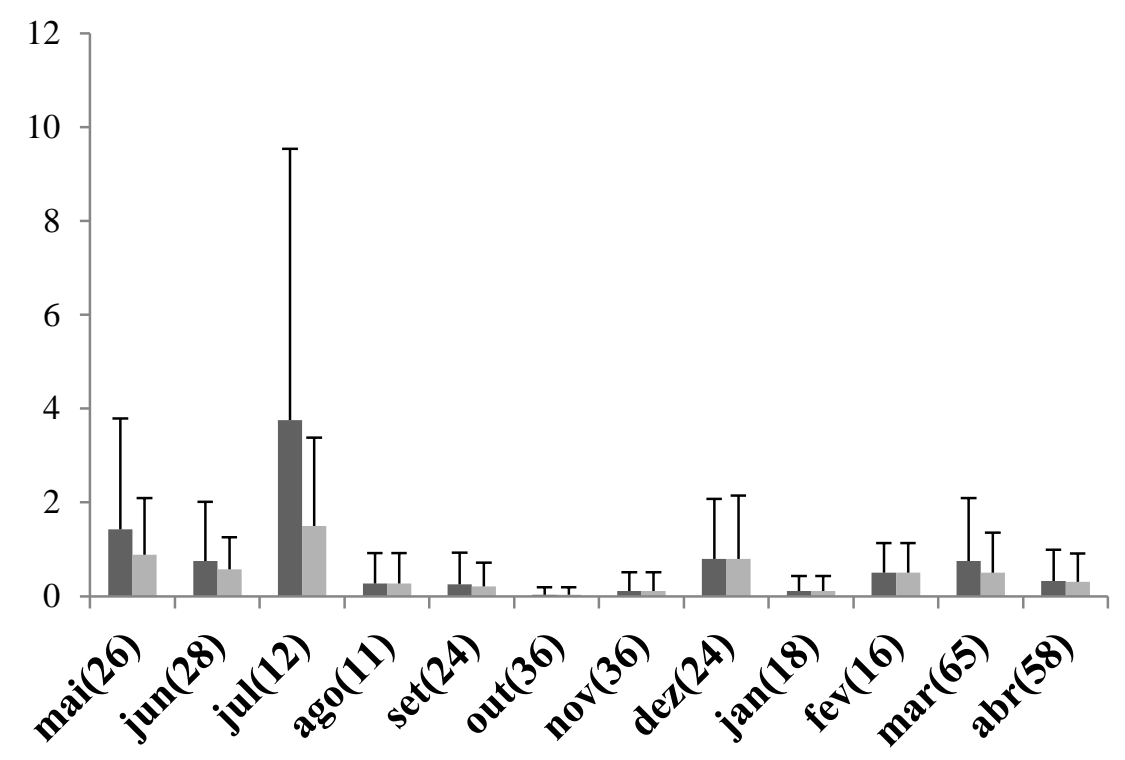

- Abundância média de Lepidoptera por parcela

$\square$ Riqueza média de Lepidoptera por parcela

Figura 6. Abundância e riqueza média de lagartas por parcela mensal em matas de galeria amostradas no DF e no Goiás de maio de 2015 a abril de 2016 (Tabela 3). ( ) =número de parcelas amostradas no mês.

A abundância de Lepidoptera nas parcelas diferiu significativamente entre as estações seca e chuvosa ( $\mathrm{F}=277.9 ; \mathrm{P}=$ <.0001; Figura 7), e explicou 9\% da variação. 
Uma maior abundância de Lepidoptera por parcela foi encontrada na estação seca. A riqueza de Lepidoptera nas parcelas não diferiu significativamente entre as estações seca e chuvosa $(\mathrm{F}=0.308 ; \mathrm{P}=0.5792)$.

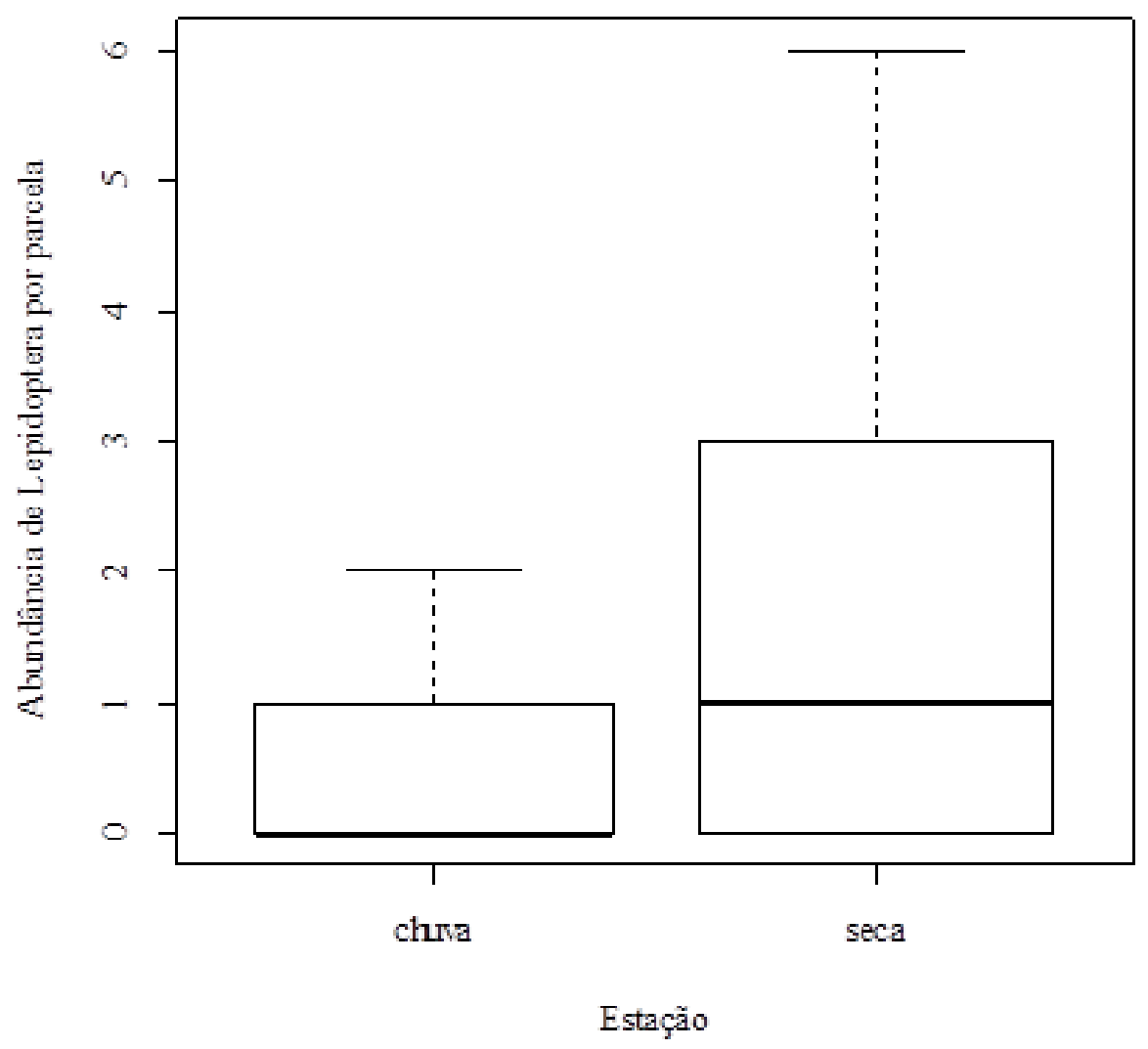

Figura 7. Estações seca e chuvosa e abundância de Lepidoptera por parcela nas matas de galeria do DF e Goiás amostradas, de maio/2015 a abril/2016. A linha mais larga representa a mediana, e a linha tracejada representa o desvio padrão.

A distribuição temporal das espécies de Lepidoptera nas áreas amostradas, em geral, não variou entre as estações. A maioria das espécies ocorreu tanto na estação seca como na chuvosa. Entretanto, em geral, um maior número de espécies ocorreu de forma contínua por três ou mais meses na estação seca (Tabela 8). 
Tabela 8. Ocorrência temporal de espécies de lagartas de Lepidoptera, folívoras externas, encontradas em Piper spp. nas áreas amostradas, de maio de 2015 a abril de 2016 (singletons não foram considerados).

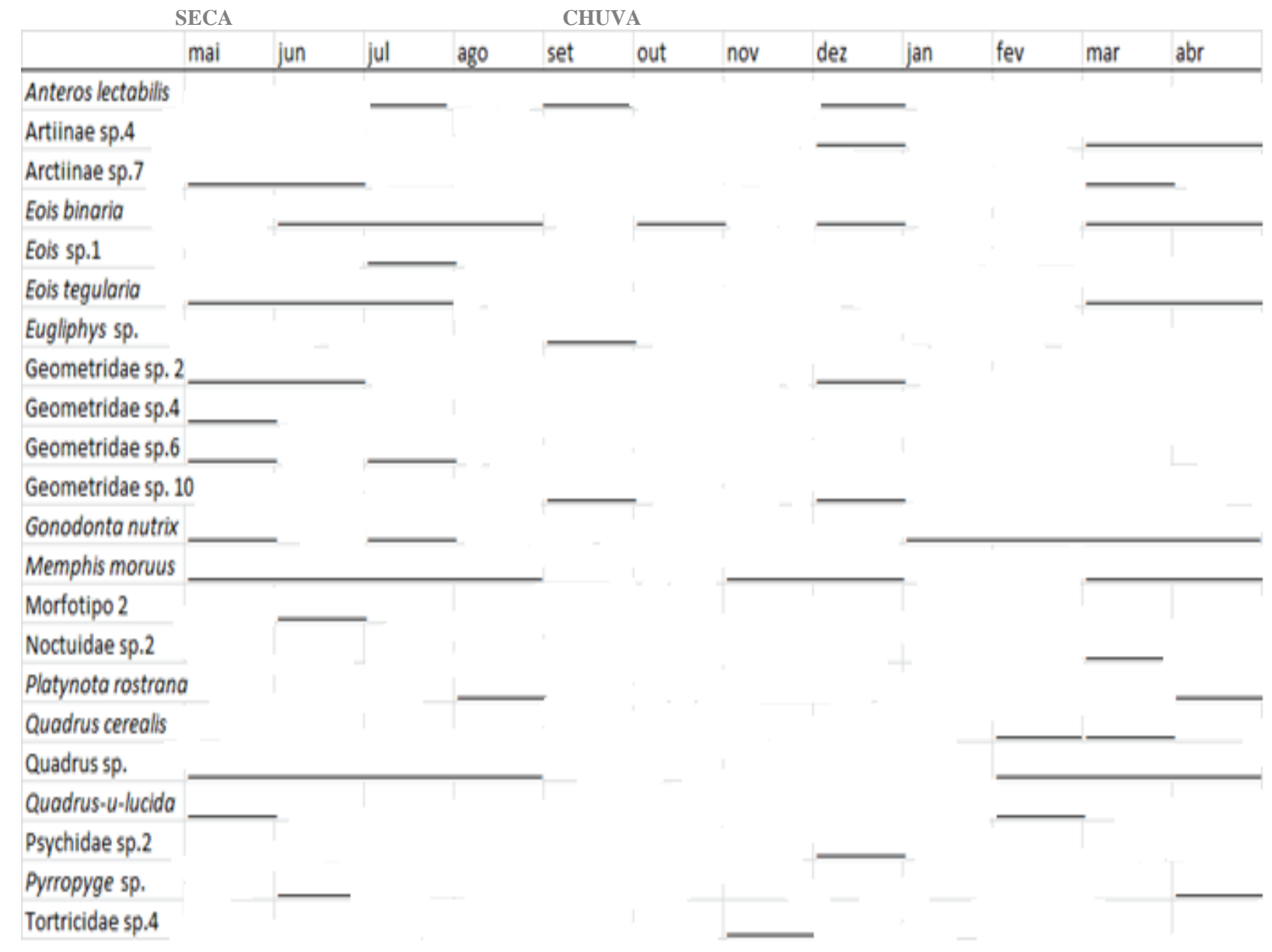

\section{DISCUSSÃO}

\section{Riqueza e Abundância}

Este é um capítulo descritivo sobre a fauna de Lepidoptera associada à 12 espécies de Piper. Estas amostras em sete áreas de mata de galeria, separadas por diferentes distâncias, que variam de 8 até $230 \mathrm{~km}$, são representativas da comunidade de Piper e de seus lepidópteros associados. Assim, temos um sistema de plantas 
hospedeiras diversas, distribuídas espacialmente de maneira não uniforme e com densidades variáveis.

Os resultados obtidos mostram uma fauna de Lepidoptera associada ao gênero Piper bastante rica (60 espécies) com variações, espaciais e temporais, significativas na composição, estrutura da comunidade, abundância, frequência nas plantas, diversidade e nas porcentagens de parasitismo das lagartas.

A abundância das espécies sofre variações espaciais, e desta forma, uma espécie pode ser comum em alguns lugares e rara em outros (Gaston, 1994). No Cerrado, notadamente, ocorre uma extrema variação espacial e temporal das espécies de lepidópteros, o que pode estar relacionado à alta incidência de espécies raras (Diniz \& Morais, 1997). A maioria das espécies de Lepidoptera encontrada em Piper pode ser considerada rara, com ocorrência menor do que 10 indivíduos em todas as parcelas (54/60 espécies). A alta riqueza de espécies raras (incluindo os singletons) de Lepidoptera já havia sido observada em plantas do gênero Erytroxylum (Erytroxylaceae) no cerrado sentido restrito do Distrito Federal (Price et al., 1995), como também em outros gêneros de plantas hospedeiras (Diniz \& Morais, 1997; Andrade et al., 1999). Assim, este parece ser um padrão recorrente tanto para a fitofisionomia savânica quanto para a florestal (Mata de Galeria) no Cerrado do Brasil Central. A alta riqueza de espécies raras pode ser explicada, em parte, tanto pela presença de lepidópteros de dieta especializada com baixa densidade populacional como por espécies generalistas que, ocasionalmente, se alimentam do sistema herbívoro-hospedeiro estudado e, ainda, por limitações devido às variáveis ambientais, como fatores bióticos, tais como diversidades genética e fitoquímica e, ainda, da fenologia da planta hospedeira, como também aos fatores abióticos (Novotny \& Basset, 2000). 
A alta riqueza de espécies raras e as variações da composição de espécies espacial (entre áreas) e temporal (entre períodos) foi também responsável pelo alto número de espécies não compartilhadas incluindo aquelas áreas bastante próximas. A maioria das espécies de lagartas de lepidópteros (80\%) no presente estudo, foi encontrada em apenas uma das sete áreas de estudo. Assim, a baixa similaridade da composição espacial, aliada à baixa densidade de populações de espécies de lepidópteros faz com que uma parte substancial das interações Piper/Lepidoptera seja composta por associações pouco frequentes quando considera-se várias áreas de estudo (Lewinsohn et al., 2005).

A comunidade de lagartas associada às espécies de Piper nas Matas de Galeria do Cerrado do Brasil Central apresenta, como em outros biomas e associações, aquelas espécies de dieta especialista e generalistas. Quatro gêneros de quatro famílias de lepidópteros foram considerados como especialista em Piper: Eois, Quadrus, Memphis e Gonodonta. As espécies de lagartas do gênero Eois Hubner, 1818 (Geometridae, Larentiinae) são conhecidas por sua especificidade alimentar em plantas do gênero Piper, com distribuição continental (Marquis., 1991; Dyer \& Palmer, 2004; Letourneau, 2004). No presente estudo, quatro espécies de Eois foram encontradas e representaram $22 \%$ da fauna de lepidópteros. Este resultado mostrou uma predominância deste gênero bastante inferior, por exemplo, ao encontrado em fragmentos de Mata Atlântica, São Carlos, São Paulo (Shimbori, 2009). A espécie dominante na Mata Atlântica de São Carlos foi Eois tegularia (Shimbori, 2009) em alta proporção (87\% da fauna) enquanto, no presente estudo, essa espécie representou apenas 9\% das lagartas encontradas. Resultado mais discrepante, ainda, foi encontrado em florestas tropicais úmidas do Equador e do Peru quando houve alta proporção de associação de Eois e Piper kelleyi (Tepe et al., 2014). Exemplo de espécie com ampla distribuição é Eois binaria, 
encontrada no presente estudo tanto em escala local quanto em escala regional e também registrada associada ao gênero Piper em floresta úmida tropical na Costa Rica (Marquis, 1990).

Outro gênero de lagartas de lepidópteros especialista, com distribuição continental e bastante comum em Piper é o Quadrus Lindsey, 1925 (Hesperiidae) (Marquis, 1991; Letourneau, 2004). No presente estudo as lagartas de lepidópteros desse gênero representaram $13 \%$ dos indivíduos encontrados. Quadrus cerealis é uma das espécies mais comuns associada ao Piper e com ampla distribuição geográfica na América Central, principalmente na Costa Rica, sendo registrada em vários trabalhos na região, alimentando-se de muitas espécies de Piper (Marquis, 1991, Dyer \& Gentry, 2002; Janzen \& Hallwachs, 2005), como também em fragmentos de Mata Atlântica (Shimbori, 2009). Esta espécie foi registrada nas matas de galeria amostradas no presente estudo tanto na escala local quanto na regional, o que pode indicar que esse especialista é bem distribuído entre as áreas e que a sua especificidade de dieta não é uma característica local nem regional. No presente trabalho, foram encontradas duas espécies do gênero: Quadrus cerealis e Quadrus u-lucida, muito semelhantes morfologicamente nos estágios larvais. Devido ao fato de que a maioria dos adultos não chegou à emergência, a proporção de cada uma destas espécies foi bastante subestimada. Outros dois gêneros comuns no presente estudo, Memphis Hubner, 1819 (Nymphalidae, Charaxinae) e Gonodonta Hubner, 1818 (Noctuidae), também foram registrados na América Central (Dyer \& Gentry, 2002; Janzen \& Hallwachs, 2005).

O índice de diversidade de lepidópteros nas áreas foi variável e comparativamente a área mais diversa foi a Mata de Galeria da Fazenda Água LimpaFAL, o que pode ser explicado pela alta riqueza aliada à distribuição mais equitativa da abundância das espécies nesta Mata. O Jardim Botânico de Brasília-JBB, área bem 
próxima à FAL, também apresentou uma alta diversidade, e uma das possíveis explicações sobre o seu alto valor de diversidade, é que a presença de um elevado número de singletons juntamente a ausência de uma espécie dominante nessa área, assegurou uma maior equitabilidade em comparação com outras áreas, que apresentaram sempre uma ou outra espécie dominante.

A ocupação das plantas hospedeiras pelos lepidópteros no presente trabalho foi bastante baixa (0,08 Lepidoptera/planta), sendo necessário um esforço amostral de mais de 12 indivíduos para ter probabilidade de se encontrar um lepidóptero em Piper. Esta baixa frequência ou ocorrência de lagartas de lepidópteros foi encontrada também no cerrado sentido restrito para outras espécies ou gêneros de plantas hospedeiras $(0.10$ indivíduos/planta) (Price et al., 1995). Mesmo em florestas úmidas como a da Guiana Francesa foi, também, encontrado uma baixa frequência de ocorrência de lagartas em várias espécies de árvores (Basset \& Novotny, 1999). Mesmo se considerarmos apenas uma única espécie, no caso Piper arieianum, em floresta úmida tropical na Costa Rica, a frequência de lagartas de lepidópteros por planta continua muito baixa (0.07/planta) (Marquis, 1991). Entretanto, esta proporção de ocupação de plantas pelos lepidópteros é bastante variável para cada espécie de Piper. No presente estudo houve espécies de Piper que não apresentaram nenhum lepidóptero enquanto em outra espécie a proporção chegou a 33\% das plantas vistoriadas. Esta variação é similar à obtida para as plantas hospedeiras do cerrado sentido restrito $(0.7 \%-34 \%$ por espécie de planta) (Marquis et al., 2002).

A ocorrência de espécies de lepidópteros por espécie de planta hospedeira também foi variável. No presente estudo variou de zero para $P$. regnelli até 51 espécies amostradas em P. arboreum. 


\section{Comunidade de Lepidoptera associada a Piper arboreum}

P. arboreum, selecionada como espécie central das parcelas, foi a única espécie amostrada em todas as parcelas e períodos e, portanto, possui dados mais consistentes e comparativos. A riqueza de espécies $(\mathrm{n}=51)$ de lepidópteros encontrada em $P$. arboreum foi bastante alta, comparada à riqueza média de lagartas por espécie de planta hospedeira (=28.3) encontrada em áreas de cerrado sentido restrito que margeia três das matas de galerias utilizadas no presente estudo (Diniz \& Morais, 1997), como também à média de quatro a oito espécies de lagartas por espécie de planta encontrada em Costa Rica (Janzen, 1988). Em 14 anos de amostragens não contínuas foram registradas 62 espécies de lagartas de Lepidoptera em Roupala montana (Proteaceae) no cerrado sentido restrito do Distrito Federal (Bendicho-López et al., 2006), número este bastante similar à riqueza encontrada em $P$. arboreum em apenas um ano de amostragem, no presente estudo. A ampla distribuição e a alta densidade em comparação a espécies congenéricas de $P$. arboreum nas áreas amostradas no presente estudo são provavelmente os principais fatores que contribuíram para essa alta riqueza de espécies de lagartas encontrada.

Entretanto, houve variação espacial (entre áreas de estudo) bastante evidente na composição da fauna de lepidópteros associada à $P$. arboreum, mesmo entre áreas muito próximas. Inúmeros fatores podem influenciar a variação espacial de insetos herbívoros e suas associações tróficas, seja os bióticos, entre eles a variação fitoquímica (Dyer et al., 2003, 2004) ou genética (Karban, 1992; Marquis, 1990; Mauricio, 1998; Tiffin \& Rausher, 1999) da planta hospedeira, que será objeto de investigação do capítulo II ou, ainda diversos outros fatores tanto bióticos quanto abióticos. 
Espécies localmente abundantes ou bem distribuídas em determinadas espécies ou gêneros de plantas hospedeiras, tendem a repetir este padrão em escalas espaciais maiores (Collins \& Glenn, 1990). No presente estudo, este padrão foi, em parte, corroborado. Espécies associadas à $P$. arboreum e que foram mais abundantes, ocorreram tanto em escala local (distâncias mais próximas) quanto na escala regional definida por Summerville \& Crist (2003) como aquela de distância superior a 100km.

As espécies de lepidópteros registradas em $P$. arboreum $(\mathrm{n}=51)$ tiveram compartilhamento muito baixo entre as áreas. Somente uma espécie foi registrada em todas as áreas. Este resultado foi similar ao encontrado para os Erebidae (Arcttinae) adultos que não tiveram uma única espécie compartilhada em todas as áreas em 14 localidades amostradas no Cerrado (Ferro \& Diniz, 2007). Alguns trabalhos sugerem que a similaridade entre as comunidades frequentemente diminui com o aumento da distância entre elas (Ferro \& Diniz, 2007; Novotny et al., 2007). Esta relação negativa entre a similaridade e a distância está relacionada a diversos fatores, como capacidade de dispersão das espécies (Singer \& Wee, 2005), isolamento e tamanho do habitat e a história de colonização e extinção (Nekola \& White, 1999). O presente estudo sugere que ocorreu, ao menos em parte, uma relação negativa entre a similaridade das comunidades analisadas e a distância geográfica, o que é reforçado pelos baixos valores de similaridade encontrados entre o PNCV, área mais distante, e todas as outras áreas. Entretanto, a comunidade de lepidópteros de áreas próximas apresentou baixa similaridade, por exemplo, entre a RECOR e o JBB, com menos de $10 \mathrm{~km}$ de distância e que foi inclusive mais baixa do que a que ocorreu entre RECOR e Pirenópolis com 100km de distância. Além disso, o dendograma de agrupamento, apesar de ter diferenciado áreas mais próximas como RECOR e JBB das outras áreas, não agrupou todas as áreas de acordo com as suas distâncias. As áreas FAL e RECOR, com uma 
distância de apenas $8 \mathrm{~km}$ uma da outra, foram agrupadas em grupos distintos, e as áreas PNCV e Pirenópolis foram posicionadas no mesmo grupo que as áreas PNB, ESECAE e FAL, apesar de apresentarem mais de $100 \mathrm{Km}$ de distância destas. Outros trabalhos também não encontraram uma relação forte entre a similaridade de comunidades e a distância (Harrison et al., 1992; Beck \& Ken, 2007), e indicaram que a distância pode ser o menor fator responsável pela diversidade regional.

De toda área original compreendida pelo Cerrado, estima-se que apenas $34.2 \%$ permaneçam inalteradas, como resultado de um período de pouco mais de 50 anos de ocupação antrópica em larga escala, gerando uma intensa fragmentação desse bioma (Machado et al., 2004). Possíveis mudanças nas interações entre os organismos que se estabeleceram após a fragmentação (Scriber, 2002), também pode ser uma das explicações para a baixa similaridade da fauna de lepidópteros encontrada sobre Piper arboreum entre as áreas encontrada.

\section{Sazonalidade}

O pico de abundância de lagartas de lepidópteros nas plantas hospedeiras no cerrado sentido restrito ocorre na estação seca, e este já é um padrão bem definido para este sistema (Morais et al., 1999). No presente estudo, a comunidade de lagartas de lepidópteros encontrada associada ao gênero Piper nas Matas de Galeria apresentou o mesmo padrão encontrado para o cerrado sentido restrito.

Uma das possíveis explicações para a maior abundância de lagartas de lepidópteros no cerrado sentido restrito na estação seca, é a de que a maior sincronia da floração das plantas no final da estação seca e início da estação chuvosa (Oliveira, 2008), influencia a fenologia dos lepidópteros polinizadores, os quais quando adultos, mostram uma distribuição temporal com um pico populacional no começo da estação 
chuvosa (Pinheiro et al., 2002; Oliveira \& Frizzas, 2008;), quando há uma maior disponibilidade de recursos alimentares para os mesmos. Assim, o pico de lagartas na estação seca garantiria a sincronização da emergência dos lepidópteros adultos no período de maior disponibilidade de recursos. Entretanto as características fenológicas das plantas da Mata de Galeria são bastante diferenciadas daquelas do cerrado sentido restrito, pois os eventos reprodutivos são mais bem distribuídos ao longo do ano (Gouveia \& Felfili, 1998).

Diversos trabalhos sugerem que as folhas jovens são recursos alimentares mais nutritivos do que as folhas maduras, e que ocorre uma sincronização dos herbívoros com a produção de folhas novas (Aide \& Londoño, 1989; Aide, 1993; Alonso \& Herrera, 2000; Ivashov et al., 2002). No entanto, para o cerrado sentido restrito o pico de imaturos de Lepidoptera não coincide com o pico de produção de folhas (Price et al., 1995; Morais, et al., 1999), e para as matas de galeria, essa hipótese provavelmente não se ajusta, pois estas apresentam uma produção de folhas novas bem distribuída ao longo do ano (observações pessoais de Piper no estudo experimental - ver Capítulo II).

Nas florestas úmidas de Papua Nova Guiné, não foi observada variação temporal da abundância de lagartas, sendo esta constante ao longo do ano (Novotny et al., 2002). As explicações paras as variações na abundância dos insetos e dos diferentes padrões temporais encontrados para o Cerrado ainda não estão completamente entendidas (Pinheiro et al., 2002). Uma outra explicação para a maior abundância de lagartas de lepidópteros na estação seca no Cerrado seria a de que a estação seca compreende "um espaço livre de inimigos", devido à menor abundância de parasitoides e de predadores neste período (Morais et al., 1999). No presente estudo, a proporção de lagartas parasitadas nas áreas amostradas variou de 2 a 20\%, o que não é uma pressão considerável. 


\section{REFERÊNCIAS BIBLIOGRÁFICAS}

Aide, T.M. 1993. Patterns of leaf development and herbivory in a Tropical understory community. Ecology, 74: 455-466.

Aide, T.M. \& Londono, E.C. 1989. The effects of rapid leaf expansion on the growth and survivorship of Lepidoptera. Oikos, 55: 66-70.

Alonso, C. \& Herrera, C.M. 2000. Seasonal variation in leaf characteristics and food selection by larval noctuids on an evergreen Mediterranean shrub. Acta Oecologica, 21: 257-265.

Andrade, I., Morais, H.C., Diniz, I.R. \& Berg, C. 1999. Richness and abundance of catterpillars on Byrsonima (Malpighiaceae) species in an area of cerrado vegetation in Central Brazil. Revista Biologia Tropical, 47: 691-695.

Basset, Y. \& Novotny, V. 1999. Species richness of insect herbivore communities on Ficus. Papua New Guinea. Biological Journal of Linnean Society, 67: 477-499.

Beck, J. \& Khen, C.V. 2007. Beta-diversity of geometrid moths from northern Borneo: effects of habitat, time and space. Journal Animal Ecology, 76: 230-237.

Bendicho-Lopez, A., Morais, H. C., Hay, J.D. \& Diniz, I.R. 2006. Lepidopteros folivoros em Roupala montana Aubl. (Proteaceae) no Cerrado sensu stricto. Neotropical Entomology, 35: 182-191.

Calculadora Geográfica do DPI-INPE - Divisão de Processamento de Imagens do Instituto Nacional de Pesquisas Espaciais. Disponível em: http://www.dpi.inpe.br/calcula/. Acessado em julho de 2016.

Proença, C.E B., Munhoz, C.B.R., Jorge, C.L. \& Nóbrega, M.G.G. 2001. Listagem e nível de proteção das espécies de fanerógamas do Distrito Federal, Brasil. In: Cavalcanti, T.B. \& Ramos, A.E. Flora do Distrito Federal, Brasil. Embrapa Recursos Genéticos e Biotecnologia, Brasília, 1: 87-359.

Collins, S.L. \& Glenn, S.M. 1990. A hierarchical analysis of species'abundance patterns in grassland vegetation. American Naturalist, 135: 633-648.

Dias, B.F.S. 1996. Cerrados: uma caracterização. In: Dias, B.F.S. (coord.). Alternativas de desenvolvimento dos Cerrados: manejo e conservação dos recursos naturais renováveis. Fundação Pró-Natureza, Brasília, 11-25.

Diniz, I.R. \& Morais, H.C. 1995. Larvas de Lepidoptera e suas plantas hospedeiras em um cerrado de Brasília, Distrito Federal, Brasil. Revista Brasileira de Entomologia, 39: 755-770.

Diniz, I.R. \& Morais, H.C. 1997, Lepidopteran caterpillar fauna of Cerrado host plants. Biodiversity and Conservation, 6: 817-836.

Diniz, I.R. \& Morais, H.C. 2002. Local pattern of host plant utilization by lepidopteran larvae in the cerrado vegetation. Entomotropica, 17: 115-119.

Diniz, I.R., Morais, H.C. \& Camargo, A.J.A. 2001. Host plant of lepidopteran caterpillar in the cerrado of Distrito Federal, Brazil. Revista Brasileira de Entomologia, 45: 107-122.

Dyer, L. \& Gentry, G.L. 2002. Caterpillars of La Selva, Costa Rica. Disponível em http://www.caterpillars.org. Acessado em julho de 2016.

Dyer, L.A., Dodson, C.D. \& Richards, J. 2004. Isolation, synthesis, and evolutionary ecology of Piper amides. In: Dyer, L.A \& Palmer, A.N. (eds.). Piper. A model genus for studies of evolution, chemical ecology, and trophic interactions. Kluwer Academic Publishers, Boston, 117-139.

Dyer, L.A., Dodson, C.D., Stireman, J.O., Tobler, M.A., Smilanich, A.M., Fincher, R.M. \& Letourneau, D.K. 2003. Synergistic effects of three Piper amides on generalist and specialist herbivores. Journal of Chemical Ecology, 29: 2499-2514. 
Dyer, L.A. \& Palmer, A.N. 2004. Piper. A model genus for studies of evolution, chemical ecology, and trophic interactions. In: L. Dyer, C.D. Dodson \& J. Richards (eds.). Kluwer Academic Publishers, Boston, 117-139.

Eiten, G. 1972. The cerrado vegetation of Brazil. The Botanical Review, 38: 201-341.

Espinoza, C.W., Azevedo, LG. \& Jarreta, M. 1982. O clima da região dos cerrados em relação à agricultura. Planaltina, Brasil: Embrapa-CPAC. Circular Técnica, 9: 15.

Funatura - Fundação Pró-Natureza/Ibama - Instituto Brasileiro do Meio Ambiente e dos Recursos Naturais Renováveis. 1998. Plano de Manejo do Parque Nacional de Brasília, v.1, Brasília.

Felfili, J.M. 1995. Diversity, structure and dynamics of a gallery forest in central Brazil. Vegetation, 117: 1-15.

Felfili, J.M., Franco, A.C., Fagg, C.W. \& Sousa-Silva, J.C. 2001. Desenvolvimento inicial de espécies de Mata de Galeria. p. 779-811. In: Ribeiro, J.F.; Fonseca, C.E.L. \& SousaSilva, J.C. Cerrado: caracterização e recuperação de Matas de Galeria. Planaltina, Embrapa Cerrados.

Felfili, J.M. \& Silva-Júnior, M.C. 1992. Floristic composition, phytosociology and comparison of cerrado and gallery forests at Fazenda Água Limpa, Federal District, Brazil. In: Nature and dynamics of forest-savanna boundaries. Chapman \& Hall, London, 393-415.

Ferro, V.G. \& Diniz, I.R. 2007. Composicao de especies de Arctiidae (Insecta, Lepidoptera) em areas de Cerrado. Revista Brasileira de Zoologia, 24: 635-646.

Gaston, K.J. 1994. Rarity: Population and community biology series 13. London: Chapman $\&$ Hall.

Gouveia, G.P \& Felfili, J.M. 1998. Fenologia de comunidades de matas de galeria e de cerrado no Distrito Federal. Revista Árvore, Viçosa, 22: 443-450.

Guarino, E. D. S. G. \& Walter, B. M. T. 2005. Fitossociologia de dois trechos inundáveis de Matas de Galeria no Distrito Federal, Brasil.Acta Botanica Brasilica, 19: 431-442.

Guimarães, E.F.; Ichaso, C.L.F. \& Costa, C.G. 1978. Piperáceas. In: Reitz, R. (ed.) Flora Ilustrada Catarinense. Fasciculo. Piper. Itajaí: Raulino Reitz, 27p.

Hammer, O., Harper, D.A.T. \& Ryan P. D. 2001. PAST: Paleontological Statistics Software Package for Education and Data Analysis. Palaeontologia Electronica, 4: 9p.

Harrison, S., Ross, S.J. \& Lawton, J.H. 1992. Beta diversity on geographic gradients in Britain. Journal of Animal Ecology, 61: 151-158.

Ibama/Proaves. 1998. Parque Nacional da Chapada dos Veadeiros: Plano de manejo - Fase 3 (versão preliminar). Ibama/Proaves, Brasília.

Jaramillo, M.A. \& Manos, P.S. 2001. Phylogeny and patterns of floral diversity in the genus Piper (Piperaceae). American Journal of Botany, 88: 706-716.

Janzen, D. H. 1988. Ecological characterization of Costa Rica dry forest caterpillar fauna. Biotropica, 20: 120-35.

Janzen, D. H., Hallwachs, W. 2005. Dynamic database for an inventory of the macrocaterpillar fauna, and its food plants and parasitoids, of the Area de Conservacion Guanacaste (ACG), northwestern Costa Rica. Disponível em: http://janzen.sas.upenn.edu/84. Acessado em julho de 2016.

Karban R. 1992. Plant variation: its effects on populations of herbivorous insects. In: Fritz, R.S., Simms, E.L. (eds). Plant resistance to herbivores and pathogens. Chicago, IL, USA: The University of Chicago Press, 195-215.

Letourneau, D. K. 2004. Mutualism, antiherbivore defense, and trophic cascades: Piper antplants as a mesocosm for experimentation. In: Dyer, L.A \& Palmer, A.N. Piper: A model genus for studies of phytochemistry, ecology, and evolution, Springer US, 5-32. 
Lewinsohn, T.M., Novotny, V. \& Basset, Y. 2005. Insects on plants: diversity of herbivore assemblages revisited. Annual Review of Ecology, Evolution and Systematics, 36: 597620.

Lima, W.P. \& Zakia, M.J. B. 2001. "Hidrologia de Matas Ciliares." In: Rodrigues, R.R. \& Leitão Filho, H.F (eds.). Matas Ciliares: Conservação e Recuperação, São Paulo, Editora de Universidade De São Paulo, Fapesp, 33-44.

Machado, R.B., Ramos Neto, M.B., Pereira, P.G.P., Caldas, E.F., Gonçalves, D.A., Santos, N.S., Tabor, k. \& Steininger, M. 2004. Estimativas de perda da área do Cerrado brasileiro. Conservação Internacional, Brasília, DF.

Maia, J.M.F. \& Baptista, G.M.M. Clima. In: Fonseca, F.O. (Org.). 2008. Águas Emendadas. Brasília: SEDUMA, 101-109.

Marquis, R. J. 1990. Genotypic variation in leaf damage in Piper arieianum (Piperaceae) by a multispecies assemblage of herbivores. Evolution, 104-120.

Marquis, R. J. 1991. Herbivore fauna of Piper (Piperaceae) in a Costa Rican wet forest: Diversity, specificity, and impact. In: Price, P.W., Lewinsohn, T.M., Fernandes, G.M. \& Benson, W.W. (eds). Plant-Animal Interactions: Evolutionary Ecology in Tropical and Temperate Regions, New York: John Wiley, 179-208.

Marquis, R.J., Morais, H.C. \& Diniz, I.R. 2002. Interactions among cerrado plants and their herbivores: Unique or Typical? In: Oliveira, P.S. \& Marquis, R.J. (eds.). The Cerrados of Brazil. New York: Columbia University Press, 306-328.

Mauricio, R. 1998. Costs of resistance to natural enemies in field populations of the annual plant Arabidopsis thaliana. American Naturalist, 151: 20-28.

Meave, J., Kellman, M., Mac Dougall, D. \& Rosles, J. 1991. Riparian habitats as tropical forests refugia. Global Ecology and Biogeography Letters, 1: 69-76.

Mendonça, R.C., Felfili, J.M., Walter, B.M.T., Silva Jr., M.C., Rezende, A.V., Filgueiras, T.S., Nogueira, P.E. \& Fagg, C.W. 2008. Flora Vascular do bioma Cerrado: checklist com 12.356 espécies. In: Sano, S.M., Almeida, S.P. \& Ribeiro, J.F., eds. Cerrado: ecologia e flora. Embrapa Cerrados, Planaltina, DF, 2: 421-1.219.

Morais, H.C., Diniz, I.R. \& Silva, D.M.S. 1999. Caterpillar seasonality in a central Brazilian cerrado. Revista de Biologia Tropical, 47: 1025-1033.

Nekola, J.C. \& White, P.S. 1999. The distance decay of similarity in biogeography and ecology. Journal of Biogeography, 26: 867-878.

Novotny, V. \& Basset, Y. 2000. Rare species in communities of tropical insect herbivores: pondering the mystery of singletons. Oikos, 89: 564-572.

Novotny, V., Miller, S.E., Basset, Y., Cizek, L., Drozd, P., Darrow, K., \& Leps, J. 2002a. Predictably simple: assemblages of caterpillars (Lepidoptera) feeding on rainforest trees in Papua New Guinea. The Royal Society, 269: 2337-2344.

Novotny, V., Mille, S.E., Hulcr, J., Drew, R.A.I., Basset, Y.,Janda, M., Setliff, G.P., Darrow, K., Stewart, A.J.A., Auga, J., Isua, B., Molem, K.,Manumbor, M., Tamtiai, E., Mogia, M. \& Weiblen, G.D. 2007. Low beta diversity of herbivorous insects in tropical forests. Nature, 448: 392-397.

Odegaard, F. 2006. Host specificity, alpha- and beta-diversity of phytophagous beetles in two tropical forests in Panama. Biodiversity and conservation, 15: 83-105.

Oliveira, C.M. \& Frizzas, M.R. 2008. Insetos de cerrado: distribuição estacional e abundância. Planaltina: Embrapa.

Oliveira-Filho, A.T. \& Ratter, J.A. 1995. A study of the origin of Central Brazilian forests by the analysis of plant distribuition pattems. Edinburgh Journal of Botany, 52: 1-54.

Oliveira, P.E.A.M. 2008. Fenologia e biologia reprodutiva das especies de cerrado. In: Sano, S., Almeida, S.P. \& Ribeiro (eds.). Cerrado: Ecologia e flora. Brasilia: Embrapa, 6188. 
Pinheiro, F., Diniz, I.R., Coelho, D. \& Bandeira, M.P.S. 2002. Seasonal pattern of insect abundance in the Brazilian cerrado. Austral Ecology, 27: 132-136.

Price, P.W., Diniz, I.R., Morais, H.C. \& Marques, E.S.A. 1995. The abundance of insect herbivore species in the tropics: the high local richness of rare species. Biotropica, 27: 468-478.

R Core Team. 2016. R: A language and environment for statisticalcomputing. R Foundation for Statistical Computing, Vienna, Austria. Disponível em: https://www.R-project.org/.

Ratter, J.A., Ribeiro, J.F. \& Bridgewater, S.1997. The Brazilian cerrado vegetation and threats to its biodiversity. Annals of Botany, 80: 223-230.

Ribeiro, J.F. \& Walter, B.M.T. 1998. Fitofisionomias do bioma Cerrado. In: Sano, S.M. \& Almeida, S.P. (eds.). Cerrado: ambiente e flora. Planaltina, Embrapa - CPAC, 89-166.

Ribeiro, J.F. \& Walter, B. M. T. 2008. As principais fitofitofisionomias do bioma Cerrado. In: Sano, S. M., Almeida, S. P. \& Ribeiro, J. F.(eds.). Cerrado:ecologia e flora. Brasília: Embrapa, 151-212.

Rizzini, C. T. 1979. Tratado de fitogeografia do Brasil. Hucitec Edusp,SP, São Paulo, 2, 374 p.

Santos, R.A.L. \& Henriques, R.P.B. 2010. Variação espacial e influência do habitat na estrutura de comunidades de pequenos mamíferos em áreas de campo rupestre no Distrito Federal. Biota Neotropica, 10: 31-38.

Scherrer, S., Diniz, I.R. \& Morais, H.C. 2010. Climate and host plant characteristics effects on lepidopteran caterpillar abundance on Miconia ferruginata DC. and Miconia pohliana Cogn (Melastomataceae). Brazilian Journal of Biology, 70: 103-109.

Scherrer, S., Lepesqueur, C., Vieira, M.C., Almeida-Neto, M., Dyer, L., Forister, M. \& Diniz, I.R. 2016. Seasonal variation in diet breadth of folivorous Lepidoptera in the Brazilian cerrado.Biotropica, 48: 491-498.

Scriber, J.M. 2002. Evolution of insect-plant relationships: chemical constraints, coadaptation, and concordance of insect/plant traits. Entomologia Experimentalis et Applicata, 104: 217-235.

Singer, M.C. \& WEE, B. 2005. Spacial pattern in checkerspot butterfly-host plant association at local, metapopulation and regional scales. Annual Zoological Fennici, 42: 347-361.

Shimbori, E.M. 2009. Sistema hospedeiro-parasitoide associado à Piper glabratum Künth e P. mollicomum Künth (Piperaceae) no município de São Carlos, SP. Tese (Doutorado em Ciências Biológicas) - Universidade Federal de São Carlos, São Carlos, 185 p.

Summerville, K.S. \& CRIST, T.O. 2003. Determinants of lepidopteran community composition and species diversity in eastern deciduous forests: roles of season, ecoregion and patch size. Oikos, 100: 134-148.

Tepe, E.J., Rodríguez-Castañeda, G., Glassmire, A.E. \& Dyer, L.A. 2014. Piper kelleyi, a hotspot of ecological interactions and a new species from Ecuador and Peru. PhytoKeys, 34: 19-32.

Tiffin, P., Rausher, M.D. 1999. Genetic constraints and selection acting on tolerance to herbivory in the common morning glory Ipomoea purpurea. American Naturalist, 154: 700-716.

Veloso, H. P. 1963. Os grandes clímaces do Brasil. III - Considerações gerais sobre a vegetação da região centro-Oeste. Memórias do Instituto Oswaldo Cruz, 61: 357-370.

Venturoli, F., Felfili, J.M. \& Fagg, C.W. 2011. Avaliação temporal da regeneração natural em uma floresta estacional semidecídua secundária, em Pirenópolis, Goiás. Revista Árvore, 35: 473-483.

Yuncker, T. G. 1972. The Piperaceae of Brazil: 1. Piper-group 1, 2, 3, 4. Hoehnea, 2: 21366. 


\section{Capítulo II}

Efeitos da origem do genótipo (populações) e fitoquímica de Piper arboreum (Piperaceae) na herbivoria e nos seus herbívoros 


\section{INTRODUÇÃO}

As interações tróficas dos insetos herbívoros são determinadas pelas variações ambientais como clima, tipo de solo e pela composição de espécies da flora e fauna. As plantas hospedeiras podem apresentar diversidade taxonômica, genética e bioquímica (funcional) (Dyer et al., 2010), podendo desencadear respostas diversas dos herbívoros entre paisagens.

A diversidade genética intraespecífica constitui-se em uma medida da magnitude da variabilidade genética dentro de uma população, sendo uma fonte fundamental de biodiversidade (Hughes et al., 2008). A literatura é extremamente rica em fatos que comprovam a ocorrência substancial da variabilidade genética dentro e entre populações de plantas (ver Gray, 1987; Linhart \& Grant, 1996; von Flue et al., 1999; Billeter et al., 2002), e essa variação reflete adaptações aos diferentes ambientes (Linhart \& Grant, 1996). Insetos herbívoros podem responder a variações genéticas de plantas (Marquis, 1990; Kotowska et al., 2010), e em interações parasita-hospedeiro, como a existente entre plantas e insetos herbívoros, os parasitas são esperados exibir adaptação local sobre seus hospedeiros (Lively, 1989; Ebert, 1994). Essa adaptação é revelada pela maior adaptação de parasitas sobre seus hospedeiros locais do que sobre hospedeiros alopátricos (Kawecki \& Ebert, 2004).

Assumindo que distâncias físicas correspondem à diferenças genéticas entre populações, a distância entre populações pode ser negativamente correlacionada com a adaptação (Gandon et al., 1996); assim, parasitas devem ser mais adaptados a hospedeiros locais ou de populações mais próximas à local que a hospedeiros de populações mais distantes (Kaltz \& Shykoff, 2002).

Plantas produzem uma mistura bastante complexa de compostos secundários utilizados como mecanismo de defesa contra herbívoros e microrganismos patogênicos 
(Fraenkel, 1959; Swain, 1977; Wink, 1988; 2008a, b). A composição e concentração de compostos secundários específicos de uma planta é bastante variável e estas podem ser afetadas por diversos fatores, entre eles, o ambiente e os estágios fenológicos. Assim, a diversidade fitoquímica, assim como a genética, varia dentro e entre as populações de plantas (Wink, 2003, 2008a), o que pode levar a um mosaico geográfico de especializações adaptadas aos diferentes gradientes ambientais, com considerável variação nas associações entre química, especialização e diversidade nos níveis tróficos (Thompson, 1997).

A análise filogenética da diversidade fitoquímica de plantas já mostrou que algumas plantas tendem a aumentar suas defesas contra herbívoros durante a história evolutiva pelo aumento da diversidade fitoquímica, apresentando uma maior diversidade e complexidade estrutural química (Becerra et al., 2009). Ademais, misturas de compostos secundários podem ter um efeito ecológico sinergístico, causando maiores impactos negativos sobre herbívoros que quando comparadas com concentrações iguais de um único composto, como já visto para amidas de Piper (Richards et al., 2010).

O gênero Piper (Piperaceae) é composto por cerca de 1.000 espécies, que se distribuem em uma ampla variedade de habitats, com maior diversidade concentrada nos Neotrópicos (Dyer \& Palmer, 2004). Como resultado de tamanha riqueza, somente 10\% das espécies têm sido investigadas quimicamente. Entretanto, já foi encontrada uma grande variedade de compostos nas espécies já analisadas (Dyer et al., 2004).

Inúmeros herbívoros utilizam folhas, ramos e partes reprodutivas de Piper para se alimentar, sendo os insetos os principais consumidores, tanto os mastigadores quanto os sugadores, e entre eles podemos citar os Lepidoptera dos gêneros Eois (Geometridae, Larentiinae), Quadrus (Hesperiidae) e Epimecis (Geometridae, Enominae); os Coleoptera (Curculionidae); os Hemiptera; os Hymenoptera; os Diptera e os Orthoptera 
(Marquis, 1991). Há várias evidências dos fortes efeitos dos compostos secundários presentes em espécies de Piper nos herbívoros e patógenos que os consomem (Dyer et al., 2003, 2004; Marques et al., 2008; Continguiba et al., 2009; Rapado et al., 2013; Jeffrey et al., 2014). Sendo assim, podem influenciar toda a comunidade onde as espécies de Piper são encontradas (Dodson et al., 2004).

Há poucos registros sobre herbivoria em Matas de Galeria do Cerrado. Plantas do gênero Myrcia apresentaram herbivoria entre 5,5 a 19\% e em Clethra entre 19 a 23\% em uma Mata de Galeria no Parque Estadual do Itacolimi, em Ouro Preto/Mariana MG (Pereira, 2015). Existe um maior número de informação sobre herbivoria para outras formações florestais desse bioma. Françoso e colaboradores (2013) avaliaram a herbivoria em Peltogyne confertiflora (Mart. ex Hayne) Benth. em uma área de Mata Ciliar de Cerrado em Mato Grosso e encontraram uma herbivoria média de 15,1 $\pm 6,1$. No Cerrado Pé-de-Gigante, Santa Rita do Passa Quatro, SP, foi encontrada uma herbivoria de 2,16\% em Didymopanax vinosum (Apiaceae) para o Cerradão (Varanda \& Pais, 2006).

A análise da estrutura genética de duas populações de Calophyllum brasiliense Camb. (Clusiaceae) de Matas de Galeria revelou que o fluxo gênico estimado não foi suficiente para contrapor os efeitos da deriva genética (Souza et al., 2007). Jaeger (2004) realizou a caracterização genética de duas populações de Xylopia emarginata Mart. (Annonaceae) de Matas de Galeria, sendo essas divididas em cinco subpopulações devido a interrupções naturais, e encontrou forte divergência genética de duas subpopulações em relação às demais.

As folhas da espécie de planta, objeto do presente trabalho, Piper arboreum Aubl. (Piperaceae), têm sido bastante investigadas quimicamente e já foram identificadas amidas: N-[10-(13,14-metilenodioxifenil)-7(E),9(Z)-pentadienoil]- 
pirrolidina, arboreumina, N-[10-(13,14- metilenodioxifenil)-7(E)-pentaenoil]-pirrolidina e N-[10-(13,14- metilenodioxifenil)-7(E),9(E)-pentadienoil]-pirrolidina (Silva et al., 2002) e o novo produto natural metil 3-geranil-4-hidroxibenzoato, conhecido anteriormente apenas como um produto sintético (Inouye et al., 1979).

As plantas se destacam como um sistema ideal para testar se as variações genética e fitoquímica intraespecíficas podem afetar outros níveis tróficos como os insetos herbívoros, pois como produtoras primárias são a base do recurso alimentar da maioria das teias alimentares. O presente trabalho teve como objetivo responder as seguintes perguntas: Qual o efeito da origem do genótipo de P. arboreum na herbivoria e na abundância de Lepidoptera? A composição e a diversidade fitoquímica de $P$. arboreum afetam a herbivoria e a abundância de Lepidoptera?

A hipótese testada foi: a origem do genótipo, a diversidade fitoquímica e a composição química do $P$. arboreum afetam a resistência a herbivoria como também a comunidade de Lepidoptera. Como predição temos: 1) considerando que os genótipos originados de uma mesma população sejam mais semelhantes do que os de populações mais distantes, podemos prever que plantas originadas da mesma população ou de populações mais próximas terão uma diferença menor do que plantas de populações distantes; 2) plantas com maior diversidade fitoquímica (de grupos funcionais) apresentarão menor herbivoria como também menor abundância de Lepidoptera; 3) plantas com diferentes composições químicas (quimiotipos), apresentarão diferenças significativas na herbivoria e na abundância de Lepidoptera. 


\section{METODOLOGIA}

\section{Sistema de estudo}

O presente trabalho trata de um estudo experimental sobre os efeitos da origem do genótipo e da fitoquímica na herbivoria e nas interações tróficas entre Piper arboreum Aubl. (Piperaceae). As interações multi-tróficas associadas ao gênero de planta tropical Piper (Piperaceae), têm sido utilizadas como modelo para diversos estudos em vários ambientes na América Central e do Sul, para testar os efeitos da diversidade multidimensional na herbivoria e nos herbívoros (Alécio et al., 1998; Lago et al., 2004; Kato \& Furlan, 2007; Cotinguiba et al., 2009; Moraes et al., 2013).

\section{Montagem do experimento}

Para a montagem do experimento, foram coletadas plantas de $P$. arboreum em quatro sítios de origem (populações de $P$. arboreum), em matas de galeria situadas: (1) Reserva Ecológica do Roncador - RECOR (1556'49.6”S; 4752’08.5”W; $1.115 \mathrm{~m}$ de altitude, DF) (2) Parque Nacional de Brasília-PNB (1543'54.2”S; 4754’57.1”W; 1.013m, DF) (3), Estação Ecológica de Águas Emendadas-ESECAE (15³2’34.2”S; 47³4'43.7”W; 1.022m, DF) e (4) Parque Nacional da Chapada dos Veadeiros-PNCV (1408'07.7'S; 4740’14.4”; 1.247m, GO), esta última considerada um sítio remoto de escala regional, com mais de $100 \mathrm{~km}$ de distância de qualquer um dos outros três primeiros. Todos os sítios de origem apresentam distância mínima de $20 \mathrm{~km}$ um em relação ao outro (Tabela 1), o que provavelmente assegura populações de plantas geneticamente diferentes e os diferencia como locais (Summerville \& Crist, 2003). Esta distância entre áreas ultrapassa, em muito, aquela percorrida pelo morcego Carollia perspicillata após comer o fruto de $P$. arboreum, que é de 1,6 Km (Heithaus \& Fleming, 1978), principal dispersor de semente de P. arboreum no Cerrado do Distrito Federal 
(Bizerril, 1995).

Tabela1 - Distância em Km em linha reta (calculadas usando as coordenadas geográficas pela calculadora geográfica online da Divisão de Processamento de Imagens do Instituto Nacional de Pesquisas Espaciais; DPI-INPE) entre sítios de origem das plantas de $P$. arboreum utilizadas no experimento. RECOR=Reserva Ecológica do Roncador, $\mathrm{PNB}=$ Parque Nacional de Brasília e ESECAE= Estação Ecológica de Águas Emendadas, DF; PNVC= Parque Nacional da Chapada dos Veadeiros, GO.

\begin{tabular}{l|lll}
\hline Áreas & RECOR & PNB & ESECAE \\
\hline PNB & 24,357 & & \\
ESECAE & 54,52 & 41,778 & \\
PNCV & 201,606 & 178,608 & 156,037 \\
\hline
\end{tabular}

As plantas dos quatro sítios de origem foram coletadas em março de 2015. Em cada sítio foram coletados três indivíduos de P. arboreum, considerados como plantasmãe. Cada planta-mãe foi cortada em seis partes contendo um nó e três folhas para a formação de estaquias. Cada planta-mãe, assim, deu origem a seis clones (estaquias de um mesmo genótipo), conforme metodologia já utilizada por Dyer \& Palmer (2004) e Rodriguez-Castañeda et al. (2010). Cada estaquia (muda) foi plantada em um balde de 10 litros, todos preenchidos com o mesmo tipo de solo até o nível de $10 \mathrm{~cm}$ de distância da borda (Figura 1). Como de cada um dos quatro sítios de origem (populações) foram amostrados três indivíduos (= três genótipos), com seis réplicas (clones) de cada um, foram plantadas 72 mudas (três plantas-mãe de cada sítio/população x seis estaquiasclones por planta-mãe $(\mathrm{n}=18)$ x quatro sítios de origem=72).

Foram selecionadas três áreas experimentais no interior de matas de galeria para o estabelecimento do experimento, todas localizadas em Unidades de Conservação do 
Distrito Federal: (1) RECOR, (2) PNB e (3) ESECAE. A seleção destas três áreas foi devido à condição de estarem bem preservadas, de fácil acesso e segurança para o acompanhamento do experimento como, também, pelo fato de a espécie $P$. arboreum estar amplamente distribuída, o que teoricamente garantiria a presença dos seus insetos herbívoros.

As 18 estaquias (três genótipos x seis réplicas) obtidas das três plantas-mãe em cada um dos quatro sítios de origem foram distribuídas entre as três áreas experimentais, e assim, cada uma das três áreas abrigou uma repetição do experimento (seis vasos com plantas-clones) de genótipos originados em cada um dos quatro sítios de origem (populações; Tabela 2), com diferentes distâncias um do outro (proximidade genética das plantas de P. arboreum), e do local da área experimental (Figura 1), totalizando 24 indivíduos por área experimental (Tabela 2). Como as áreas experimentais coincidem com três dos quatro sítios de origem das plantas-mãe, em cada uma das áreas experimentais, houve uma repetição que é de um genótipo originado da população de $P$. arboreum local. A distribuição das 24 plantas em cada área experimental foi aleatória, obedecendo a distância mínima de $2 \mathrm{~m}$ entre cada um dos baldes-vasos (Figuras 2 e 3). Todas as plantas experimentais foram acompanhadas, mensalmente, de abril de 2015 a março de 2016. 
Tabela 2. Sítios de origem (populações A, B, C, D), genótipos (A-D de 1 a 3), áreas experimentais e repetições (seis clones de cada genótipo). Áreas exper.=áreas experimentais; RECOR=Reserva Ecológica do Roncador, $\mathrm{PNB}=$ Parque Nacional de Brasília, e ESECAE=Estação Ecológica de Águas Emendadas-DF; PNCV=Parque Nacional da Chapada dos Veadeiros-GO.

\begin{tabular}{|c|c|c|c|c|c|c|c|c|c|c|c|c|}
\hline $\begin{array}{l}\text { Sítios de } \\
\text { origem }\end{array}$ & RECOR & PNB & ESECAE & PNCV & RECOR & PNB & ESECAE & PNCV & RECOR & PNB & ESECAE & PNCV \\
\hline \multirow{8}{*}{$\begin{array}{l}\text { Genótipos } \\
\text { Áreas exper. } \\
\text { Repetições }\end{array}$} & A1 & $\mathrm{B} 1$ & $\mathrm{C} 1$ & D1 & A2 & B2 & $\mathrm{C} 2$ & $\mathrm{D} 2$ & A3 & B3 & $\mathrm{C} 3$ & D3 \\
\hline & \multicolumn{4}{|l|}{ RECOR } & \multicolumn{4}{|l|}{ PNB } & \multicolumn{4}{|l|}{ ESECAE } \\
\hline & A1.1 & B1.1 & $\mathrm{C} 1.1$ & D1.1 & A2.1 & B2.1 & $\mathrm{C} 2.1$ & D2.1 & A3.1 & B3.1 & C3.1 & D3.1 \\
\hline & A1.2 & B1.2 & $\mathrm{C} 1.2$ & D1.2 & $\mathrm{A} 2.2$ & B2.2 & $\mathrm{C} 2.2$ & $\mathrm{D} 2.2$ & A 3.2 & B3.2 & C3.2 & D 3.2 \\
\hline & A1.3 & B1.3 & C1.3 & D1.3 & A 2.3 & B2.3 & $\mathrm{C} 2.3$ & $\mathrm{D} 2.3$ & A 3.3 & B3.3 & C 3.3 & D3.3 \\
\hline & A1.4 & B1.4 & C1.4 & D1.4 & A2.4 & B2.4 & $\mathrm{C} 2.4$ & D2.4 & A 3.4 & B3.4 & C 3.4 & D3.4 \\
\hline & A 1.5 & B1.5 & C1.5 & D1.5 & A2. 5 & B2.5 & $\mathrm{C} 2.5$ & D2.5 & A 3.5 & B3.5 & C 3.5 & D3.5 \\
\hline & A1.6 & B1.6 & C1.6 & D1.6 & A2. 6 & B2.6 & $\mathrm{C} 2.6$ & $\mathrm{D} 2.6$ & A 3.6 & B3.6 & C3.6 & D3.6 \\
\hline
\end{tabular}

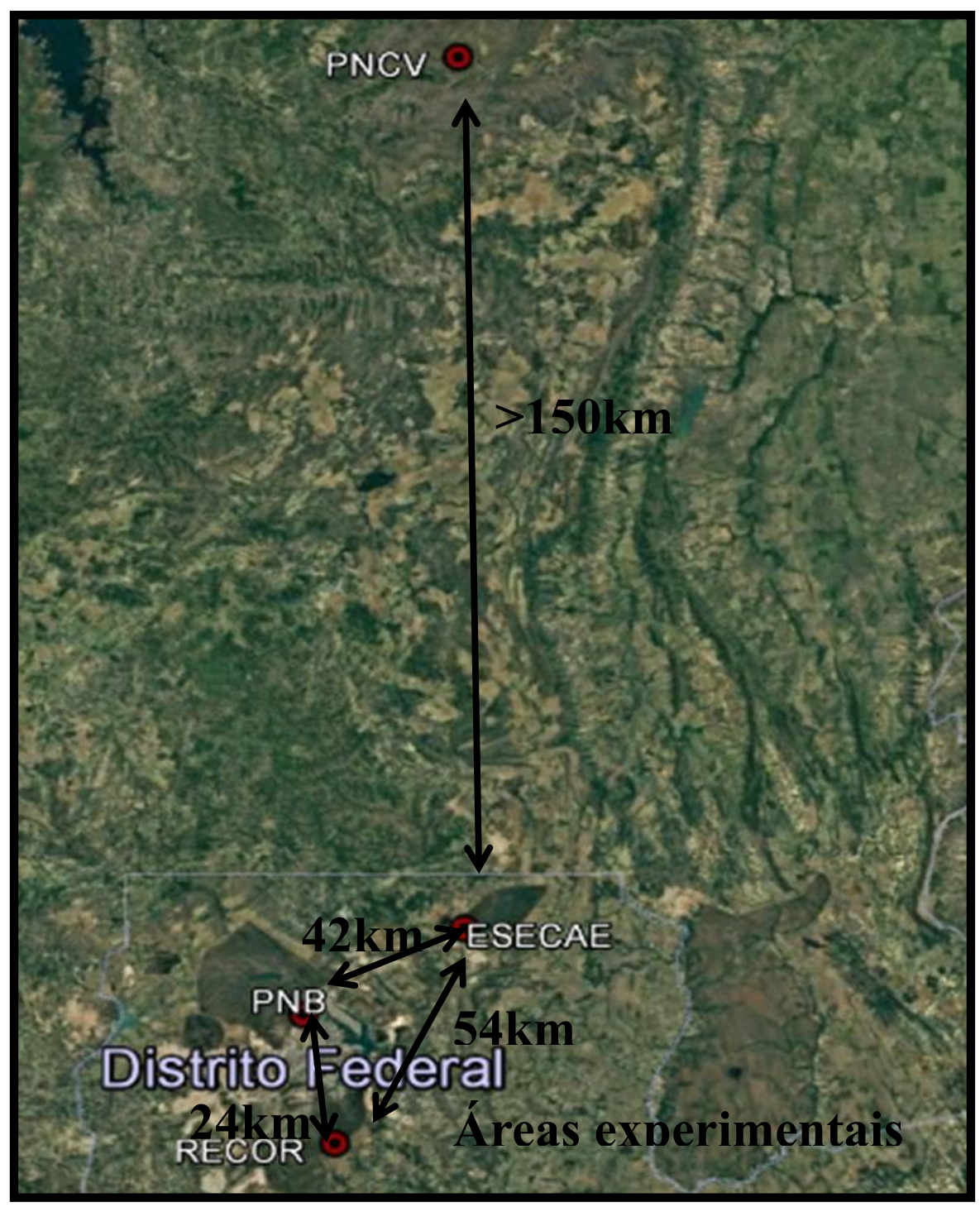


Figura 1. Sítios de origem (populações A-D) de genótipos de $P$. arboreum com diferentes distâncias um do outro e de cada área experimental. RECOR=Reserva Ecológica do Roncador, PNB=Parque Nacional de Brasília, e ESECAE=Estação Ecológica de Águas Emendadas-DF; PNCV=Parque Nacional da Chapada dos Veadeiros-GO.
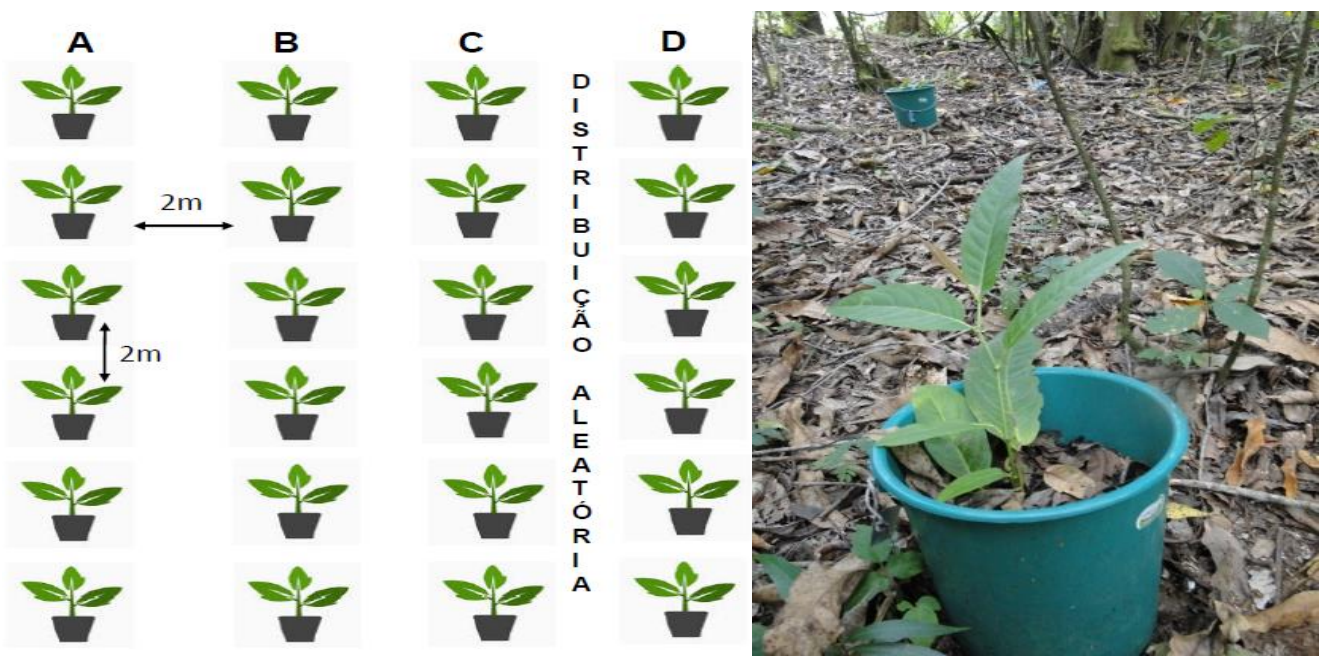

Figura 2. Exemplo de repetições do experimento (seis clones de um genótipo) em uma área experimental, originadas em cada um dos quatro sítios ou populações de origem ( $\mathrm{A}=$ Reserva Ecológica do Roncador-DF; $\mathrm{B}=$ Parque Nacional de Brasília-DF; $\mathrm{C}=$ Estação Ecológica de Águas Emendadas-DF; D=Parque Nacional da Chapada dos Veadeiros-GO). As plantas foram distribuídas aleatoriamente na área, respeitando a distância mínima de $2 \mathrm{~m}$ de distância entre cada um dos clones. À direita, vaso-balde contendo uma planta de P. arboreum oriunda de estaquia (clone) de um genótipo originado em um dos quatro sítios de origem, plantada em março de 2015 (Foto: Raiane Serejo). 


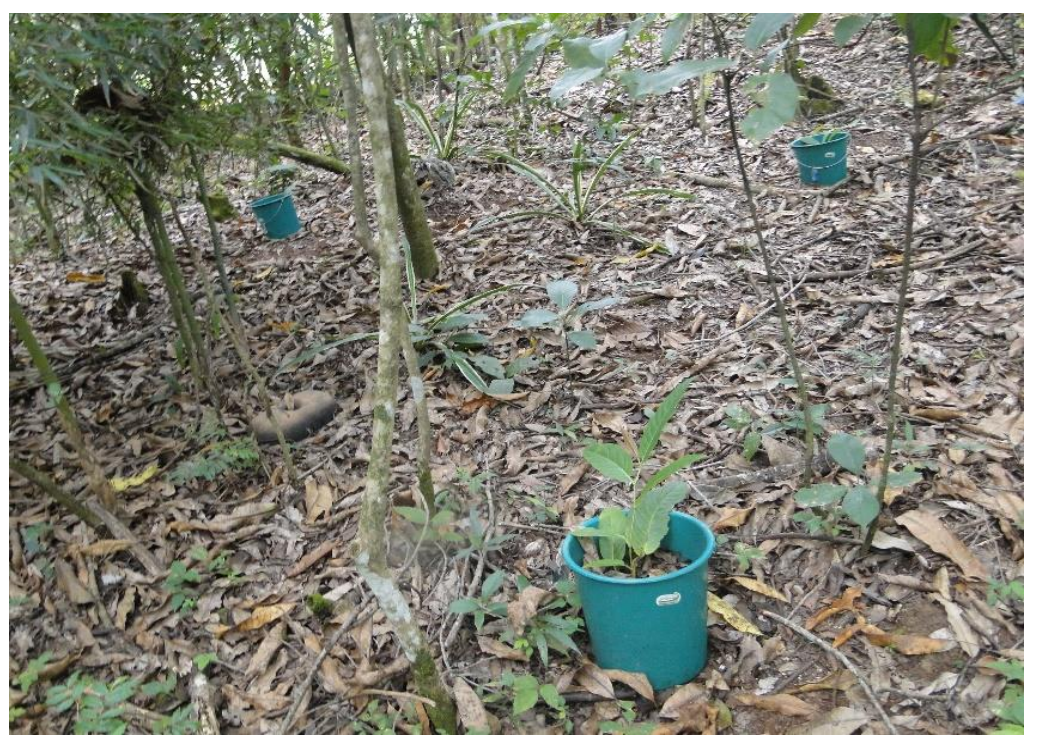

Figura 3. Distância (2m) e a disposição aleatória das plantas experimentais no interior da Mata de Galeria - área experimental do Parque Nacional de Brasília (Foto: Raiane Serejo).

\section{Acompanhamento do experimento}

A partir de um mês depois de plantadas (tempo previsto para o estabelecimento das plantas) foram iniciadas as observações e medidas. As plantas das três áreas experimentais foram monitoradas mensalmente, a partir de abril de 2015, e uma vez por mês foi registrada a abundância de larvas de Lepidoptera para cada planta experimental. No último mês do experimento foi calculada a porcentagem de área foliar danificada pelos insetos herbívoros para cada planta experimental. As áreas foliares, total e danificada, foram calculadas pelo software ImageJ (Rasband, 2006), a partir de fotos de todas as folhas de cada planta, sobre uma superfície plana de fundo branco com uma régua para o ajuste da escala do software. Posteriormente, foi calculada a porcentagem de herbivoria ocasionada por insetos mastigadores no conjunto de folhas de cada planta (soma da área danificada das folhas/soma da área total das folhas x 100).

Todos os ovos, larvas e pupas de Lepidoptera, encontrados em cada planta, não 
foram coletados e sim fotografados e registrados em planilha. Essa metodologia permitiu que as taxas de herbivoria não fossem afetadas pela interferência da retirada de herbívoros.

\section{Origem do genótipo}

Para a análise do efeito da origem do genótipo consideramos os genótipos originados em cada sítio de origem (A, B, C e D). Como todos os sítios situavam-se distantes uns dos outros por, pelo menos, $20 \mathrm{~km}$, as plantas-mãe e seus respectivos clones de cada sítio representaram genótipos originados em diferentes populações de $P$. arboreum.

\section{Análise fitoquímica}

Amostras de folhas de todas as plantas-mãe (três plantas mãe de cada um dos quatro sítios de origem=12) foram coletadas, antes da produção das estaquias, para análise da diversidade fitoquímica (de grupos funcionais) e da composição química, a ser realizada na USP, parceira nesse projeto. As folhas para a análise fitoquímica foram armazenadas em sacos de papel pardo, secadas à temperatura ambiente, e mantidas em recipiente com sílica gel azul 4-8mm ${ }^{\circledR}$, para a devida conservação.

As folhas secas foram moídas e 100 miligramas foram extraídos de cada amostra, utilizando uma mistura de $\mathrm{H} 2 \mathrm{O}: \mathrm{MeOH}: \mathrm{CHCl} 3(1: 1: 2)(800 \mu \mathrm{L})$. Em seguida, as amostras foram centrifugadas a $10.000 \mathrm{rpm}$ por $20 \mathrm{~min}$. As fases aquosas e orgânicas foram coletadas separadamente. As fases clorofórmicas foram dissolvidas em $\mathrm{CDCl} 3$ e analisadas por RMN $500 \mathrm{MHz}$, Bruker. As análises foram tratadas com o programa MestReNova (6.0.2). Foram realizados "binning" do espectro a cada 0,005 ppms, de 3 a $8,5 \mathrm{ppm}$, e esses foram normalizados pelo maior pico. Os dados foram transferidos para 
o excell e picos correspondentes aos ácidos graxos (5,17ppm) e ao $\mathrm{CDCl} 3$ (7,26 ppm) foram retirados.

Foi calculada a diversidade fitoquímica de cada amostra, usando três a 8.5 ppm., através do índice de Simpson, e a partir deste foi obtido o número efetivo de grupos funcionais (Jost, 2006), utilizado como medida da diversidade fitoquímica (de grupos funcionais) de cada planta, no presente estudo. As análises foram realizadas no software R 3.3.1 (R Development Core Team 2016).

A análise multivariada PCA (Análise de Componente Principal), uma técnica de reconhecimento de padrões extremamente útil para extrair informação pertinente de dados multivariados, e já testada para $P$. arboreum (Duarte et al., 2016), também foi realizada utilizando-se o programa Unscrambler® $\mathrm{X}$ v10 (CAMO S.A.), para verificação dos compostos principais (composição química - quimiotipo) de cada planta-mãe $(\mathrm{N}=12)$ utilizada para elaboração das estaquias.

\section{Análise estatística}

Para verificar o efeito da origem do genótipo na herbivoria, foram utilizados, primeiramente, modelos lineares generalizados (GLM). Foram feitos modelos separados para cada uma das áreas experimentais. Devido à morte de três clones do genótipo originado da população D da RECOR, foram utilizadas para o modelo dessa área apenas os clones dos genótipos originados das populações A, B e C (Figura 2). Da ESECAE morreram quatro clones, um de cada um dos genótipos originados das populações A e $\mathrm{B}$, e dois da $\mathrm{C}$, e devido a isso foram considerados apenas quatro clones de cada população para o modelo dessa área. Foram feitos modelos lineares generalizados contendo a origem do genótipo como efeito fixo e a herbivoria como variável resposta. 
Os modelos foram ajustados para a família binomial para dados de proporção, já que os dados de herbivoria foram apresentados em porcentagem, corrigida para quasibinomial, para dados de proporção sobredispersos.

Para verificar se os genótipos originados em uma mesma população diferiram quanto a sua resposta à herbivoria, também foram elaborados modelos lineares generalizados ajustados para a família binomial corrigida para quasibinomial, para dados de proporção sobredispersos. Foram feitos modelos separados para os genótipos originados em cada população (Tabela 2), contendo a área experimental (correspondentes aos genótipos originados de uma mesma população; Tabela 2) como variável explicativa, e a herbivoria dos genótipos originados na população como variável resposta. Devido a morte de alguns clones, afim de igualar o número de clones dos genótipos originados em uma mesma população de cada área experimental, foram utilizadas de cada área experimental para as análises: cinco plantas das populações A e $\mathrm{B}$, quatro plantas da população $\mathrm{C}$ e três plantas da população $\mathrm{D}$, igualando assim o número de clones dos genótipos originados em uma mesma população de cada área experimental utilizados.

Para verificar se a diferença de composição química entre as plantas (ver resultados) afetou a herbivoria, foi feito um modelo linear de efeito misto, contendo a composição química como efeito fixo, a área experimental como efeito aleatório e a herbivoria como variável resposta. O teste Shapiro Wilk foi procedido para analisar a normalidade da variável resposta, e a herbivoria foi transformada em $\log (\mathrm{x}+1)$, para assumir o pressuposto de normalidade dos dados nesse tipo de análise. Para estas análises, foram utilizadas todas as plantas disponíveis do quimiotipo com mistura de amidas como predominante (plantas do genótipo originado na população A do PNB, e do genótipo originado na população D de todas as áreas experimentais, totalizando 21 
plantas, devido à morte de três plantas do genótipo originado na população $\mathrm{D}$ da RECOR), e as plantas do genótipo originado na população B do PNB e seis plantas do genótipo originado na população C do PNB e da ESECAE, e apenas três plantas do genótipo originado na população $\mathrm{C}$ da RECOR, totalizando 21 plantas com $\mathrm{o}$ quimiotipo baseado no composto metil 3-geranil-4-hidroxibenzoato como principal, igualando assim o número de plantas de cada quimiotipo situados em cada área experimental para a realização das análises.

Para verificar o efeito da diversidade fitoquímica na herbivoria, foi elaborado um modelo linear de efeito misto, contendo a diversidade fitoquímica como efeito fixo, a área experimental como efeito aleatório e a herbivoria como variável resposta. O teste Shapiro Wilk foi procedido para analisar a normalidade da variável resposta, e então a herbivoria foi transformada em $\log (\mathrm{x}+1)$, para assumir o pressuposto de normalidade dos dados nesse tipo de análise. Todas as análises foram realizadas utilizando o software R 3.3.1 (R Development Core Team, 2016).

\section{RESULTADOS}

Foram encontrados 42 indivíduos de Lepidoptera nas plantas experimentais, durante os 12 meses de experimento; em média 3,5 indivíduos por mês. Destes, 14,3\% foram encontrados nos clones dos genótipos originados da população A, 33,3\% da população B, $28,6 \%$ da população C e $23.8 \%$ nos clones dos genótipos originados da população D. Devido aos baixos valores de abundância de Lepidoptera encontrados durante todo o período do experimento, considerados insuficientes para demostrar a existência de um padrão em relação as variáveis testadas, esta foi desconsiderada nas análises.

A origem do genótipo apresentou um efeito significativo na herbivoria apenas na 
área experimental do PNB (Tabela 3). Uma herbivoria significativamente maior foi encontrada no genótipo originado na população B (população local; Figura 4). Nas áreas experimentais da RECOR e da ESECAE, não houve um efeito significativo da origem do genótipo na herbivoria (Tabela 3).

Tabela 3. Modelos lineares generalizados (GLM) para avaliar o efeito da origem do genótipo sobre a herbivoria, para cada uma das áreas experimentais. Os modelos foram ajustados para a distribuição de erros quasibinomial (Área exper=área experimental; Var. resposta=variável resposta; Var. explicativa=variável explicativa; $R E C O R=$ Reserva Ecológica do Roncador-DF; PNB=Parque Nacional de Brasília-DF; ESECAE=Estação Ecológica de Águas Emendadas-DF).

\begin{tabular}{llllllll}
\hline Var. resposta & Var. explicativa & Área exper. & G.L. Desvio & G.L. Residual & Desvio Residual & $\mathrm{P}(>$ Chi $)$ \\
\hline Herbivoria(\%) & Origem do genótipo & Modelo Nulo & & & 17 & 0,99 & \\
& & RECOR & 2 & 0,21 & 15 & 0,78 & 0,12 \\
& & Modelo Nulo & & & 23 & 1,53 & \\
& & PNB & 3 & 0,56 & 20 & 0,98 & $0,01 *$ \\
& & Modelo Nulo & & & 15 & 1,01 & \\
& & ESECAE & 3 & 0,34 & 12 & 0,67 & 0,13 \\
\hline
\end{tabular}

*Variável explicativa retida no modelo mínimo adequado $(\mathrm{p}<0.05)$. 


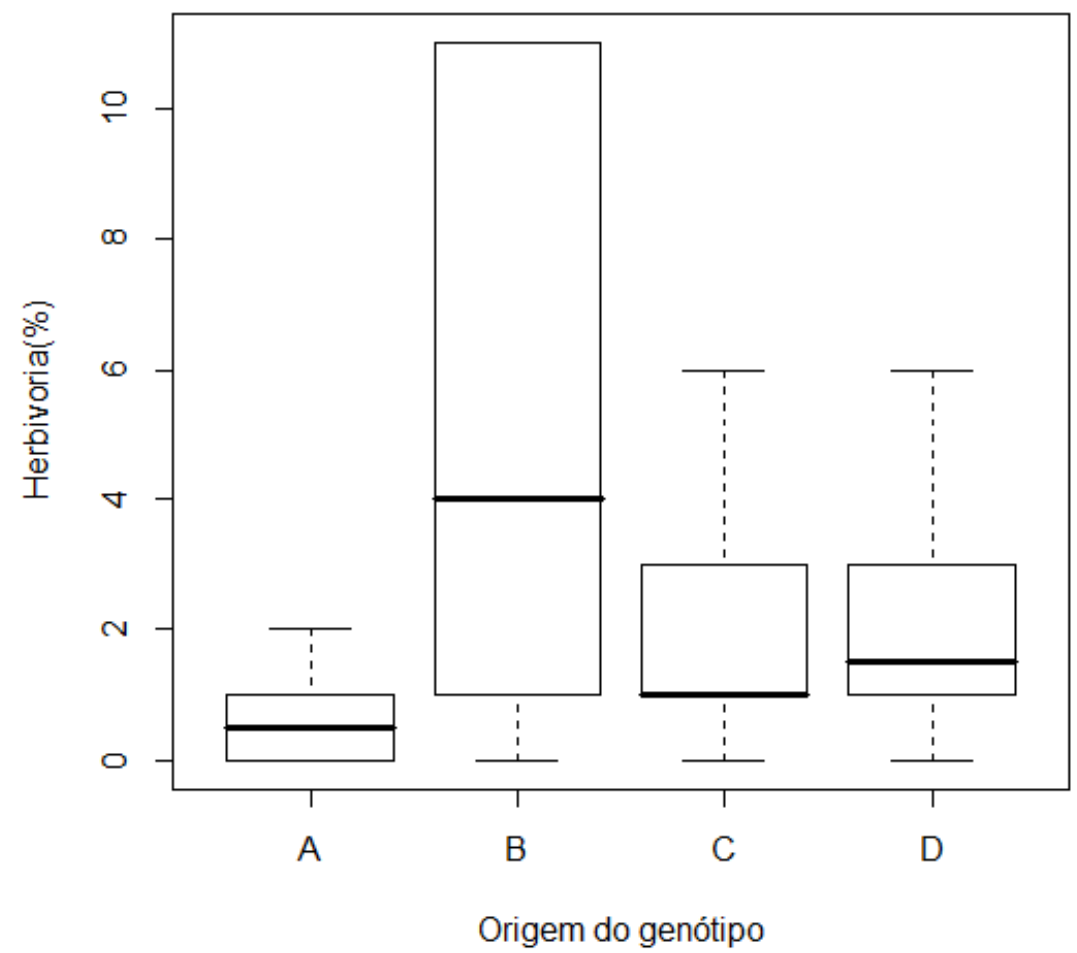

Figura 4. Efeito da origem do genótipo na herbivoria da comunidade de herbívoros em P. arboreum da área experimental do Parque Nacional de Brasília. A linha central representa a mediana, e a linha tracejada representa o desvio padrão $(\mathrm{A}=$ Reserva Ecológica do Roncador-DF; B=Parque Nacional de Brasília-DF; C= Estação Ecológica de Águas Emendadas-DF; D=Parque Nacional da Chapada dos Veadeiros-GO).

Os genótipos originados da população $\mathrm{B}$ (do PNB) diferiram quanto à sua resposta à herbivoria (Tabela 4). Uma maior herbivoria foi observada no genótipo originado dessa população situado no PNB (seu habitat local), e uma menor no genótipo originado dessa população situado na ESECAE (Figura 5). Os genótipos originados nas outras populações não diferiram quanto á herbivoria (Tabela 4). 
Tabela 4. Modelos lineares generalizados (GLM) para verificar se os genótipos originados em uma mesma população diferiram quanto à herbivoria, tendo como variável explicativa a área experimental (correspondentes aos genótipos originados de uma mesma população; Tabela 2) e como variável resposta a herbivoria dos genótipos originados na população. Os modelos foram ajustados para a distribuição de erros Quasibinomial (Var. resposta= variável resposta; Var. explicativa $=$ variável explicativa; $\mathrm{A}=$ genótipos originados na população da $\mathrm{RECOR} ; \mathrm{B}=$ genótipos originados na população do $\mathrm{PNB} ; \mathrm{C}=$ genótipos originados na população da ESECAE; D= genótipos originados na população do PNCV).

\begin{tabular}{llccccr}
\hline Var. resposta & $\begin{array}{l}\text { Var. } \\
\text { explicativa }\end{array}$ & G.L. & Desvio & G.L. Residual & Desvio Residual & P(>Chi) \\
\hline Herbivoria(\%) & Modelo Nulo & & & 14 & 0,73 & 0,09 \\
A & Área & 2 & 0,22 & 12 & 0,51 & \\
& Modelo Nulo & & & 14 & 1,44 & $0,01 *$ \\
B & Area & 2 & 0,69 & 12 & 0,75 & 0,28 \\
& Modelo Nulo & & & 11 & 0,44 & 0,35 \\
C & Area & 2 & 0,10 & 9 & 0,32 & 0,18 \\
& Modelo Nulo & & & 8 & 0,20 & \\
D & Area & 2 & 0,11 & 6 & & \\
\hline
\end{tabular}

*Variável explicativa retida no modelo mínimo adequado $(\mathrm{p}<0.05)$. 


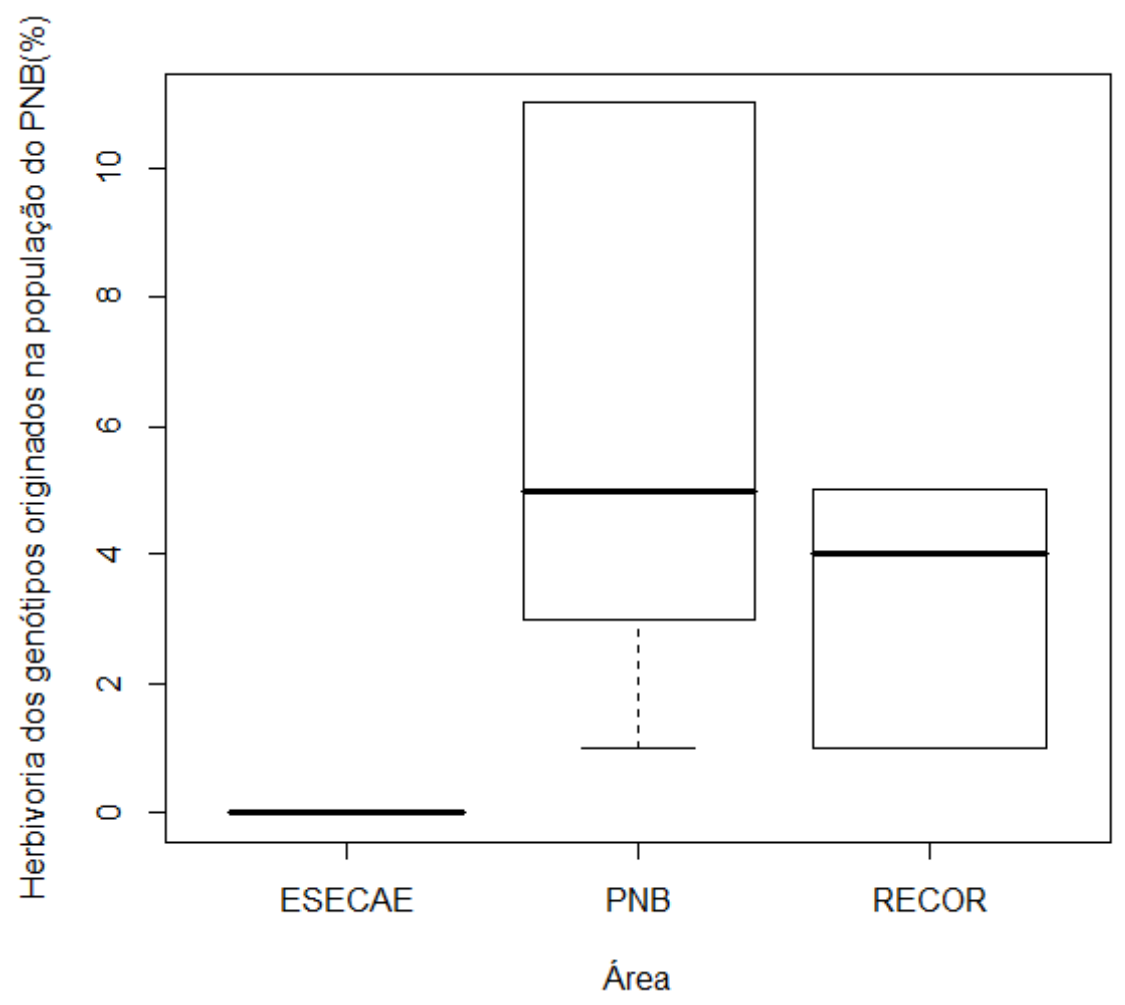

Figura 5. Herbivoria dos genótipos originados na população B (do PNB) nas três áreas experimentais do experimento (correspondentes aos genótipos originados de uma mesma população; Tabela 2). A linha central representa a mediana de herbivoria, e a linha tracejada representa o desvio padrão (ESECAE= Estação Ecológica de Águas Emendadas; RECOR=Reserva Ecológica do Roncador; $\mathrm{PNB}=$ Parque Nacional de Brasília).

A análise multivariada PCA revelou que as plantas-mãe se separaram em dois quimiotipos, de acordo com a sua composição química. As plantas-mãe originadas do PNB, ESECAE e as plantas-mãe originadas da RECOR situadas nas áreas experimentais da RECOR e da ESECAE apresentaram o composto metil 3-geranil-4hidroxibenzoato como principal (Figura 6). Já as plantas-mãe originadas do PNCV e a planta-mãe originada da RECOR situada na área experimental do PNB, apresentaram um perfil químico distinto, devido a uma mistura complexa de amidas, não havendo 
nessa mistura uma amida predominante. Provavelmente, essas amidas são as mesmas já isoladas para P. arboreum (Silva et al., 2002).

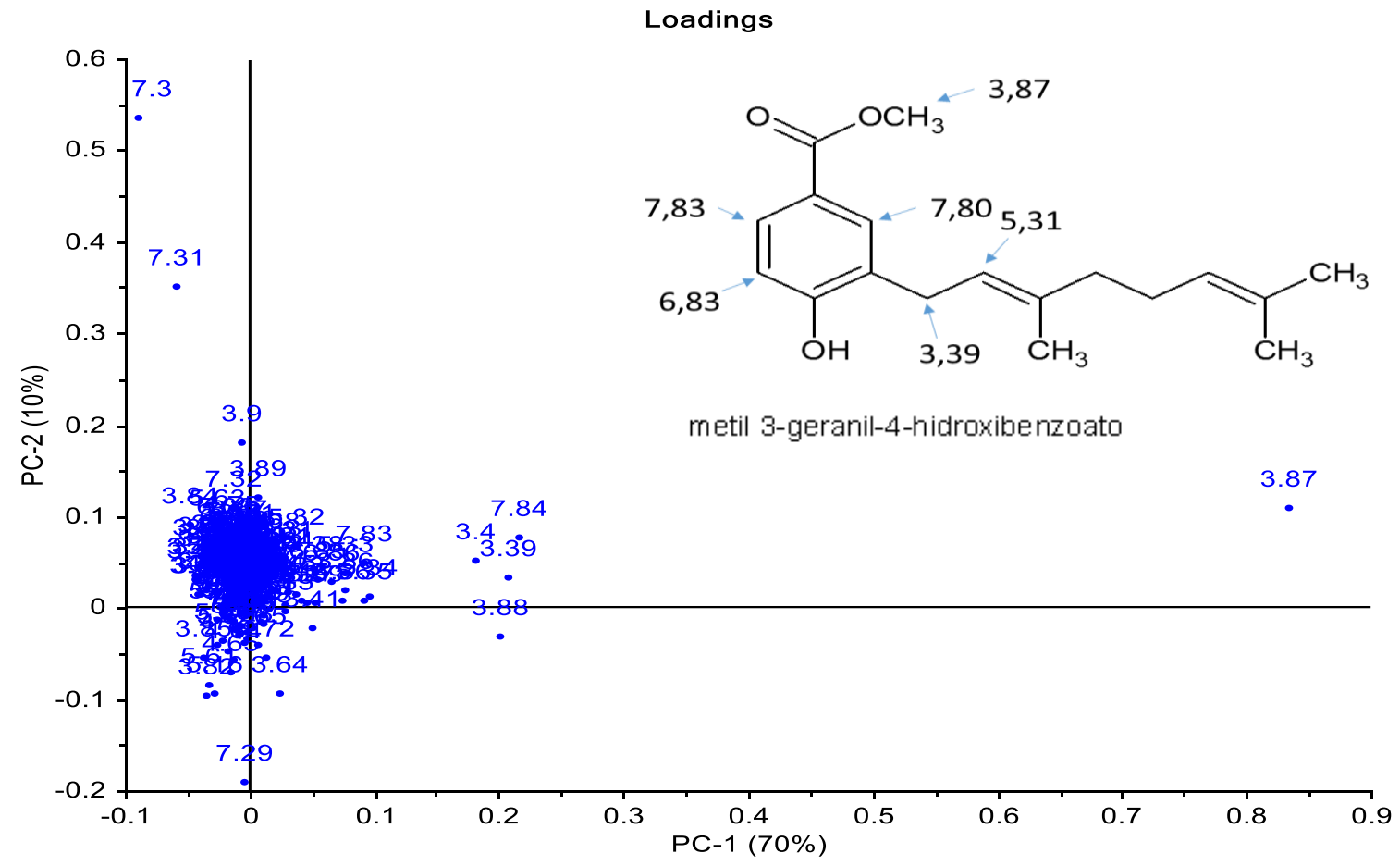

Figura 6. Estrutura química do composto principal das plantas-mãe de $P$. arboreum originadas do PNB e da ESECAE e de duas plantas-mãe da RECOR.

A composição química de $P$. arboreum afetou a porcentagem de herbivoria ocasionada pelos insetos mastigadores (Tabela 5). Uma menor herbivoria foi observada no quimiotipo com uma mistura complexa de amidas (Figura 7). 
Tabela 5. Modelo linear de efeito misto contendo a composição química das plantas de P. arboreum como efeito fixo, o local (área experimental) como efeito aleatório, e a porcentagem de herbivoria como variável resposta.

\begin{tabular}{cccccc} 
Variável resposta & Variável explicativa & numG.L. & denG.L. & F & $P(>\mathrm{F})$ \\
\hline Herbivoria $(\%)$ & & & & & \\
& Composição química & 1 & 29 & 5,99 & $\mathbf{0 , 0 2}^{*}$ \\
\hline
\end{tabular}

*Variável explicativa retida no modelo mínimo adequado $(\mathrm{p}<0.05)$.

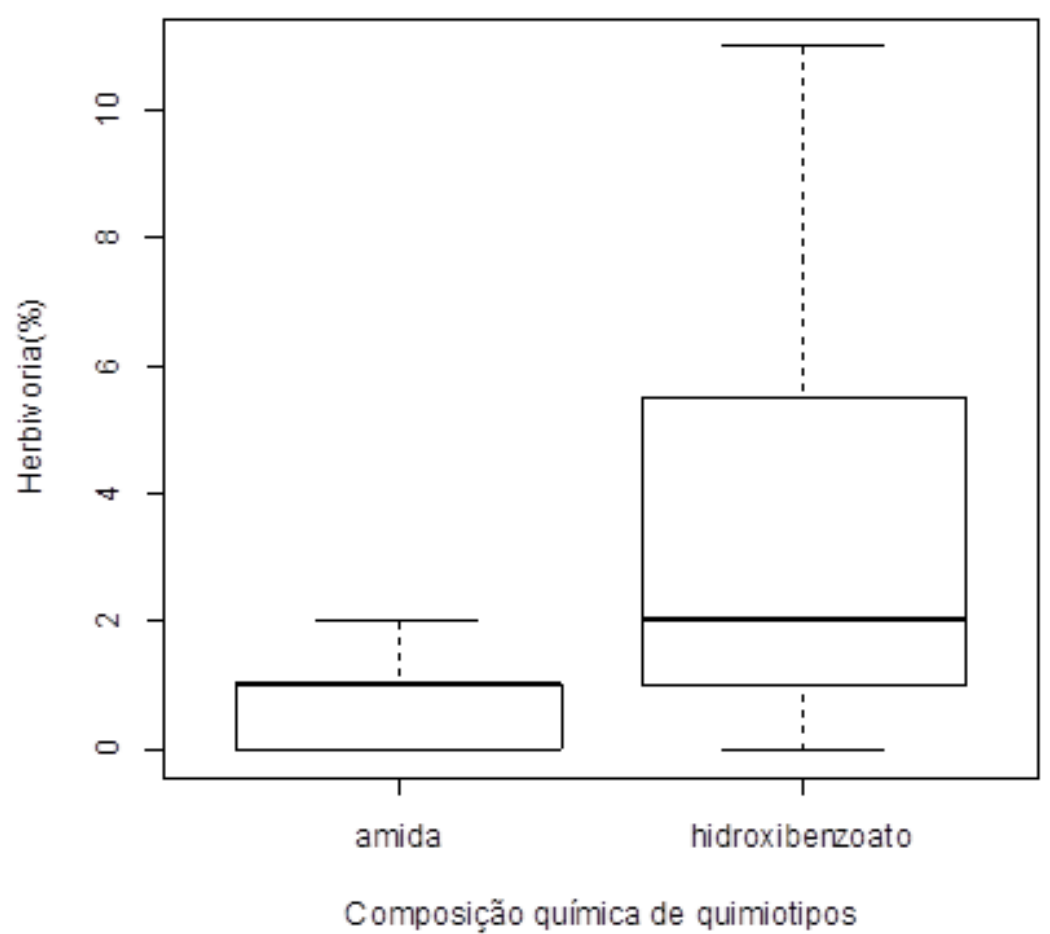

Figura 7. Composição química de $P$. arboreum e herbivoria. Os dois quimiotipos encontrados em $P$. arboreum, amida e hidroxibenzoato (eixo x), e a porcentagem de herbivoria (eixo y). A linha central representa a mediana, e a linha tracejada representa o desvio padrão.

A diversidade fitoquímica (nímero efetivo de grupos funcionais) das plantas não afetou a herbivoria. $(\mathrm{F}=0,40, \mathrm{P}=0,53$; Anexo 3$)$. 


\section{DISCUSSÃO}

No presente estudo, a origem do genótipo afetou a resistência a herbivoria em apenas uma das áreas experimentais. Entretanto, experimentos realizados em ambientes naturais podem ter muitas variáveis diferentes incontroláveis, de forma que a interpretação se torna excessivamente difícil (Fritz \& Simms, 1992). Assim, não é possível pelos resultados obtidos, afirmar que a origem do genótipo não afetou a herbivoria nas outras áreas experimentais, pois esse efeito pode ter sido mascarado por outras variáveis ambientais não controladas. Apesar dos problemas que experimentos em ambientes naturais, sem variáveis controladas, acarretam, são de suma importância, pois resultados obtidos em condições ambientais restritas não podem ser extrapolados para fazer inferência sobre o comportamento de populações de insetos herbívoros em ambientes naturais (Fritz \& Simms, 1992).

Marquis (1990), em um estudo similar em floresta úmida tropical na Costa Rica, avaliou as diferenças de resistência à herbivoria de quatro genótipos locais de Piper arieianum, os diferenciando apenas pela distância mínima de $1 \mathrm{~km}$, por um experimento com duas parcelas, e encontrou em ambas as parcelas, uma diferença entre os genótipos quanto à resistência a herbivoria. $\mathrm{O}$ experimento foi realizado durante três anos e meio mas, as medidas de herbivoria foram realizadas periodicamente, com um intervalo máximo de um ano e quatro meses, o que indica que a escala temporal utilizada no presente estudo não foi um problema. Além disso, estes resultados indicam que a distância mínima de $20 \mathrm{~km}$ utilizada para a diferenciação da origem do genótipo no presente estudo foi suficiente para levar à uma diferenciação quanto à resistência a herbivoria.

Além do experimento de Marquis (1990), há várias evidências na literatura de que a variação genética afeta a resistência à herbivoria e pode existir em populações 
naturais de plantas (ex: Karban, 1992; Mauricio, 1998; Tiffin \& Rausher, 1999; Pilson, 2000; Cronin \& Abrahamson, 2001, Stinchcombe \& Rausher, 2001; O’Reilly Wapstra et al., 2002; Juenger et al., 2005). Tal variação genética é um pré-requisito indispensável para que se possa considerar a pressão seletiva de herbívoros como um agente indutor da evolução de características de defesas de plantas (Marquis 1990).

Os genótipos de apenas uma das populações de plantas utilizadas no presente estudo diferiram quanto à herbivoria. Houve uma relação negativa entre a distância da área experimental que o genótipo foi situado do habitat local dessa população e a herbivoria. Além disso, na área experimental onde a origem do genótipo apresentou um efeito significativo na herbivoria, o genótipo originado na população local apresentou uma herbivoria significativamente maior que a dos outros genótipos alopátricos. Esses resultados sugerem a existência de uma adaptação local dos herbívoros aos genótipos locais. Em interações parasita-hospedeiro, como a existente entre plantas e insetos herbívoros, os parasitas são esperados exibir adaptação local sobre seus hospedeiros, devido a seus tempos de gerações mais curtos, maiores tamanhos populacionais e maiores taxas de mutação (Lively, 1999; Ebert, 1994). Evidências de adaptação local já foram encontradas em vários estudos tanto em escala regional (Parker, 1985; Lively, 1989; Ebert, 1994; Guarrido et al., 2012) quanto em escala local (Karban, 1989; Edmunds \& Alstad, 1978), entretanto, outros estudos empíricos utilizando sistemas herbívoros-planta, não foram capazes de detectar adaptação local de herbívoros (Davelo et al., 1996; Dufva, 1996; Strauss, 1997; Zangerl \& Berenbaum, 1990; Mutikainen et al., 2000). Essa pode ser uma possível força que esteja moldando os padrões encontrados em sistemas herbívoros-plantas em ambientes naturais.

A variação genética também pode influenciar os insetos herbívoros se a característica afetada pela genética atingir o fitness ou o comportamento dos mesmos 
(Hairston et al., 2005; Hughes et al., 2008), como já observado para a resposta diferenciada de herbívoros à variação genética intraespecífica de compostos secundários (Hwang \& Lindroth, 1997).

No presente estudo, também foi observada uma resposta de herbívoros à variação genética intraespecífica de compostos secundários da planta examinada. $\mathrm{O}$ quimiotipo com uma mistura de amidas como componente principal afetou negativamente a herbivoria. Compostos secundários específicos de plantas podem determinar a abundância, a herbivoria e a performance de insetos herbívoros (Rodman \& Chew, 1980, Poelman et al., 2009; Kleine \& Müller, 2011). Há varias evidências na literatura dos fortes efeitos das amidas de Piper em herbívoros e patógenos (Bernard et al., 1995; Navickiene et al., 2000; Siddiqui et al., 2002; Yang et al., 2002). Como esse quimiotipo apresenta uma mistura de amidas, não só a ação de suas amidas isoladamente, mais também possíveis efeitos sinergéticos, já encontrados para amidas de Piper sobre herbívoros (Richards et al., 2010), podem ser responsáveis por esse resultado.

Não foram encontrados registros na literatura de trabalhos testando os efeitos do composto metil 3-geranil-4-hidroxibenzoato em herbívoros. De acordo com os resultados do presente trabalho, em comparação com as amidas, esse composto apresenta uma maior palatabilidade para insetos herbívoros.

Fatores químicos únicos não compartilhados para a maioria das outras plantas podem reduzir a susceptibilidade de plantas a herbivoria (Lavandero et al., 2009). Dessa forma, o fato do quimiotipo com amidas como componente principal ser raro ou ausente em duas das áreas experimentais, pode ter contribuído para diminuição da herbivoria nos indivíduos desse quimiotipo nessas áreas. Kursar e colaboradores (2009) encontraram que defesas químicas mais raras aumentam o fitness de plantas nos 
Neotrópicos, o que implica que interações com herbívoros podem ser um importante eixo de diferenciação de nicho que permite a coexistência de muitas espécies dentro de um único local. Como só três indivíduos de $P$. arboreum de cada área experimental foram analisados quimicamente, a análise de mais indivíduos dessas áreas experimentais seria necessária para confirmar se esse quimiotipo é raro ou ausente nesses locais.

A diversidade fitoquímica das plantas não apresentou um efeito significativo sobre a herbivoria no presente estudo. Schuldt e colaboradores (2012) encontraram resultado similar. Richards e colaboradores (2015), encontraram que uma maior diversidade fitoquímica na planta reduz os danos por herbívoros, através da exploração de modos únicos de toxicidade, como fototoxicidade, ou através da ação sinergética de misturas fitoquímicas. Lavandero e colaboradores (2009) não detectaram uma relação significativa entre a diversidade fitoquímica da planta e a riqueza de insetos herbívoros. Há poucos registros na literatura de trabalhos relacionando à diversidade fitoquímica das plantas e seu efeito em herbívoros, e devido a isso, mais estudos são necessários para uma melhor determinação desses efeitos.

\section{REFERÊNCIAS BIBLIOGRÁFICAS}

Alécio, A.C., Bolzani, V.D.S.,Young, M.C.M., Kato, M.J. \& Furlan, M. 1998. Antifungal amide from leaves of Piper hispidum Journal of Natural Products, 61: 637-639.

Becerra, J.X., Noge, K. \& Venable, D.L. 2009. Macroevolutionary chemical escalation in an ancient plant-herbivore arms race. Proceedings of the National Academy of Sciences, 106: 18062-18066.

Bernard, C.B., Krishnamurty, H.G., Chauret, D., Durst, T., Philogene, B.J.R., Sanchezvindas, P., Hasbun, C., Poveda, L., Sanroman, L. \& Arnason, J.T. 1995. Insecticidal defenses of Piperaceae from the Neotropics. Journal of Chemical Ecology, 21: 801-814.

Billeter, R., Schneller, J. \& Diemer, M. 2002. Genetic diversity of Carex davalliana and Succisa pratensis in mown and abandoned fen meadows. Bulletin of the Geobotanical Institute ETH, 68: 45-54. 
Bizerril, M.X.A. 1995. Utilização dos frutos de Piper arboreum (Piperaceae) por morcegos. Dissertação de Mestrado em Ecologia. Universidade de Brasília, 64 p.

Calculadora Geográfica do DPI-INPE - Divisão de Processamento de Imagens do Instituto Nacional de Pesquisas Espaciais. Disponível em: http://www.dpi.inpe.br/calcula/. Acessado em julho de 2016.

Cotinguiba, F., Regasini, L.O., Bolzani, V.D., Debonsi, H.M., Passerini, G.D., Cicarelli, R.M.B., Kato, M.J., Furlan, M. 2009. Piperamides and their derivatives as potential anti-trypanosomal agents. Medicinal Chemistry Research, 18: 703-711.

Cronin, J.T., Abrahamson, W.G. 2001. Goldenrod stem galler preference and performance: effects of multiple herbivores and plant genotypes. Oecologia,127: 87-96.

Davelos, A.L., Alexander, H.M., Slade, N.A. 1996. Ecological genetic interactions between a clonal host plant (Spartina pectinata) and associated rust fungi Puccinia seymouriana and Puccinia sparganioides. Oecologia, 105: 205-213.

Dodson, L.A., Letourneau, C.D., Tobler, D.K., Hsu, M.A. \& Stireman III J.O. 2004. Ecological causes and consequences of variation in defensive chemistry of a Neotropical shrub. Ecology, 85: 2795-2803.

Duarte, M.S., Pontes, M.J.C., RAmos, C.S. 2016. Differentiation of the chemical profile of Piper arboreum tissues using NIR spectrometry and principal component analysis. Journal of Applied Spectroscopy, 82: 1042-1045.

Dufva, R. 1996. Sympatric and allopatric combinations of hen fleas and great tits: a test of the local adaptation hypothesis. Journal of Evolutionary Biology, 9: 505-510.

Dyer, L.A., Dodson, C.D. \& Richards, J. 2004. Isolation, synthesis, and evolutionary ecology of Piper amides. In: Dyer, L.A \& Palmer, A.N. (eds.). Piper. A model genus for studies of evolution, chemical ecology, and trophic interactions. Kluwer Academic Publishers, Boston, 117-139.

Dyer, L.A., Dodson, C.D., Stireman, J.O., Tobler, M.A., Smilanich, A.M., Fincher, R.M. \& Letourneau, D.K. 2003. Synergistic effects of three Piper amides on generalist and specialist herbivores. Journal of Chemical Ecology, 29: 2499-2514.

Dyer, L.A., Letourneau, D.K., Vega, C.G. \& Salazar, A.D. 2010. Herbivores on a dominant understory shrub increase local plant diversity in rain forest communities. Ecology, 91: 3707-3718.

Dyer, L.A. \& Palmer, A.N. 2004. Piper. A model genus for studies of evolution, chemical ecology, and trophic interactions. In L. Dyer, C.D. Dodson \& J. Richards (eds.). Kluwer Academic Publishers, Boston, 117-139.

Ebert, D. 1994. Virulence and local adaptation of a horizontally transmitted parasite. Science-New York then Washington, 265: 1084-1086.

Edmunds, G.F. \& Alstad, D.N. 1978. Coevolution in insect herbivores and conifers. Science, 199: 941-945.

Fraenkel, G. 1959. The raison d'être of secondary substances. Science, 129: 1466-1470.

Françoso, R. D., Goeller, A. J. \& Lenza, E. 2013. Herbivoria e biomassa foliar em Peltogyne confertifora (Mart. ex Hayne) Benth. Fabales Bromhead Fabaceae Lindl. em ambientes de Floresta e Cerrado. Ecología austral, 23: 222-226.

Fritz, R.S. \& Simms, E.L. (eds.). 1992.Plant resistance to herbivores and pathogens: ecology, evolution, and genetics. University of Chicago Press.

Gandon, S., Capowiez, Y., Dubois, Y., Michalakis, Y. \& Olivieri, I. 1996. Local adaptation and gene-for-gene coevolution in a metapopulation model. Proceedings of the Royal Society of London B: Biological Sciences, 263: 1003-1009.

Gray, A.J. 1987. Genetic change during succession in plants. In: Gray, A.J., Crawley, M.J. \& Edwards, P.J. (Eds.). Colonization, Succession and Stability. Blackwell. Oxford, 273-293. 
Garrido, E., Andraca-Gómez, G., \& Fornoni, J. 2012. Local adaptation: simultaneously considering herbivores and their host plants. New Phytologist, 193: 445-453.

Hairston Jr, N.G., Ellner, S.P., Geber, M.A., Yoshida, T. \& Fox, J.A. 2005. Rapid evolution and the convergence of ecological and evolutionary time. Ecology Letters, 8: 11141127.

Heithaus, E.R., Fleming, T.H. 1978. Foraging movements of a frugivorous bat, Carollia perspicillata (Phyllostomatidae). Ecological Monographs, 48: 127-143.

Hughes, A.R., Inouve, B.D. Johnson, M.T.J., Underwood, N. \& Vellend, M. 2008. Ecological consequences of genetic diversity. Ecology Letters, 11: 609-623.

Hwang, S. Y., \& Lindroth, R.L. 1997. Clonal variation in foliar chemistry of aspen: effects on gypsy moths and forest tent caterpillars. Oecologia, 111: 99-108.

Inouye, H.; Ueda, S.; Inoue, K.; Matsumura, H. 1979. Phytochemistry, 18: 1301.

Jeffrey, C.S., Leornard, M.D., Glassmire, A.E., Dodson, C.D., Richards, L.A., Kato, M.J. \& Dyer, L.A. 2014. Anti-herbivore prenylated benzoic acid derivatives from Piper kelleyi. Journal of Natural Products, 77: 148-153.

Jaeger, P. 2004. Caracterização genética e demográfica de populações de Xilopia emarginata Mart.(Annonaceae). Dissertação (Mestrado em Engenharia Florestal) - Universidade federal de Lavras, Lavras, 113p.

Jost, L. 2006. Entropy and diversity. Oikos, 113: 363-375.

Juenger, T., Morton, T.C., Miller, R.E., Bergelson, J. 2005. Scarlet gilia resistance to insect herbivory: the effects of early season browsing, plant apparency, and phytochemistry on patterns of seed fly attack. Evolutionary Ecology, 19: 79-101.

Kaltz, O. \& Shykoff, J. A. 2002. Within-and among-population variation in infectivity, latency and spore production in a host-pathogen system. Journal of Evolutionary Biology, 15: 850-860.

Karban, R. 1989. Fine-scale adaptation of herbivorous thrips to individual host plants. Nature, 340: 60-61.

Karban R. 1992. Plant variation: its effects on populations of herbivorous insects. In: Fritz, R.S., Simms, E.L. (eds). Plant resistance to herbivores and pathogens. Chicago, IL, USA: The University of Chicago Press, 195-215.

Kato, M.J. \& Furlan, M. 2007. Chemistry and evolution of the Piperaceae. Pure and Applied Chemistry, 79: 529-538.

Kawecki, T. J., \& Ebert, D. 2004. Conceptual issues in local adaptation. Ecology letters, 7: 1225-1241.

Kleine, S. \& Müller, C. 2011. Intraspecific plant chemical diversity and its relation to herbivory.Oecologia,166: 175-186.

Kotowska, A.M.; Cahill, J.R., James, F. \& Keddie, B.A. 2010. Plant genetic diversity yields increased plant productivity and herbivore performance. Journal of Ecology, 98: 237245.

Kursar, T.A., Dexter, K.G., Lokvam, J., Pennington, R.T., Richardson, J.E., Weber, M.G., $\&$ Coley, P.D. 2009. The evolution of antiherbivore defenses and their contribution to species coexistence in the tropical tree genus Inga.Proceedings of the National Academy of Sciences, 106: 18073-18078.

Lago, J.H.G., Ramos, C.S., Casanova, D.C.C., Morandim, A.D., Bergamo, D.C.B., Cavalheiro, A.J., Bolzani, V.D.S., Furlan, M., Guimarães, E.F., Young, M.C.M. \& Kato, M.J. 2004. Benzoic acid derivatives from piper species and their fungitoxic activity against Cladosporium cladosporioides and C-sphaerospermum. Journal of Natural Products, 67: 1783-1788.

Lavandero, B., Labra, A., Ramírez, C.C., Niemeyer, H.M. \& Fuentes-Contreras, E. 2009. Species richness of herbivorous insects on Nothofagus trees in South America and New 
Zealand: the importance of chemical attributes of the host. Basic and Applied Ecology, 10: $10-18$.

Linhart, Y.B. \& Grant, M.C. 1996. Evolutionary significance of local genetic differentiation in plants. Annual Review Ecology and Systematics, 27: 237-277.

Lively, C. M. 1989. Adaptation by a parasitic trematode to local populations of its snail host. Evolution, 43: 1663-1671.

Lively, C. M. 1999. Migration, virulence, and the geographic mosaic of adaptation by parasites.The American Naturalist,153: 34-47.

Marques, J.V., Kitamura, R.O.S., Lago, J.H.G., Young, M.C.M., Guimarães, E.F., Kato, M.J. 2008. Antifungal amides from Piper scutifolium and Piper hoffmanseggianum. Journal of Natural Products, 70: 2036-2039.

Marquis, R.J. 1990. Genotypic variation in leaf damage in Piper arieianum (Piperaceae) by a multispecies assemblage of herbivores.Evolution, 44: 104-120.

Marquis, R.J. 1991. Herbivore fauna of Piper (Piperaceae) in a Costa Rican wet forest: diversity, specificity, and impact, pp. 179-208.In: Price, P.W., Lewinsohn, T.M., Fernandes, G.W. \& Benson, W.W. (eds.). Plant-animal interactions - evolutionary ecology in tropical and temperate regions,John Wiley \& Sons, Inc., New York.

Mauricio, R. 1998. Costs of resistance to natural enemies in field populations of the annual plant Arabidopsis thaliana. American Naturalist, 151: 20-28.

Moraes, J., Keiser, J., Ingram, K., Nascimento, C., Yamaguchi, L.F., Bittencourt, C. R., Bemquerer, M.P., Leite, J.R., Kato, M.J. \& Nakano, E. 2013. In Vitro sinergistic interaction between amide piplartine and antimicrobial peptide dermaseptin against Schistosoma mansoni schistosomula and adult worms. Current Medicinal Chemistry, 20: 301-309.

Mutikainen, P., Salonen, V., Puustinen, S., \& Koskela, T. 2000. Local adaptation, resistance, and virulence in a hemiparasitic plant-host plant interaction. Evolution, 54: 433-440.

Navickiene, H.M.D., Alecio, A.C., Kato, M.J., Bolzani, V.D., Young, M.C.M., Cavalheiro, A.J. \& Furlan, M. 2000. Antifungal amides from Piper hispidum and Piper tuberculatum. Phytochemistry, 55: 621-626.

O'Reilly-Wapstra, J.M., McArthur, C., Potts, B.M. 2002. Genetic variation in resistance of Eucalyptus globulus to marsupial browsers, Oecologia 130: 289-296.

Parker, M.A. 1985. Local population differentiation for compatibility in an annual legume and its host-specific fungal pathogen,. Evolution, 39: 713-723.

Pereira, J. A. 2015. Herbivoria foliar em populações e espécies arbóreas cogenéricas entre florestas paludosas e de encosta. Tese (Doutorado em Ecologia) - Universidade federal de Ouro Preto, Ouro Preto, 54p.

Pilson D. 2000. The evolution of plant response to herbivory: simultaneously considering resistance and tolerance in Brassica rapa. Evolutionary Ecology, 14: 457-489.

Poelman, E.H., Dam, N.M., Loon, J.J.A., Vet, L.E., \& Dicke, M. 2009. Chemical diversity in Brassica oleracea affects biodiversity of insect herbivores. Ecology, 90: 1863-1877.

Rapado, L.N., De Sa Pinheiro, A., Lopes, P., Fokoue, H.H., Scotti, M.T., Marques, J.V., Ohlweiler, F.P., Borrely, S.I., Pereira, C.A.D., Kato, M.J., Nakano, E., Yamaguchi, L.F. 2013. Schistosomiasis control using piplartine against Biomphalaria glabrata at different developmental stages. Plos Neglected Tropical Diseases, 7.

Rasband, W.S. 2006. ImageJ. Bethesda, Maryland: US National Institutes of Health. http://rsb.info.nih gov/ij, 1997-2009.

R Core Team. 2016. R: A language and environment for statisticalcomputing. R Foundation for Statistical Computing, Vienna, Austria. Disponível em: https://www.R-project.org/. 
Richards, L.A., Dyer, L.A., Forister, M.L., Smilanich, A.M., Dodson, C.D., Leonard, M.D., \& Jeffrey, C.S. 2015. Phytochemical diversity drives plant-insect community diversity. Proceedings of the National Academy of Sciences, 112: 10973-10978.

Richards L.A., Dyer, L.A., Smilanich, A.M., Dodson, C.D. 2010. Synergistic effects of amides from two Piper species on generalist and specialist herbivores, Journal of Chemical Ecology, 36: 1105-1113.

Rodman, J.E., \& Chew, F.S. 1980. Phytochemical correlates of herbivory in a community of native and naturalized Cruciferae. Biochemical Systematics and Ecology, 8: 43-50.

Rodriguez-Castañeda, G., Forkner, R.E., Tepe, E.J., Gentry, G.L. \& Dyer, L.A. 2011. Weighing defensive and nutritive roles of ant mutualists across a tropical altitudinal gradient. Biotropica, 43:343-350.

Schuldt, A., Bruelheide, H., Durka, W., Eichenberg, D., Fischer, M., Kröber, W. \& Schmid, B. 2012. Plant traits affecting herbivory on tree recruits in highly diverse subtropical forests. Ecology Letters, 15: 732-739.

Siddiqui, B.S., Gulzar,T. \& Begum, S. 2002. Amides from the seeds of Piper nigrum Linn. and their insecticidal activity. Heterocycles, 57: 1653-1658.

Silva, R.V., Navickiene, H.M.D., Kato, M.J., Bolzani, V.D.A.S., Méda, C.I., Young, M.C.M., Furlan, M. 2002. Phytochemistry, 59: 521.

Souza, A. M. D., Carvalho, D. D., Vieira, F. D. A., Nascimento, L. H. D. \& Lima, D. C. D. 2007. Estrutura genética e espacial de populações naturais de Calophyllum brasiliense Camb. em mata de galeria. Cerne, 13: 239-247.

Stinchcombe, J.R. \& Rausher, M.D. 2001. Diffuse selection on resistance to deer herbivory in the ivyleaf morning glory, Ipomoea hederacea. American Naturalist, 158: 376-388.

Strauss, S.Y. 1997. Lack of evidence for local adaptation to individual plant clones or site by a mobile specialist herbivore. Oecologia, 110: 77-85.

Summerville, K.S. \& Crist, T.O. 2003. Determinants of lepidopteran community composition and species diversity in eastern deciduous forests: roles of season, ecoregion and patch size. Oikos, 100: 134-148.

Swain, T. 1977. Secondary compounds as protective agents. Annual Review of Plant Physiology, 28: 479-501.

Thompson, J.N. 1997. Conserving interaction biodiversity. In: Pickett, S.T.A., Ostfeld, R.S., Shachak, M. \& Likens, G.E. (eds.), The ecological basis of conservation: heterogeneity, ecosystems, and biodiversity. Chapman \& Hall.

Tiffin, P., Rausher, M.D. 1999. Genetic constraints and selection acting on tolerance to herbivory in the common morning glory Ipomoea purpurea. American Naturalist, 154: 700-716.

Varanda, E. M. \& Pais, M. P. 2006. Insect folivory in Didymopanax vinosum (Apiaceae) in a vegetation mosaic of Brazilian Cerrado. Brazilian Journal of Biology, 66: 671-680.

Von Flue, I., Gurgeli, F., Holderegger, R. \& Schneller, J. 1999. Genetic and morphological variability in alpine Saxifraga oppositifolia L. after colonization. Feddes Repert, 110: $555-559$.

Zangerl, A.R. \& Berenbaum, M.R. 1990. Furanocoumarin induction in wild parsnip: genetics and population variation. Ecology, 71: 1933-1940.

Wink, M. 1988. Plant breeding: importance of plant secondary metabolites for protection against pathogens and herbivores. Theoretical and Applied Genetics, 75: 225-233.

Wink, M. 2003. Evolution of secondary metabolites from an ecological and molecular phylogenetic perspective. Phytochemistry, 64: 3-19.

Wink, M. 2008a. Plant secondary metabolism: diversity, function and its evolution. Natural Products Communications, 3: 1205-1216.

Wink, M. 2008b. Evolutionary advantage and molecular modes of action of multi- 
component mixtures used in phytomedicine. Current Drug Metabolism, 9: 996-1009. Yang, Y.C., Lee, S.G., Lee, H.K., Kim, M.K., Lee, S.H., \& Lee, H.S. 2002. A piperidine amide extracted from Piper longum $\mathrm{L}$. fruit shows activity against Aedes aegypti mosquito larvae. Journal of Agricultural and Food Chemistry, 50: 3765-3767. 


\section{CONSIDERAÇÕES FINAIS}

Espécies de Piper nas Matas de Galeria apresentam a maioria dos padrões de riqueza e abundância de lagartas de lepidópteros similares aos encontrados para o cerrado sentido restrito; alta riqueza e baixa abundância de espécies, baixa frequência em plantas hospedeiras e pico de abundância na estação seca. A espécie com maior densidade nas áreas amostradas foi Piper arboreum. Como no cerrado sentido restrito, foi encontrada uma alta riqueza de espécies raras de lagartas de lepidópteros associada à espécie $P$. arboreum nas Matas de Galeria do Cerrado do Brasil central, com grande variação espacial na composição de espécies e por isso com baixa similaridade faunística.

A origem do genótipo de $P$. arboreum afetou a herbivoria foliar em apenas uma das áreas. Neste trabalho não foi feita uma análise da diversidade genotípica intrapopulacional e isto pode ter influenciado nos resultados. O ideal seria a montagem dos experimentos com repetições com os clones derivados da mesma planta-mãe nas três áreas experimentais. A herbivoria foliar de $P$. arboreum variou entre os grupos fitoquímicos encontrados. Os resultados também sugerem que a diversidade fitoquímica da planta não afeta a comunidade de herbívoros. 
ANEXO

Anexo 1. Espécies de lagartas encontradas em Piper spp. em sete matas de galeria do Cerrado do Distrito Federal e Goiás, de maio/15 a abril/16, $\left(^{*}=\right.$ singletons; NI=não identificada).

\begin{tabular}{|c|c|c|c|c|c|c|c|c|}
\hline Família & Espécies & PNCV & ESECAE & FAL & RECOR & JBB & Pirenópolis & PNB \\
\hline 1.Bombycidae & Zanola verago* & & & & & & $\mathrm{x}$ & \\
\hline \multirow[t]{2}{*}{ 2.Elaschitidae } & Antaeotricha sp. $1^{*}$ & & & & & & $\mathrm{x}$ & \\
\hline & Antaeotricha sp. $2^{*}$ & & & & & $\mathrm{x}$ & & \\
\hline \multirow[t]{8}{*}{ 3.Erebidae } & Arctiinae sp. $1^{*}$ & & & & $\mathrm{x}$ & & & \\
\hline & Arctiinae sp. $2^{*}$ & $\mathrm{x}$ & & & & & & \\
\hline & Arctiinae sp. $3^{*}$ & & & & $\mathrm{x}$ & & & \\
\hline & Arctiinae sp. 4 & $\mathrm{x}$ & $\mathrm{x}$ & $\mathrm{x}$ & & $\mathrm{x}$ & & $\mathrm{x}$ \\
\hline & Arctiinae sp. $5^{*}$ & & & $\mathrm{x}$ & & & & \\
\hline & Acrtiinae sp. $6^{*}$ & & & $\mathrm{x}$ & & & & \\
\hline & Dysschema sp. & $\mathrm{x}$ & & & $\mathrm{x}$ & & & \\
\hline & Lophocampa sp. $1^{*}$ & $\mathrm{x}$ & & & & & & \\
\hline 4.Gelechiidae & Gelechiidae sp. $1^{*}$ & & & & & & & $\mathrm{x}$ \\
\hline \multirow[t]{13}{*}{ 5.Geometridae } & Eois binaria & $\mathrm{x}$ & $\mathrm{x}$ & $\mathrm{x}$ & $\mathrm{x}$ & & $\mathrm{x}$ & \\
\hline & Eois sp. 1 & & & $\mathrm{x}$ & & & & \\
\hline & Eois sp. $2^{*}$ & & & & & $\mathrm{x}$ & & \\
\hline & Eois tegularia & $\mathrm{x}$ & & & $\mathrm{x}$ & & & \\
\hline & Geometridae sp. $1 *$ & & & $\mathrm{x}$ & & & & \\
\hline & Geometridae sp. 2 & $\mathrm{x}$ & & $\mathrm{x}$ & & & & $\mathrm{x}$ \\
\hline & Geometridae sp. $3 *$ & & & $\mathrm{x}$ & & & & \\
\hline & Geometridae sp. 4 & $\mathrm{x}$ & & & & & & \\
\hline & Geometridae sp. $5 *$ & & & & & $\mathrm{x}$ & & \\
\hline & Geometridae sp. 6 & $\mathrm{x}$ & & $\mathrm{x}$ & & & & \\
\hline & Geometridae sp. $7 *$ & & $\mathrm{x}$ & & & & & \\
\hline & Geometridae sp. $8^{*}$ & & & $\mathrm{x}$ & & & & \\
\hline & Geometridae sp. 9 & & & $\mathrm{x}$ & & $\mathrm{x}$ & & \\
\hline \multirow[t]{5}{*}{ 6.Hesperiidae } & Hesperiidae sp. $1^{*}$ & & & $\mathrm{x}$ & & & & \\
\hline & Quadrus cerealis & & & & & & $\mathrm{x}$ & \\
\hline & Quadrus sp. & & $\mathrm{x}$ & $\mathrm{x}$ & $\mathrm{x}$ & & $\mathrm{x}$ & $\mathrm{x}$ \\
\hline & Quadrus u-lucida & & $\mathrm{x}$ & $\mathrm{x}$ & & & & \\
\hline & Pyrrhopyge sp. 1 & $\mathrm{x}$ & & $\mathrm{x}$ & & & & \\
\hline \multirow[t]{2}{*}{ 7.Lasiocampidae } & Euglyphis sp. 1 & & & $\mathrm{x}$ & & & & \\
\hline & Lasiocampidae sp. 1* $^{*}$ & & & & $\mathrm{x}$ & & & \\
\hline \multirow[t]{4}{*}{ 8.Limacodidae } & Limacodidae sp. $1^{*}$ & & & & & & $\mathrm{x}$ & \\
\hline & Limacodidae sp. $2^{*}$ & & & $\mathrm{x}$ & & & & \\
\hline & Limacodidae sp. $3 *$ & & & & & & $\mathrm{x}$ & \\
\hline & Parasa sp. 1* & & & & & $\mathrm{x}$ & & \\
\hline \multirow[t]{3}{*}{ 9.Noctuidae } & Noctuidae sp. $1^{*}$ & & & $\mathrm{x}$ & & & & \\
\hline & Noctuidae sp. 2 & $\mathrm{x}$ & & & & & & \\
\hline & Noctuidae sp. $3 *$ & & & & & $\mathrm{x}$ & & \\
\hline
\end{tabular}




\begin{tabular}{|c|c|c|c|c|c|c|c|c|}
\hline & Gonodonta nutrix & & $\mathrm{x}$ & $\mathrm{x}$ & $\mathrm{x}$ & $\mathrm{x}$ & $\mathrm{x}$ & $\mathrm{x}$ \\
\hline \multirow[t]{2}{*}{ 10.Nymphalidae } & $\begin{array}{l}\text { Heliconius sp. } 1^{*} \\
\text { Ithomia agnosia } \\
\text { zikani* }^{*}\end{array}$ & & & $\mathrm{x}$ & & $\mathrm{x}$ & & \\
\hline & Memphis moruus & $\mathrm{x}$ & $\mathrm{x}$ & $\mathrm{x}$ & $\mathrm{x}$ & $\mathrm{x}$ & $\mathrm{x}$ & $\mathrm{x}$ \\
\hline 11.Oecophoridae & Inga haemataula* & & & $\mathrm{x}$ & & & & \\
\hline \multirow[t]{2}{*}{ 12.Psychidae } & Psychidae sp. $1^{*}$ & $\mathrm{x}$ & & & & & & \\
\hline & Psychidae sp. 2 & & & $\mathrm{x}$ & & & & \\
\hline \multirow[t]{2}{*}{ 13.Riodinidae } & Anteros lectabilis & & $\mathrm{x}$ & $\mathrm{x}$ & & & & \\
\hline & Riodinidae sp. $1^{*}$ & $\mathrm{x}$ & & & & & & \\
\hline \multirow[t]{8}{*}{ 14.Tortricidae } & Platynota rostrana & & $\mathrm{x}$ & & $\mathrm{x}$ & & & \\
\hline & Tortricidae sp. $1^{*}$ & & & & & & & $\mathrm{x}$ \\
\hline & Tortricidae sp. $2^{*}$ & $\mathrm{x}$ & & & & & & \\
\hline & Tortricidae sp. $3 *$ & & & $\mathrm{x}$ & & & & \\
\hline & Tortricidae sp. 4 & & & & & $\mathrm{x}$ & & \\
\hline & Tortricidae sp. $5^{*}$ & & & & & & $\mathrm{x}$ & \\
\hline & Tortricidae sp. $6^{*}$ & $\mathrm{x}$ & & & & & & \\
\hline & Tortricidae sp. $7^{*}$ & & & & & & & $\mathrm{x}$ \\
\hline 15.Urodidae & Urodus sp. 1* & & & & & & & $\mathrm{x}$ \\
\hline \multirow[t]{4}{*}{ NI } & Morfotipo $1^{*}$ & & & $\mathrm{x}$ & & & & \\
\hline & Morfotipo 2 & & $\mathrm{x}$ & & $\mathrm{x}$ & & & \\
\hline & Morfotipo 3 & & & & & & & $\mathrm{x}$ \\
\hline & Morfotipo $4 *$ & & & & & & $\mathrm{x}$ & \\
\hline
\end{tabular}

Anexo 2. Espécies de lagartas encontradas em Piper arboreum em sete matas de galeria do Cerrado do Distrito Federal e Goiás, de maio/15 a abril/16, (*= singletons; NI=não identificada).

\begin{tabular}{|c|c|c|c|c|c|c|c|c|}
\hline Família & Espécies & PNCV & ESECAE & RECOR & JBB & FAL & Pirenópolis & PNB \\
\hline 1.Bombycidae & Zanola verago* & & & & & & $\mathrm{x}$ & \\
\hline \multirow[t]{2}{*}{ 2.Elaschitidae } & Antaeotricha sp. $1^{*}$ & & & & & & $\mathrm{x}$ & \\
\hline & Antaeotricha sp. $2 *$ & & & & $\mathrm{x}$ & & & \\
\hline \multirow[t]{6}{*}{ 3.Erebidae } & Arctiinae sp. $1^{*}$ & & & $\mathrm{x}$ & & & & \\
\hline & Arctiinae sp. $3 *$ & & & $\mathrm{x}$ & & & & \\
\hline & Arctiinae sp. 4 & $\mathrm{x}$ & $\mathrm{x}$ & & $\mathrm{x}$ & $\mathrm{x}$ & & $\mathrm{x}$ \\
\hline & Arctiinae sp. 5* & & & & & $\mathrm{x}$ & & \\
\hline & Acrtiinae sp. $6^{*}$ & & & & & $\mathrm{x}$ & & \\
\hline & Arctiinae sp. 7 & $\mathrm{x}$ & & $\mathrm{x}$ & & & & \\
\hline \multirow[t]{6}{*}{ 4.Geometridae } & Eois binaria & $\mathrm{x}$ & $\mathrm{x}$ & $\mathrm{x}$ & & $\mathrm{x}$ & & \\
\hline & Eois sp. 1 & & & & & $\mathrm{x}$ & & \\
\hline & Geometridae sp. $1 *$ & & & & & $\mathrm{x}$ & & \\
\hline & Geometridae sp. $2 *$ & & & & & & & $\mathrm{x}$ \\
\hline & Geometridae sp. $3 *$ & & & & & $\mathrm{x}$ & & \\
\hline & Geometridae sp. 4 & $\mathrm{x}$ & & & & & & \\
\hline
\end{tabular}




\begin{tabular}{|c|c|c|c|c|c|c|c|c|}
\hline & Geometridae sp. 6 & $\mathrm{x}$ & & & & $\mathrm{x}$ & & \\
\hline & Geometridae sp. $7 *$ & & $\mathrm{x}$ & & & & & \\
\hline & Geometridae sp. $8^{*}$ & & & & & $\mathrm{x}$ & & \\
\hline & Geometridae sp. 10 & & & & $\mathrm{x}$ & $\mathrm{x}$ & & \\
\hline \multirow[t]{5}{*}{ 5.Hesperiidae } & Hesperiidae sp. $1^{*}$ & & & & & $\mathrm{x}$ & & \\
\hline & Quadrus cerealis & & & & & & $\mathrm{x}$ & \\
\hline & Quadrus sp. & & $\mathrm{x}$ & $\mathrm{x}$ & & $\mathrm{x}$ & $\mathrm{x}$ & $\mathrm{x}$ \\
\hline & Quadrus u-lucida & & $\mathrm{x}$ & & & $\mathrm{x}$ & & \\
\hline & Pyrrhopyge sp. 1 & & & & & $\mathrm{x}$ & & \\
\hline 6.Lasiocampidae & Euglyphis sp. 1 & & & & & $\mathrm{x}$ & & \\
\hline \multirow[t]{4}{*}{ 7.Limacodidade } & Limacodidae sp. $1 *$ & & & & & & $\mathrm{x}$ & \\
\hline & Limacodidae sp. $2 *$ & & & & & $\mathrm{x}$ & & \\
\hline & Limacodidae sp. $3^{*}$ & & & & & & $\mathrm{x}$ & \\
\hline & Parasa sp. $1^{*}$ & & & & $\mathrm{x}$ & & & \\
\hline \multirow[t]{4}{*}{ 8.Noctuidae } & Noctuidae sp. $1^{*}$ & & & & & $\mathrm{x}$ & & \\
\hline & Noctuidae sp. 2 & $\mathrm{x}$ & & & & & & \\
\hline & Noctuidae sp. $3 *$ & & & & $\mathrm{x}$ & & & \\
\hline & Gonodonta nutrix & & $\mathrm{x}$ & $\mathrm{x}$ & $\mathrm{x}$ & $\mathrm{x}$ & $\mathrm{x}$ & $\mathrm{x}$ \\
\hline \multirow[t]{2}{*}{ 9.Nymphalidae } & Ithomia agnosia zikani ${ }^{*}$ & & & & & $\mathrm{x}$ & & \\
\hline & Memphis moruus & & $\mathrm{x}$ & $\mathrm{x}$ & $\mathrm{x}$ & $\mathrm{x}$ & $\mathrm{x}$ & $\mathrm{x}$ \\
\hline 10.Oecophoridae & Inga haemataula* & & & & & $\mathrm{x}$ & & \\
\hline \multirow[t]{2}{*}{ 11.Psychidae } & Psychidae sp. $1^{*}$ & $\mathrm{x}$ & & & & & & \\
\hline & Psychidae sp. 2 & & & & & $\mathrm{x}$ & & \\
\hline 12.Riodinidae & Anteros lectabilis & & $\mathrm{x}$ & & & $\mathrm{x}$ & & \\
\hline \multirow[t]{6}{*}{ 13.Tortricidae } & Platynota rostrana* & & $\mathrm{x}$ & & & & & \\
\hline & Tortricidae sp. $1^{*}$ & & & & & & & $\mathrm{x}$ \\
\hline & Tortricidae sp. $3 *$ & & & & & $x$ & & \\
\hline & Tortricidae sp. 4 & & & & $\mathrm{x}$ & & & \\
\hline & Tortricidae sp. $5^{*}$ & & & & & & $\mathrm{x}$ & \\
\hline & Tortricidae sp. $7 *$ & & & & & & & $\mathrm{x}$ \\
\hline 14.Urodidae & Urodidae sp. $1^{*}$ & & & & & & & $\mathrm{x}$ \\
\hline \multirow[t]{5}{*}{ NI } & Morfotipo $1^{*}$ & & & & & $\mathrm{x}$ & & \\
\hline & Morfotipo $2 *$ & & $\mathrm{x}$ & & & & & \\
\hline & Morfotipo 3* & & & & & & & $\mathrm{x}$ \\
\hline & Morfotipo 4* & & & & & & $\mathrm{x}$ & \\
\hline & Morfotipo 5* & & & & & & & $\mathrm{x}$ \\
\hline
\end{tabular}




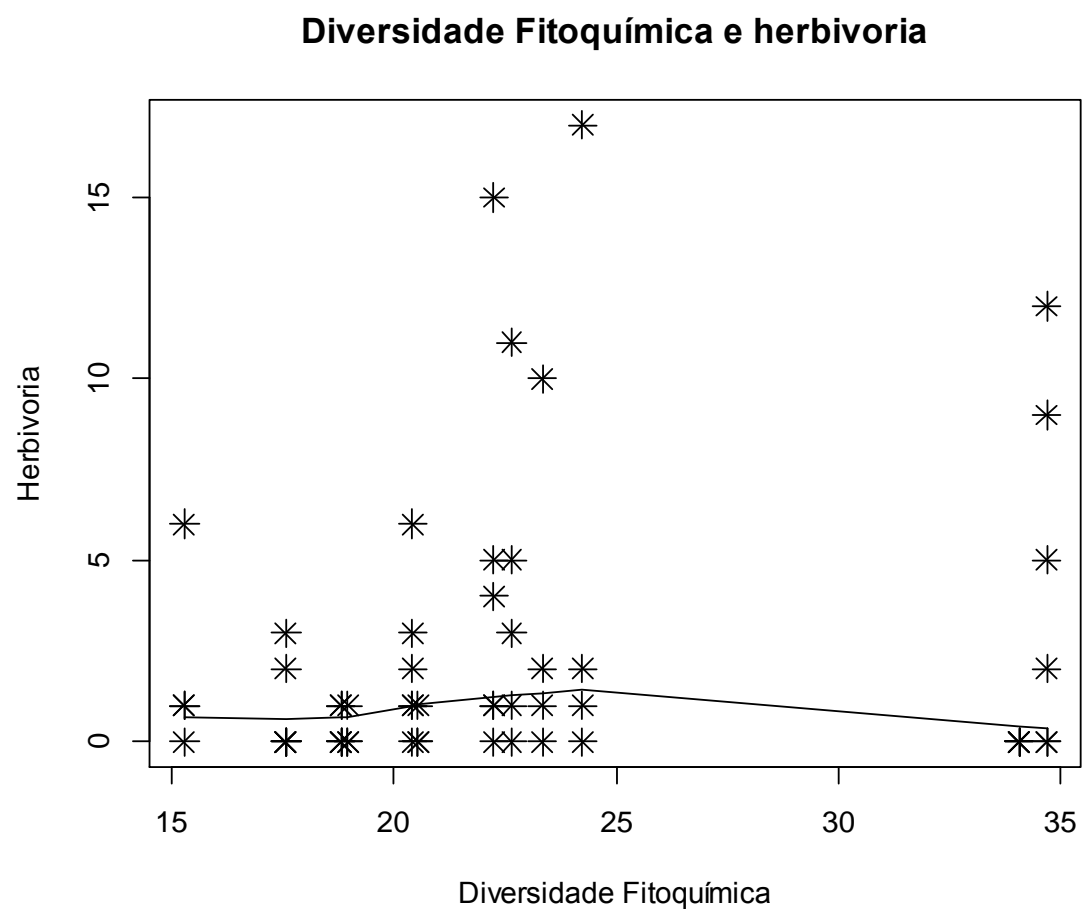

Anexo 3. Diversidade fitoquímica (de grupos funcionais) de indivíduo de Piper arboreum em relação à herbivoria (\%) foliar cumulativa. 


\section{APÊNDICE}

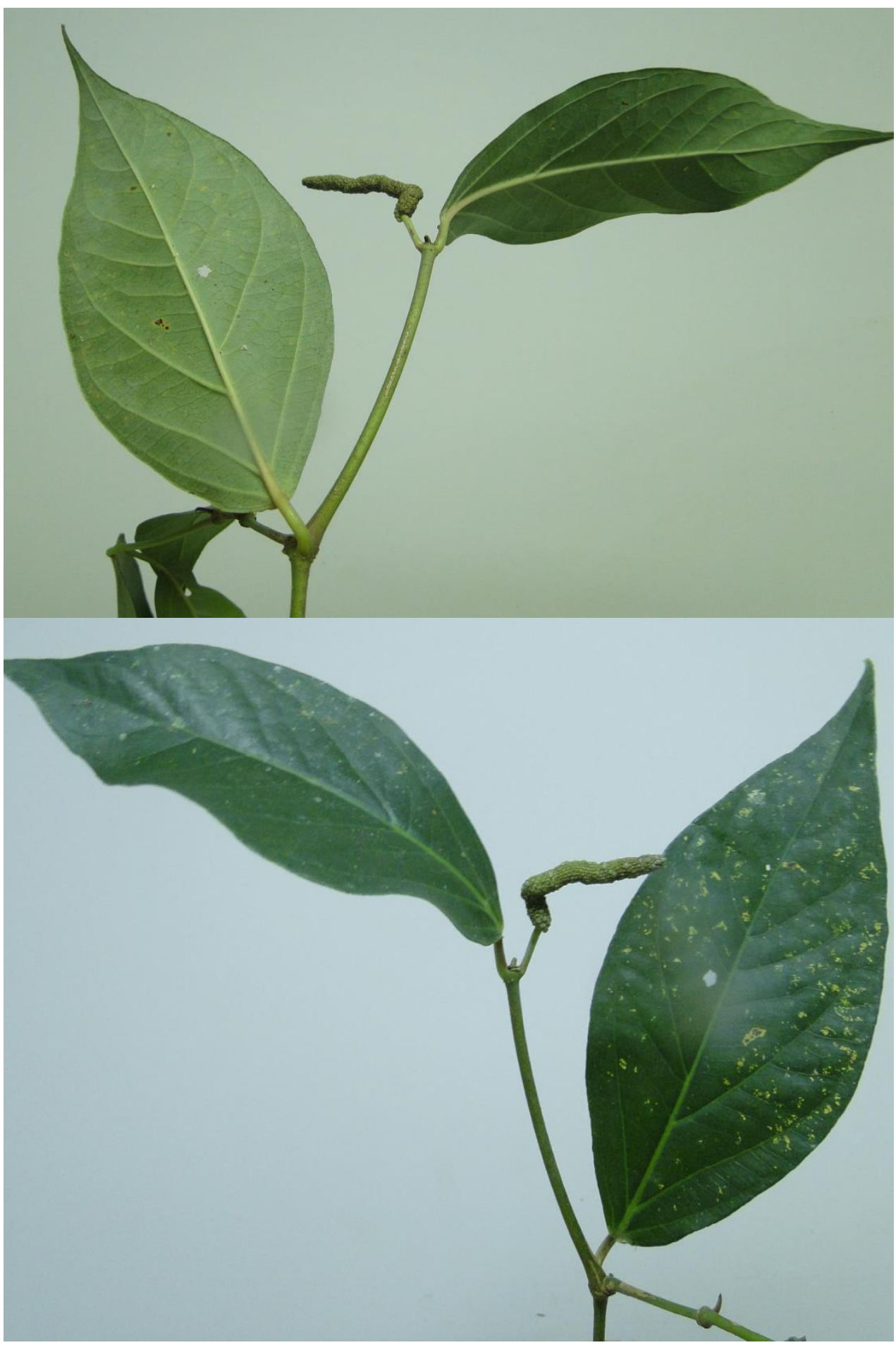

Apêndice 1. Espécie de Piper, denominada Morfoespécie 4, encontrada no Parque Nacional da Chapada dos Veadeiros (Fotos: Raiane Serejo). 


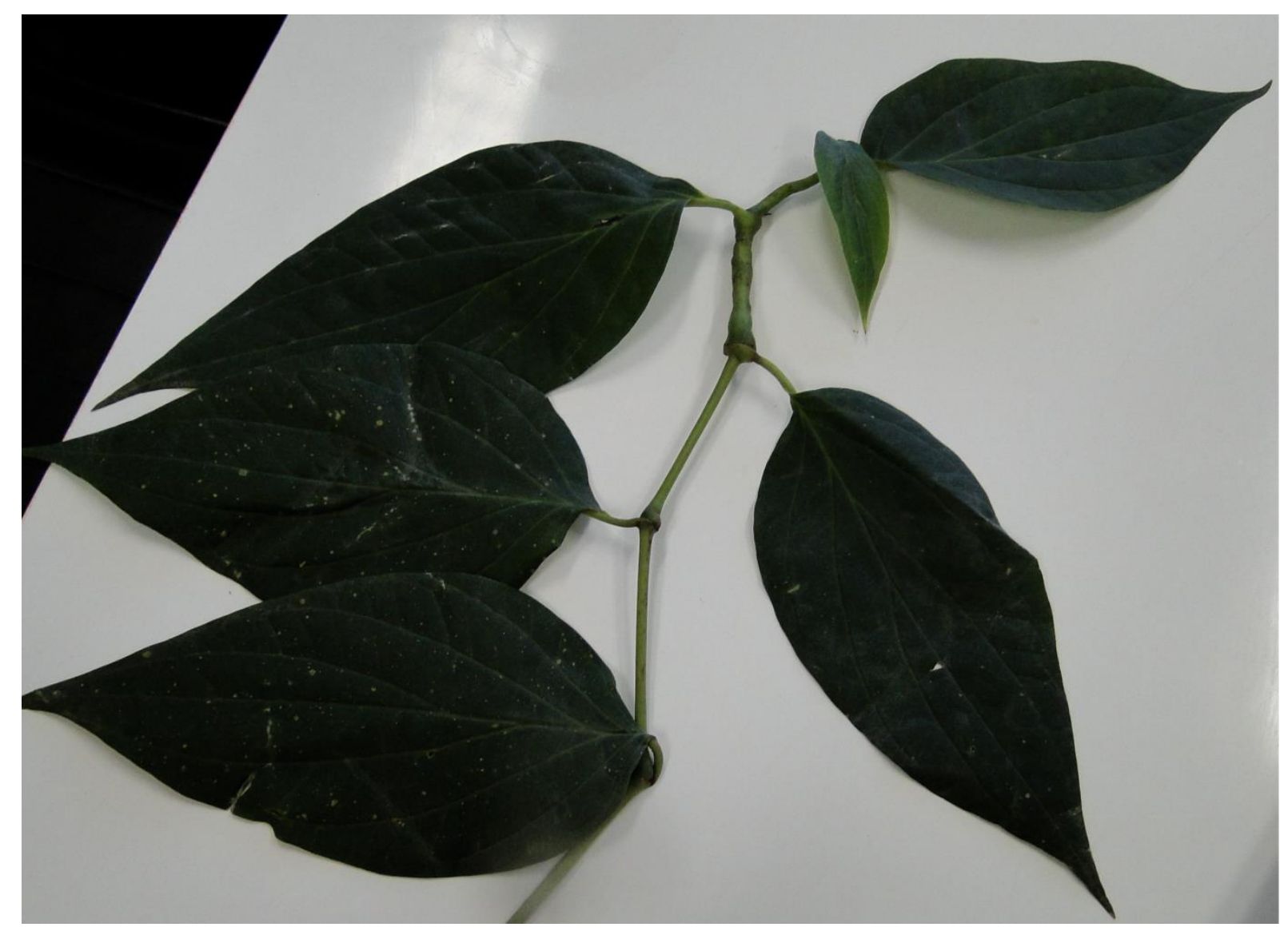

Apêndice 2. Espécie de Piper, denominada Morfoespécie 5, encontrada no Jardim Botânico de Brasília e no Parque Nacional da Chapada dos Veadeiros (Foto: Raiane Serejo). 


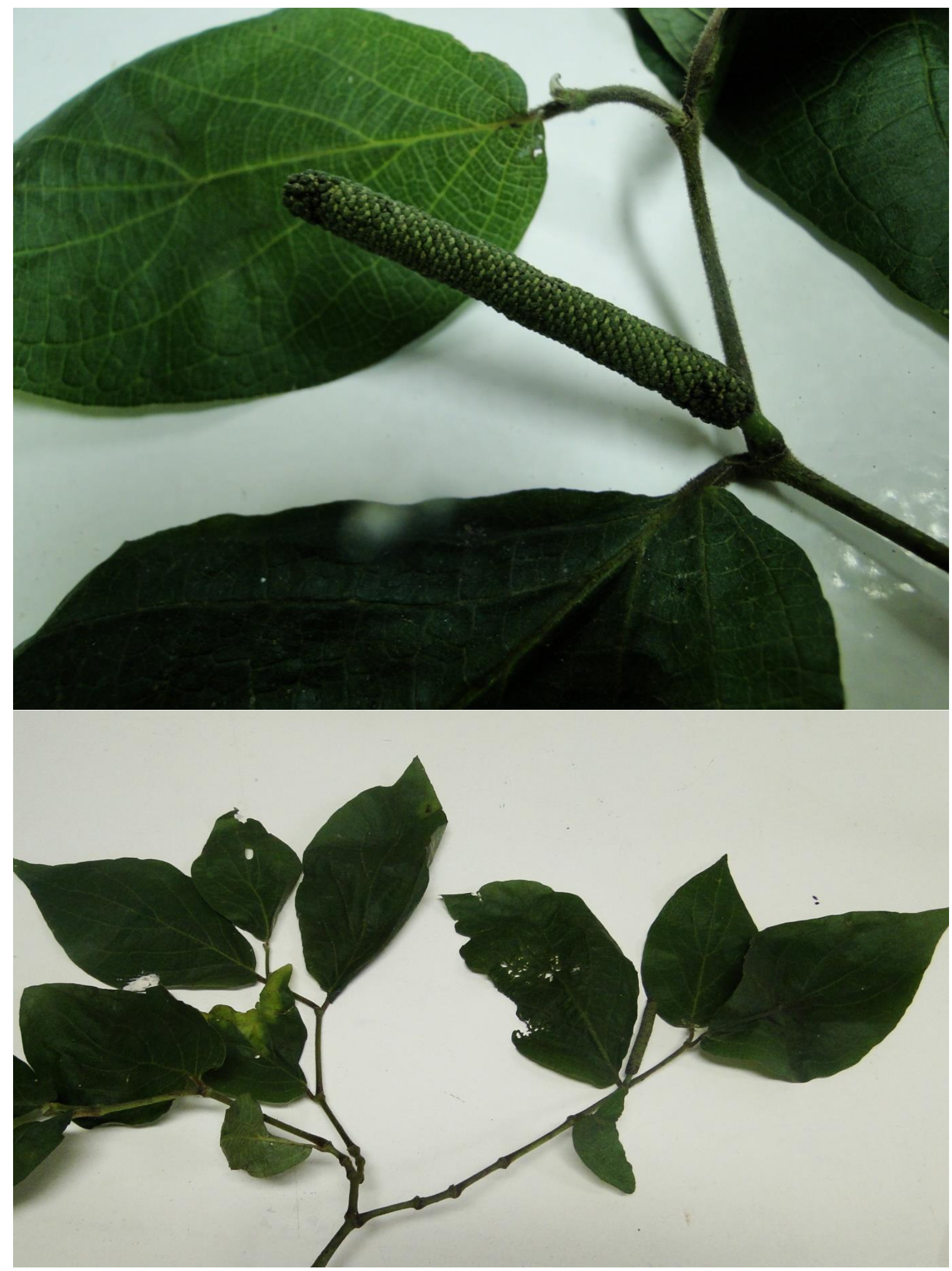

Apêndice 3. Espécie de Piper, denominada Morfoespécie 6, encontrada no Parque Nacional da Chapada dos Veadeiros (Foto: Raiane Serejo). 


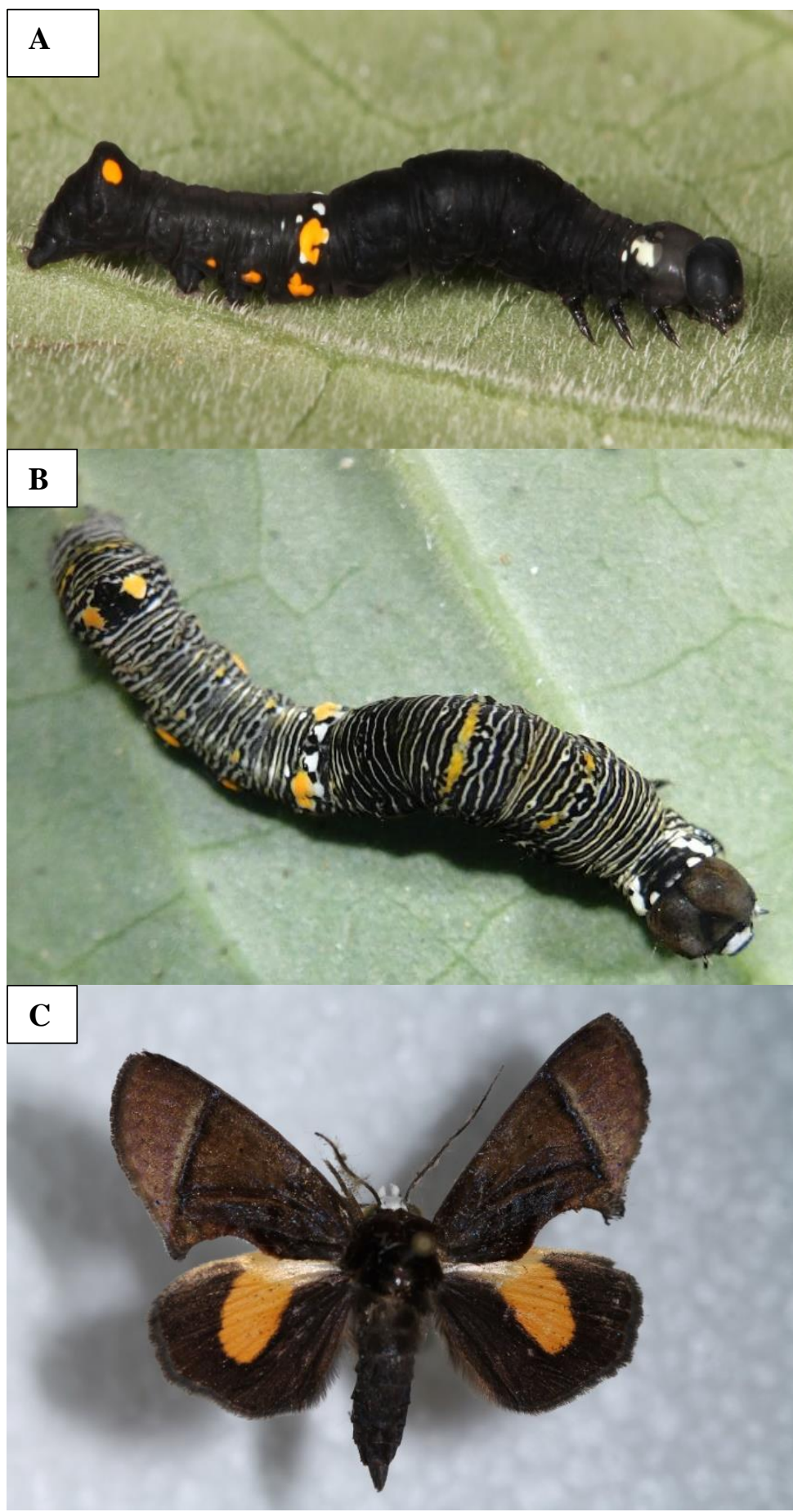

Apêndice 4. Gonodonta nutrix (Noctuidae) (A) lagarta em primeiros instares; (B) lagarta nos últimos instares; (C) mariposa adulta . A lagarta é solitária, vive exposta na folha, e é folívora externa. (Foto: Raiane Serejo) 

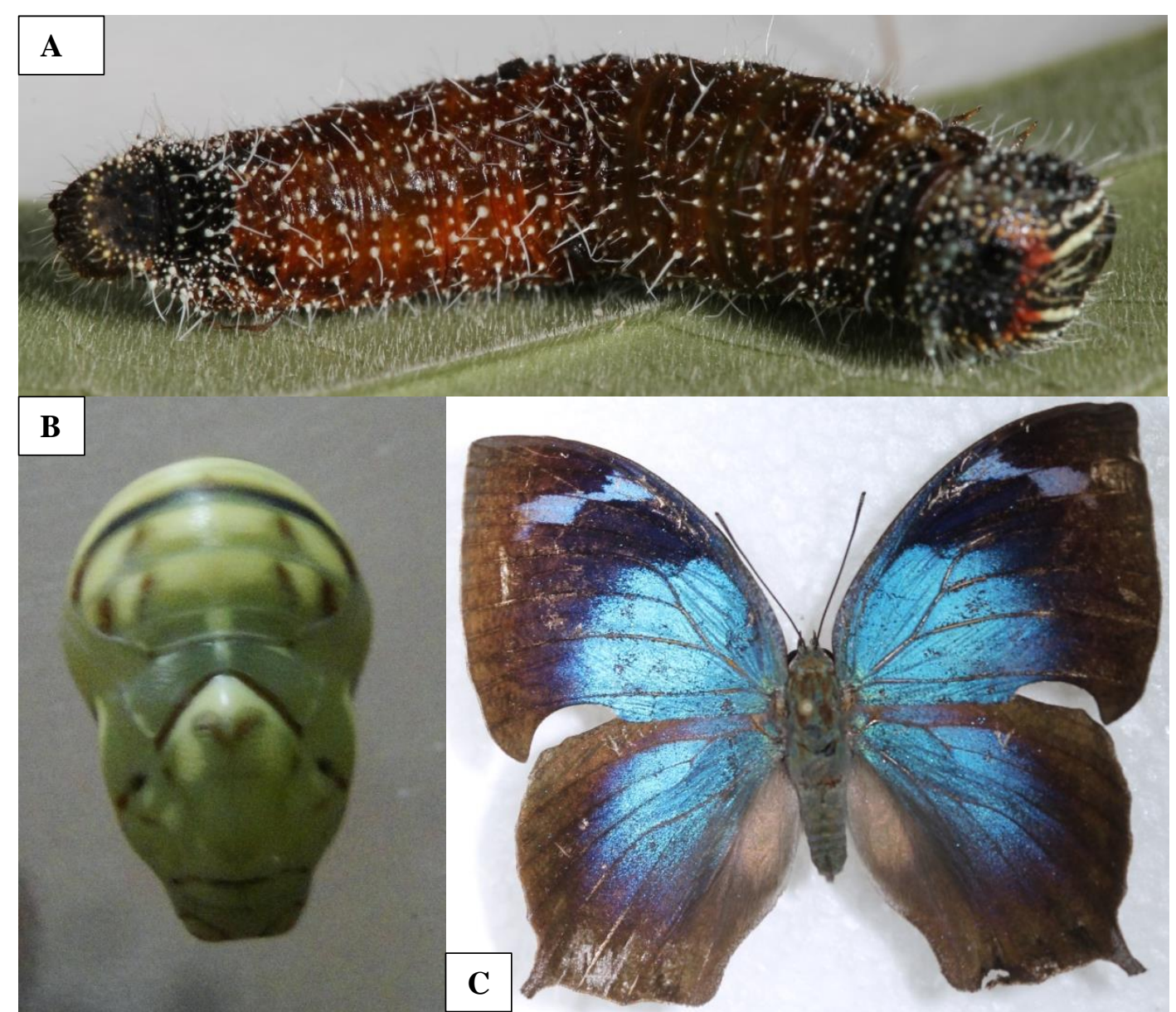

Apêndice 5. Memphis moruus (Nymphalidae) (A) Lagarta, (B) pupa e (C) borboleta adulta . A lagarta é solitária, vive exposta na folha, e é folívora externa. (Foto: Raiane Serejo).

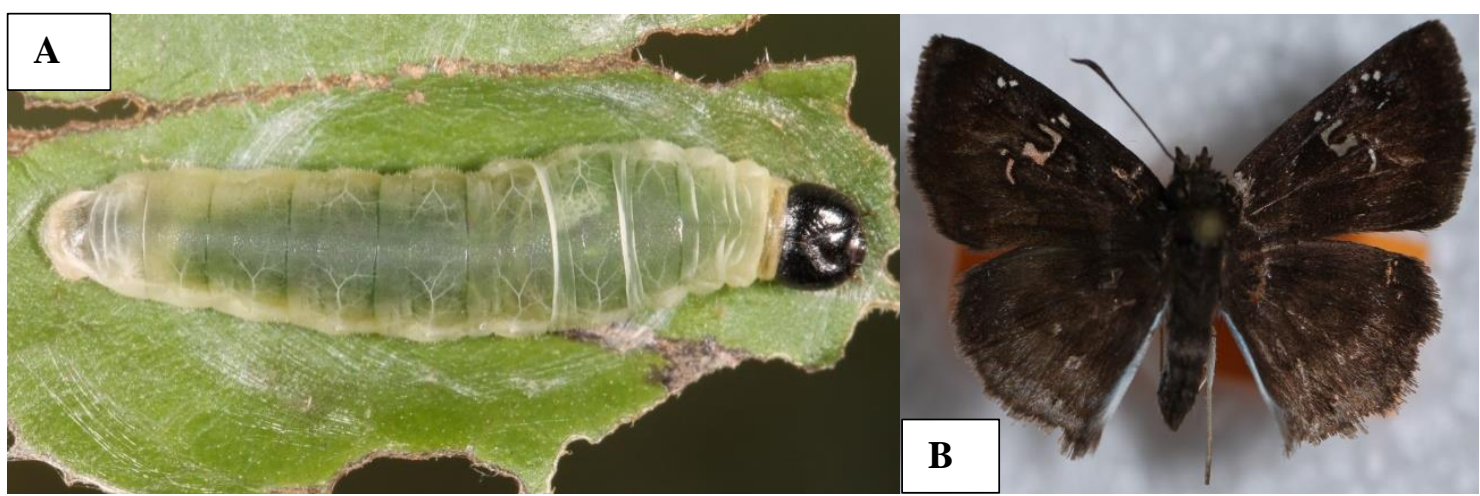

Apêndice 6. Quadrus-u-lucida (Hesperiidae) (A) Lagarta e (B) adulto. A lagarta é solitária, construtora de abrigo, e folívora externa. (Foto: Raiane Serejo) 


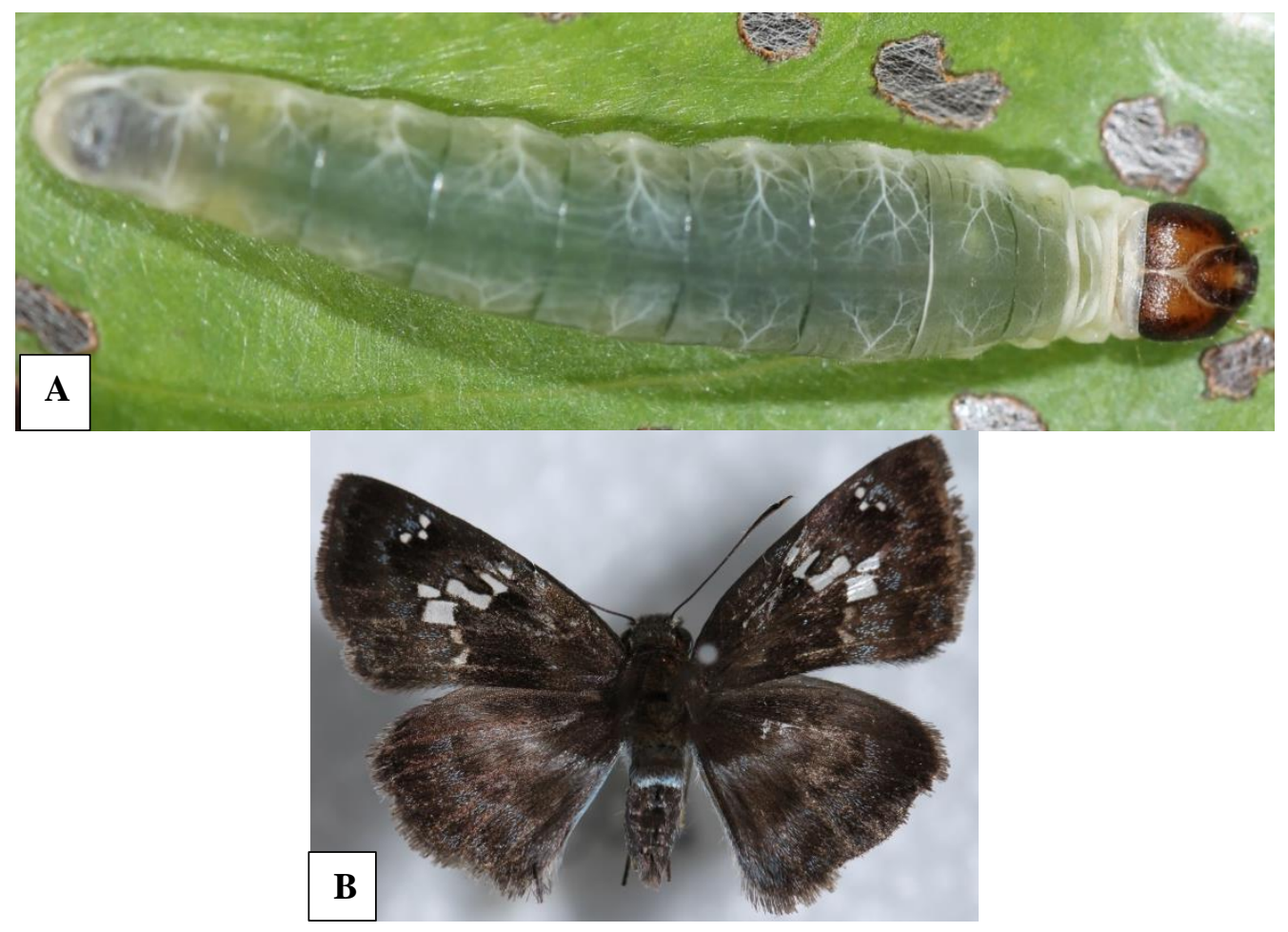

Apêndice 7.Quadrus cerealis (Hesperiidae) (A) Lagarta e (B) adulto . A lagarta é solitária, construtora de abrigo, e folívora externa. (Foto: Raiane Serejo). 


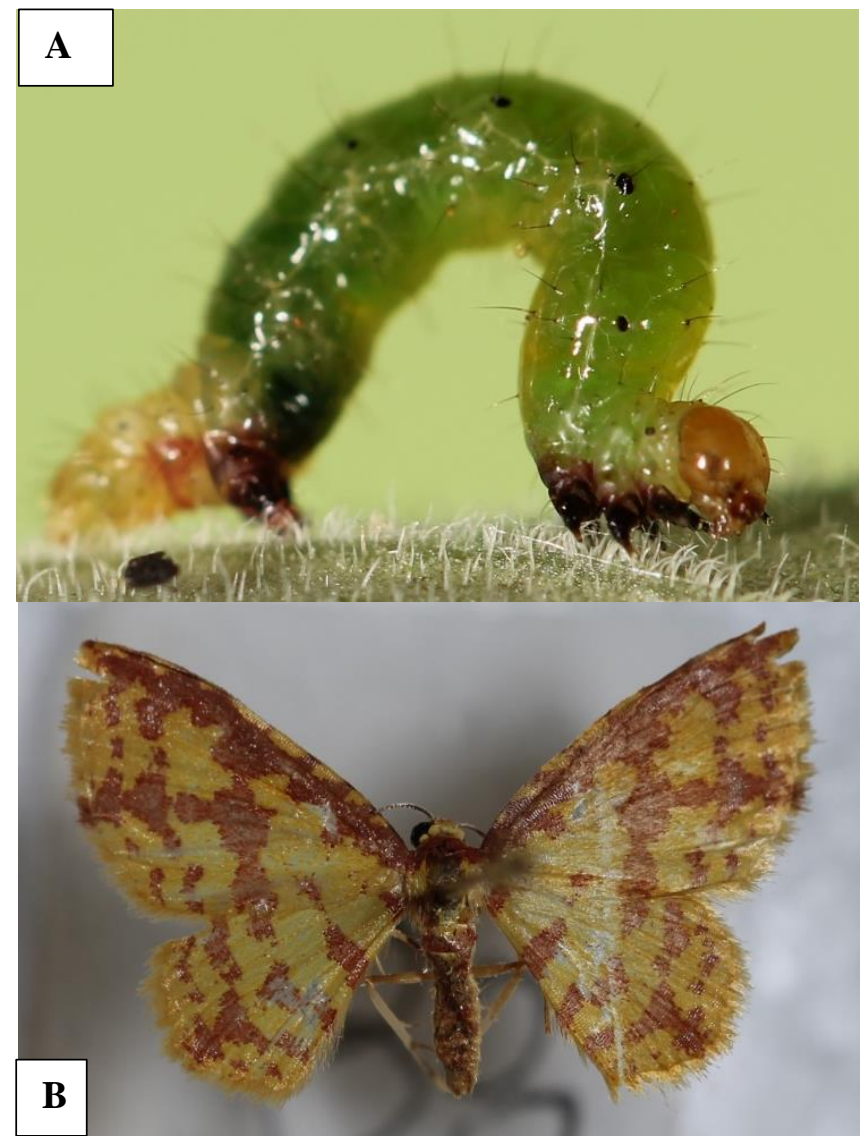

Apêndice 8. Eois binaria (Geometridae) (A) lagarta e (B) mariposa adulta. A lagarta é solitária, vive exposta na folha, e é folívora externa. (Foto: Raiane Serejo). 


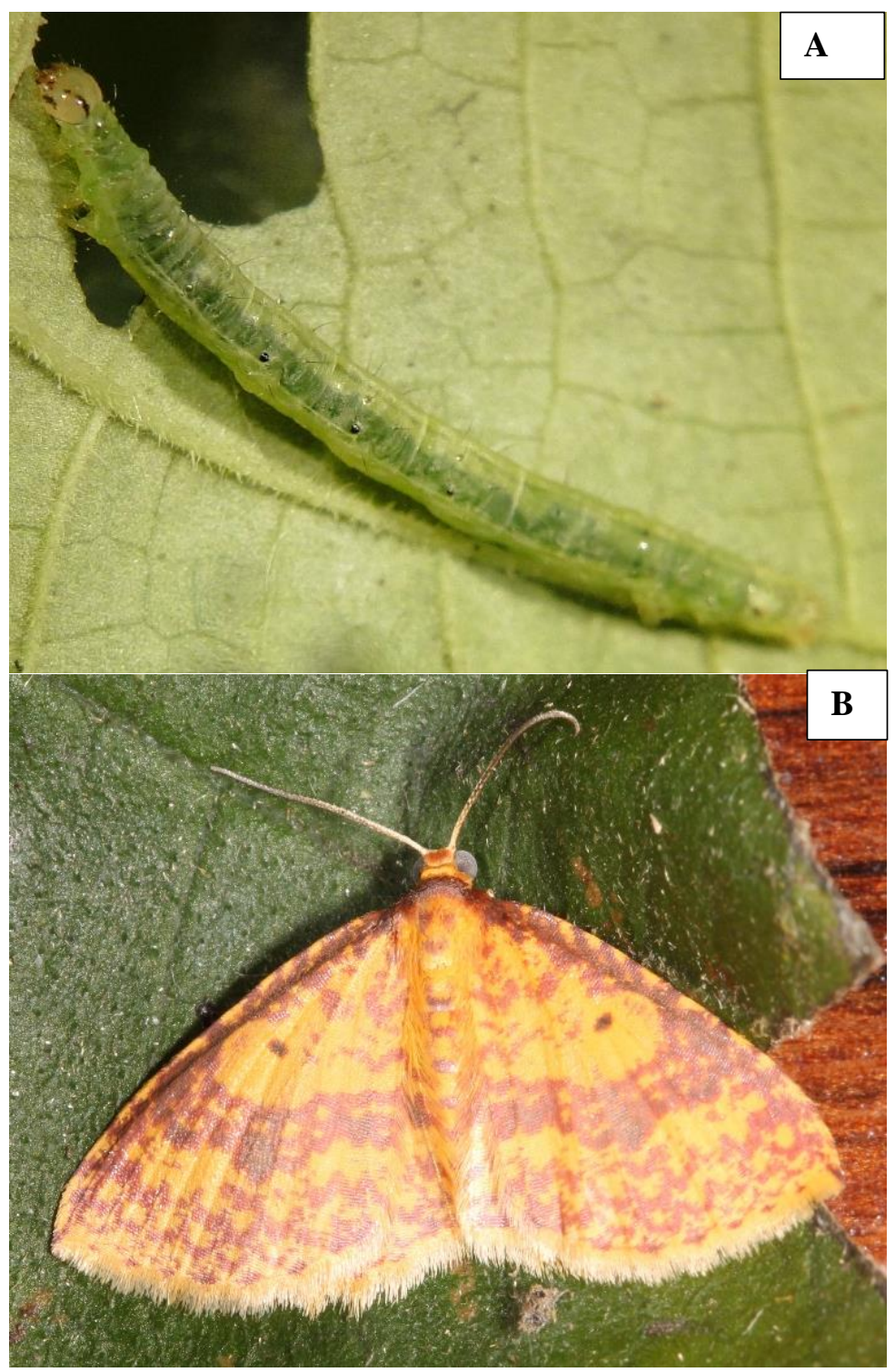

Apêndice 9. Eois tegularia (Geometridae) (A) lagarta e (B) mariposa adulta. A lagarta é solitária, vive exposta na folha, e é folívora externa. (Foto: Raiane Serejo). 


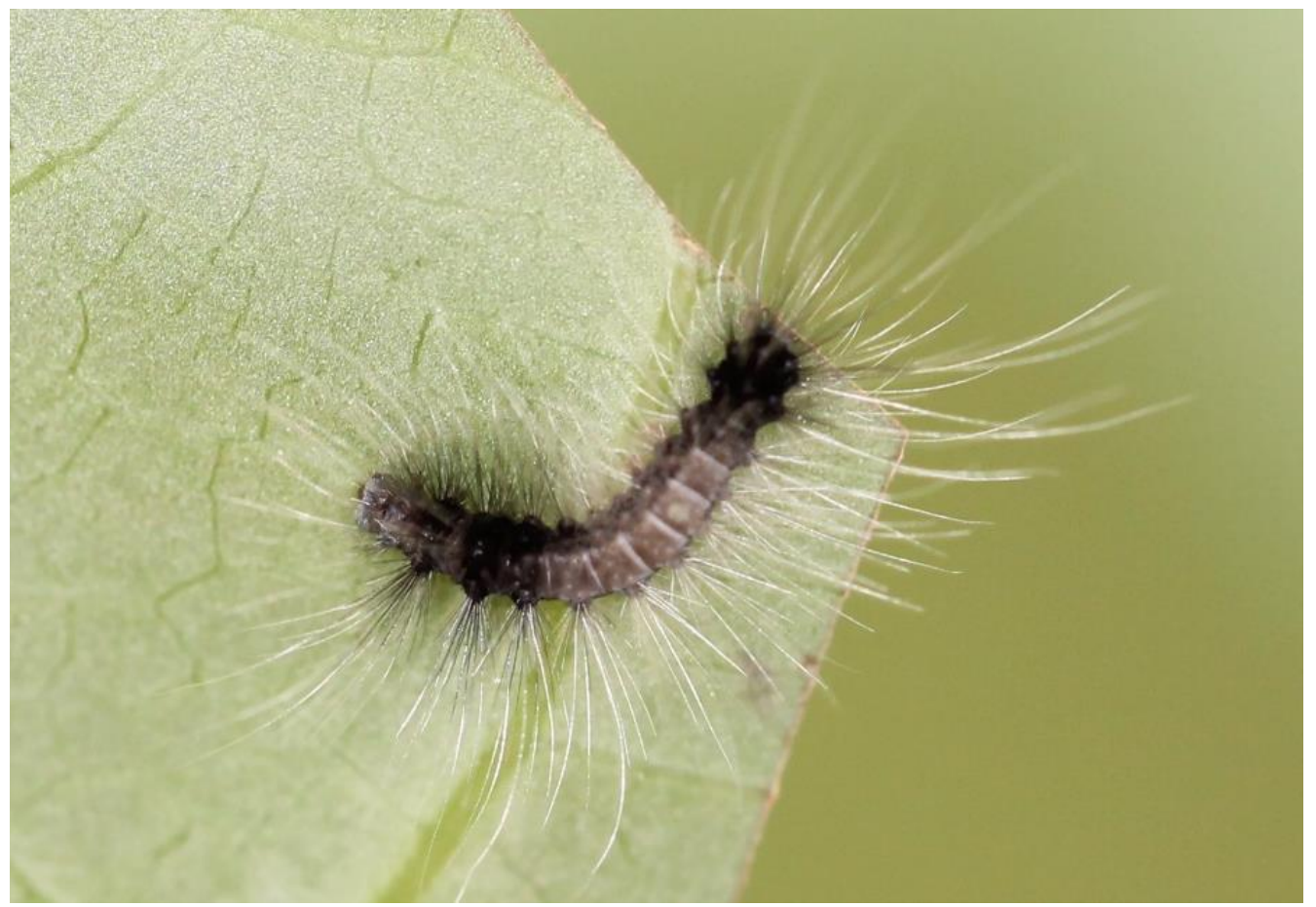

Apêndice 10. Morfoespécie Arctiinae sp.4 (Erebidae). A lagarta é solitária, vive exposta na folha, e é folívora externa. (Foto: Raiane Serejo).

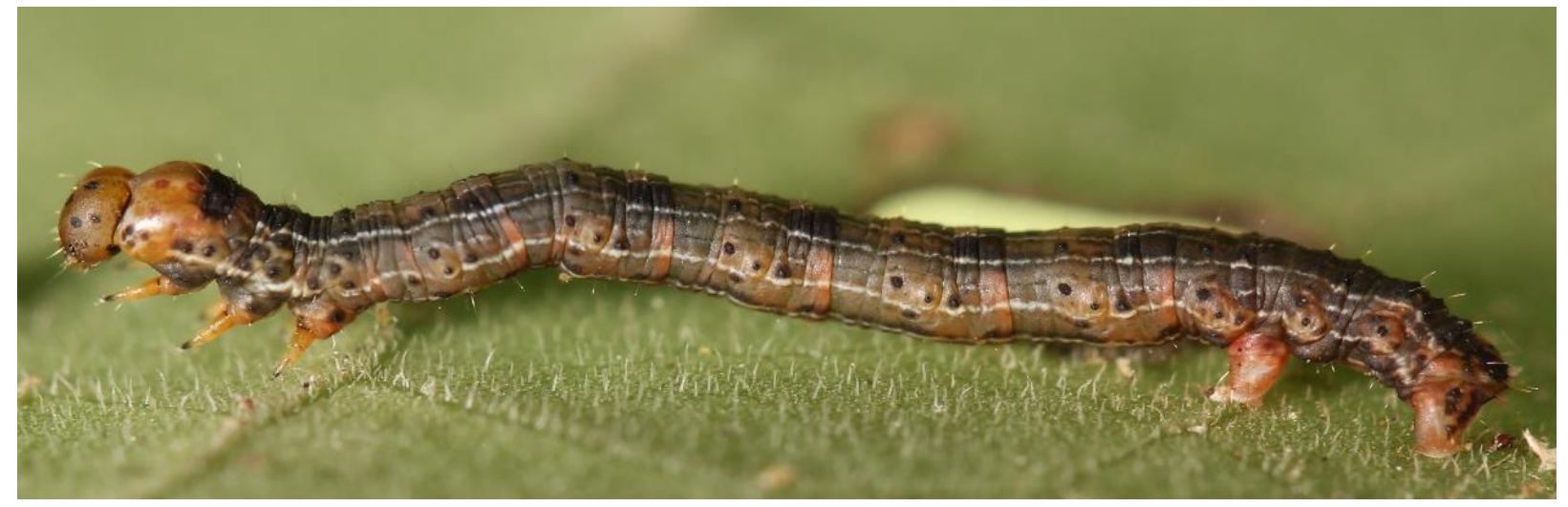

Apêndice 11. Geometridae sp.6 (Geometridae). A lagarta é solitária, vive exposta na superfície foliar e é folívora externa. (Foto: Raiane Serejo). 